\title{
Semiconductor Electrochemistry for Clean Energy Conversion and Storage
}

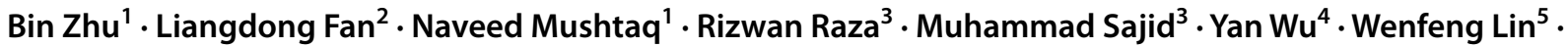 \\ Jung-Sik Kim ${ }^{6} \cdot$ Peter D. Lund ${ }^{7}$. Sining Yun ${ }^{8}$
}

Received: 11 January 2021 / Revised: 29 March 2021 / Accepted: 2 June 2021 / Published online: 25 October 2021

(c) The Author(s) 2021, corrected publication 2022

\begin{abstract}
Semiconductors and the associated methodologies applied to electrochemistry have recently grown as an emerging field in energy materials and technologies. For example, semiconductor membranes and heterostructure fuel cells are new technological trend, which differ from the traditional fuel cell electrochemistry principle employing three basic functional components: anode, electrolyte, and cathode. The electrolyte is key to the device performance by providing an ionic charge flow pathway between the anode and cathode while preventing electron passage. In contrast, semiconductors and derived heterostructures with electron (hole) conducting materials have demonstrated to be much better ionic conductors than the conventional ionic electrolytes. The energy band structure and alignment, band bending and built-in electric field are all important elements in this context to realize the necessary fuel cell functionalities. This review further extends to semiconductor-based electrochemical energy conversion and storage, describing their fundamentals and working principles, with the intention of advancing the understanding of the roles of semiconductors and energy bands in electrochemical devices for energy conversion and storage, as well as applications to meet emerging demands widely involved in energy applications, such as photocatalysis/water splitting devices, batteries and solar cells. This review provides new ideas and new solutions to problems beyond the conventional electrochemistry and presents new interdisciplinary approaches to develop clean energy conversion and storage technologies.
\end{abstract}

Keywords Semiconductor electrochemistry $\cdot$ Fuel cells $\cdot$ Lithium-ion batteries · Solar cells · Built-in electric field · Energy system integration

\section{Introduction}

Electrochemical devices, including fuel cells, batteries and electrolyzers have shown great potential for large-scale clean energy conversion and storage applications. In clean

Bin Zhu, Liangdong Fan, Rizwan Raza, Naveed Mushtaq contributed equally to this work.

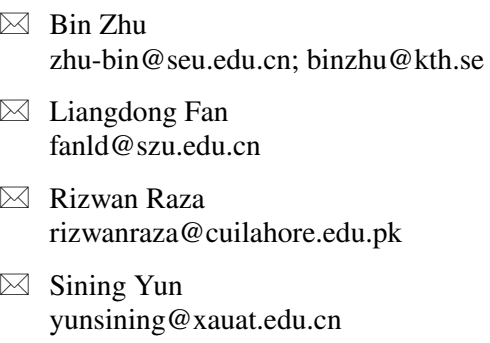

Extended author information available on the last page of the article energy conversion, fuel cells directly convert the chemical energy from fuels into electricity with high efficiency and low emissions, while in clean energy storage, a battery is a typical storage device with high energy density and good reversibility and durability. We selected these two systems for the present study, because they represent the current and near-future energy conversion and storage technologies with a high potential to be combined with renewable and sustainable energy sources. We use them as examples to give a comprehensive review of current research frontiers with emphases on semiconductor and band theory applications in both materials and devices/technologies as well as fundamental sciences, followed by extensions to related fields, e.g., photoelectrolysis or photocatalysts, solar cells, metal-air batteries, and electrolyzers.

The knowledge and operating principles of fuel cells have largely remained the same over the last century [1, 2]. The yttrium-stabilized zirconia (YSZ) electrolyte, a 
typical oxide material, has been the main focus of research and development for solid oxide fuel cells (SOFCs). However, the full and successful commercialization of SOFCs is hampered by the requirement for high temperature materials associated with high costs despite the inherent benefits of the technology. The high operating temperature, which is directly related to the ionic conductivity of solid oxide electrolytes, requires special attention from the aspects of the material durability and manufacturing. It also adversely affects the costs, impeding wide application of SOFC technology. For instance, many works have focused on developing ultrathin film electrolyte layers of YSZ and alternative doped ceria (e.g., $\mathrm{Sm}_{0.2} \mathrm{Ce}_{0.8} \mathrm{O}_{2-\delta}$ (SDC)) to minimize device ohmic loss and maintain desirable power output at reduced temperatures.

The oxygen transport properties in the electrode and electrolyte materials are not only of technological interest, as noted above, but also of fundamental importance. The energetics of oxygen transport in these oxides are affected by the material structure, composition, oxygen stoichiometry, doping and elastic strain, which comprise a wide range of parameters in optimizing the transport properties. In addition, lowering the temperature can cause slower electrode and electrolyte dynamic processes. To speed up the development of SOFCs, new solutions to these key challenges for the electrolytes and electrodes need to be found, i.e., to achieve sufficient ionic conductivity electrolytes and highly electrocatalytically active electrodes at lower operating temperatures. In addition, more radical approaches alternative to the traditional approach of using the three-layer anode-electrolyte-cathode electrochemical device structure and material systems are greatly sought after. In 2013, Singh et al. [3] noted that the anode, cathode and electrolyte in SOFCs, in terms of semiconductor principles, can be associated with an n-type regime, a p-type regime and an ion conducting electrolyte, respectively, as shown in Fig. 1a. In 2018, Asghar et al. [4] further proposed that wide bandgap semiconductors can be used for replicating the electrolyte functionality. This means that an SOFC could be conceptually handled as a semiconductor fuel cell system. If the middle electrolyte layer of the SOFC is removed or replaced with a wide bandgap semiconductor, then the fuel cell effectively resembles a $\mathrm{p}-\mathrm{n}$ junction device (as Fig. 1b); i.e., a $\mathrm{p}-\mathrm{n}$ junction is formed in situ under a fuel cell atmosphere by the same material that can block electrons, thus preventing short circuiting of the fuel cell in much the same way as in solar cells. Based on this principle, two types of novel fuel cell devices may be constructed based on either $\mathrm{O}^{2-}$ or $\mathrm{H}^{+}$conduction/transfer, as illustrated in Fig. 1c, d. We designate these devices as electrolyte-layer-free fuel cells (EFFCs) to distinguish them from the traditional SOFC structure. Naturally, the EFFC has the same functionalities as the traditional SOFC, but these can be realized through a different methodology employing a vastly simplified configuration. This difference delivers several advantages over a conventional three-layer fuel cell such as the following: (1) the two anode/electrolyte and cathode/electrolyte interfaces that cause major power loss due to the ionic/electronic interfacial polarizations are eliminated $[1,5]$; (2) redox reactions, such as the hydrogen oxidation reaction (HOR) and the oxygen reduction reaction (ORR), can be readily performed to generate electricity on the spot, and ionic transport occurs in a more efficient way to complete the fuel cell reactions (Fig. 1a); and (3) a built-in electric field is formed at the anode (n) and cathode (p) junction, which can increase the $\mathrm{H}^{+}$(Fig. 1c) and $\mathrm{O}^{2-}$ (Fig. 1d) transfer mechanics to enhance the overall efficiency of the cell. EFFCs with simpler configurations and harmonious cell components have led to significant progress in the SOFC field.

The transition from the conventional ionic electrochemistry to advanced semiconductor electrochemistry is widely evidenced as reported for many other energy conversion and storage devices $[6,7]$, which makes the application of semiconductors and associated methodologies to the electrochemistry in energy materials and relevant electrochemical devices an emerging field. For instance, the successful development of photoelectrolysis from photoelectrochemical devices using semiconductors has made photocatalysts and water splitting hot topics [8-10]. Lithium-ion batteries (LIBs) have also experienced new progress based on the semiconductor properties of materials used in devices, e.g., energy band/heterojunction/built-in electric field $[11,12]$. Semiconductors and their methodologies complement the conventional electrochemistry, introducing the new topic "semiconductor electrochemistry" and a new frontier in ion conducting semiconductors and novel fuel cell devices $[1,13,14]$. The name of this topic refers to the similarities found between the development of photocatalysts and LIBs and that of fuel cells.

Fuel cells and photoelectrochemical electrolysis have much the same origin as electrolyte-based electrochemical devices with anodes and cathodes, i.e., photoelectrochemical cells (PECs). Today, PECs are well known to be transferrable to photo-water splitting based on semiconductors and band structures [15]. A similar situation occurs for batteries, where semiconductors and energy bands, as well as built-in-field effects, play a significant role in designing material functions and the device performance. Solar cells have taken a reverse route from typical physics to electrochemistry, where ions play an important role in state-ofthe-art perovskite solar cells (PSCs). The electrochemistry of the semiconductor-electrolyte interface or semiconductor-semiconductor interface provides great promise to handle these challenges through a deeper understanding. 
(a)

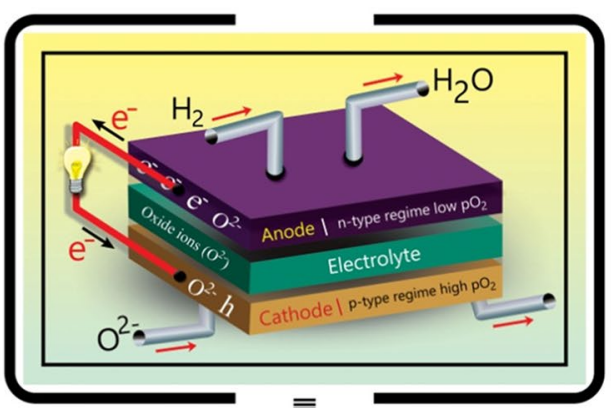

(b)

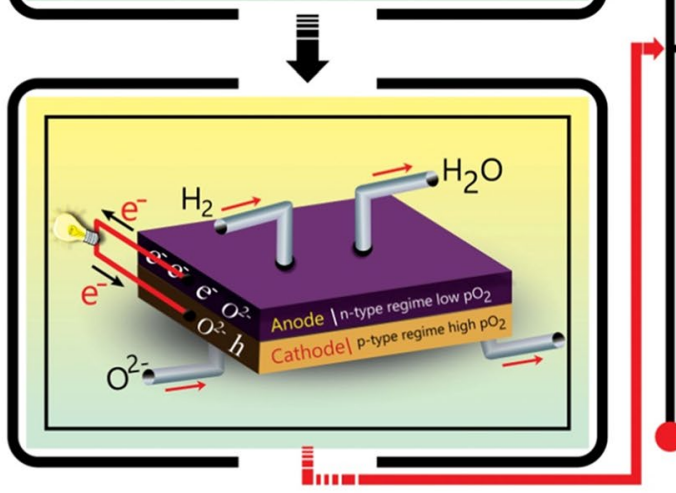

(c)

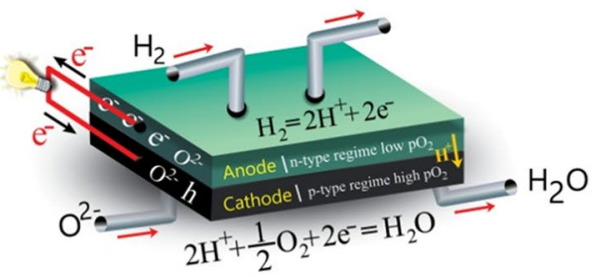

(d)

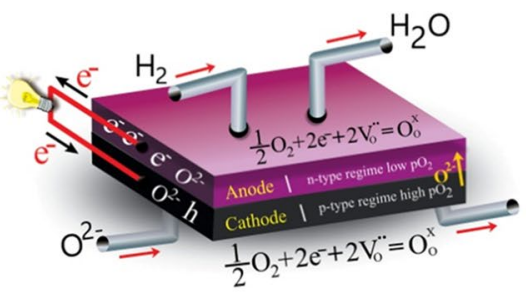

Fig. 1 Transition of the fuel cell from an ionic electrolyte device (a) to an electrolyte-layer-free device, e.g., an n-p junction assembly (b), along with the further $\mathrm{H}^{+}$conducting fuel cell (c) and the $\mathrm{O}^{2-}$ conducting fuel (d), in which a built-in electric field is formed between the anode (n) and cathode (p) junction to promote $\mathrm{H}^{+}$and

A logical deduction can be made that by employing semiconductor electrochemistry, because a semiconductor provides two energy levels (the conduction band (CB) and the valence band (VB)), the charge transfer occurring at these two energy levels can be easily controlled. Therefore, our idea about the variation in the electron density that is helpful for ionic transport at these two energy levels and the interfaces for clean energy conversion and storage devices need to be recapitulated. This work provides a new view of these novel aspects of state-of-the-art research and development in the energy sector, where the two typical fields of fuel cells and batteries are focused on realizing a comprehensive understanding of the roles of semiconductors and bands in energy conversion and storage, with extension to other energy applications in a broader view.

\section{Electrochemistry of the Semiconductor- Electrolyte Interface and Fuel Cells}

Electrochemistry is the core of developing multilayer devices and is most commonly used in assembling twoelectrode cells and for referring the voltage to a reference electrode (RE). The science of electrochemistry is central to the manufacturing, performance, and reliability of multilayer devices. Semiconductor electrochemistry is a particularly
$\mathrm{O}^{2-}$ transfer to complete the redox reactions and electricity generation on-site without the interfacial polarization and losses caused by the ionic electrolyte separator in conventional fuel cells (a) [3]. Partially redrawn with permission from Ref. [3]. Copyright 2013 RSC

relevant and fundamental area for fuel cell devices, including ion transport in fuel cells [14]. Semiconductor heterostructure-based fuel cells are convenient to scale using the energy levels relative to the vacuum level (VL) compared to those with an intrinsic ionic conductor. This allows us to track the local variations in energy, electrostatic potential, and Fermi energy $\left(E_{\mathrm{F}}\right)$ inside the solids by a standard representation. Control of the flowing charge carriers across the junction is the most important point for SOFCs in that electrons must be prevented from crossing over the electrolyte membrane. Before we discuss the properties of the semiconductor-electrolyte interface, examining some of the general aspects of electron and ion transfer reactions at the semiconductor-electrolyte interface from the perspective of the energy band positions is beneficial.

An electrochemical cell (e.g., an SOFC) contains two electrodes (anode and cathode) separated by an electrolyte for completion of the redox reactions. However, to realize the redox reactions and prevent electrons from crossing over the electrolyte membrane, many different methods can be employed, e.g., (1) creating a metal-electrolyte interface (the Schottky-type junction, see Fig. 2a, or the Mott transition from a metal conductor to an electronic insulator (Fig. 2b) related to the band description of the Mott transition induced by $\mathrm{H}_{2}$ or $\mathrm{H}^{+}$incorporation) where electrons are localized while ions conduct (a typical example is the 
strongly correlated perovskite $\mathrm{SmNiO}_{3}$, Fig. 2c); (2) constructing a semiconductor (n-type)-semiconductor (p-type) heterostructure to suppress electron conduction (Fig. 2d); (3) using electronically insulating and ionically conductive electrolytes in conventional fuel cells with the anode/electrolyte/cathode configuration (Fig. 2e); and (4) replacing this configuration by the "three-in-one" single-layer device in which macro-redox reactions occur at the anode and cathode separated by the electrolyte while nano-redox reactions can occur at nano-redox units, where each anode, electrolyte and cathode component can be compacted into n-type, ionic and p-type particles, respectively, as shown in Fig. 2f. Since a metal can provide or accept electrons easily at the surface when it is used as either an anode or a cathode, control of the semiconductor-electrolyte interface (SEI) structure and properties to allow stable ionic conductivity is a critical and highly challenging task. That is why the semiconductor-semiconductor interface (Fig. 2f, fuel cell reaction at the nanoscale) can provide more advantages than metals or SEIs because they have distinct energy levels, the CB and the VB. A spontaneous charge transfer reaction can occur depending on the nature of the doping and charge carrier density. In the case of the SEI, a spontaneous charge transfer reaction can occur depending on the nature of the energy levels or their overlap with those of the redox electrolytes. There are three distinct possibilities for such an overlap: (1) overlap with the $\mathrm{CB},(2)$ overlap with the VB, and (3) overlap with both bands. These processes lead to energy band alignment or energy band reorientation.

The electrode/electrolyte interfaces in SOFCs are of significant importance, which, on the one hand, provide the active sites for electrode electrochemical reactions and, on the other hand, contribute to a major loss of the power output due to the different ionic and electronic natures [3, 4]. Gleaning an understanding from the fundamental aspects is therefore necessary to develop sustainable SOFCs in the future. Normally, electron-hole $\left(\mathrm{e}^{-} / \mathrm{h}^{+}\right)$pairs are separated on the anode and cathode sides by the band structure, i.e., $\mathrm{CB}$ and VB, and built-in electric field (BIEF) depending on the nature of materials, so the energy band provides an important pathway for the electrochemical reactions to occur.

At the interface of two distinct materials, the free electrons and holes in the $\mathrm{CB}\left(E_{\mathrm{c}}\right)$ and the $\mathrm{VB}\left(E_{\mathrm{v}}\right)$ of the anode and cathode exchange their charges with the electrolyte by diffusion-based processes, and charge neutrality accumulates at the interface. The Fermi levels $\left(E_{\mathrm{F}}\right)$ attempt to reach an equilibrium position due to charge diffusion processes, and

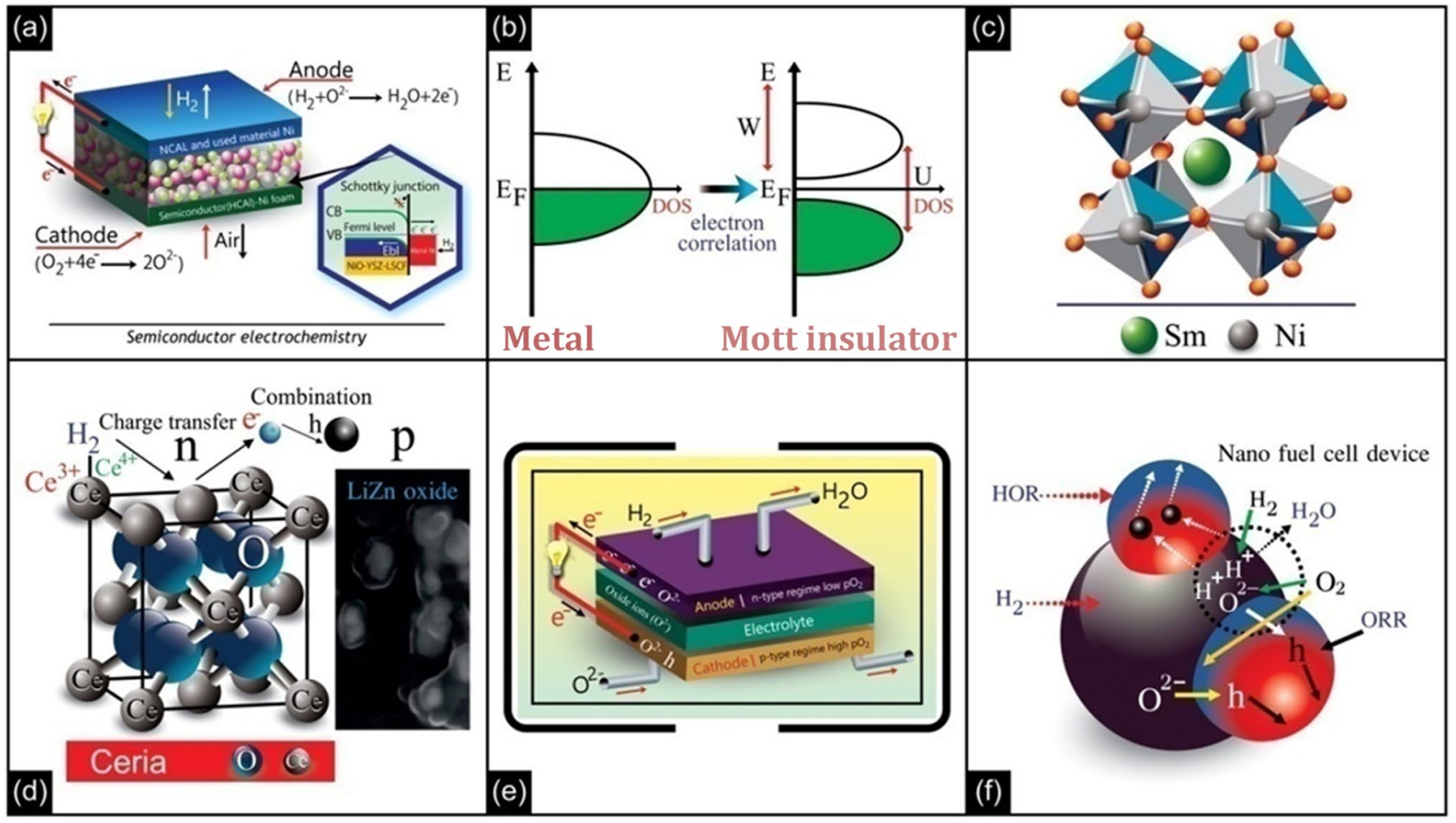

Fig. 2 Various methods to block electron transfer: a Creating a metal-electrolyte interface (the Schottky-type junction). b Using the Mott transition to block electrons transferring to the electrolyte; $\mathbf{c}$ the strongly correlated perovskite $\mathrm{SmNiO}_{3}$ is an example of such a fuel cell. Reproduced with permission from Ref. [16]. Copyright 2016
Springer Nature. d Using a $\mathrm{p}-\mathrm{n}$ heterostructure material to tune the semiconductor into an ionic conductor with no net electron conduction. Reproduced with permission from Ref. [17]. Copyright 2014 RSC. e Realizing the fuel cell redox reactions at the electrolyte-separated macroscale and $\mathbf{f}$ nonelectrolyte or EFFC nanoscale 
the resultant $E_{\mathrm{F}}$ can be associated with the difference in the positions of their respective $E_{\mathrm{F}}(\mathrm{s})$. These processes force the energy band structures to be rearranged and hence induce band bending. In semiconductors, the position of $E_{\mathrm{F}}$ normally depends on the dopants (n-type or p-type) and their contents; in addition, there are no other reference energy states to assess the energy levels. Therefore, the position of $E_{\mathrm{F}}$ is assessable only when the distance between $E_{\mathrm{F}}$ and $E_{\mathrm{c}}$ or $E_{\mathrm{v}}$ is known. The position of $E_{\mathrm{F}}$ is composed of two parts, the chemical potential $\left(\mu_{\mathrm{e}}\right)$ and electrostatic potential $\left(e_{\mathrm{x}}\right)$, and can be expressed as the following Eq. (1), providing that there is no additional charge:

$E_{\mathrm{F}}=\left(\mu_{\mathrm{e}}-e_{\mathrm{x}}\right)=-e \varphi$

where $\mu_{\mathrm{e}}$ is the chemical potential of the bulk, while $e_{\mathrm{x}}$ arises from the surface dipole; in the case of heterostructure semiconductors, dipoles are formed by the surface structure due to a particular ionic charge distribution. These effects depend on the crystal plane and the reconstruction of the surface atoms. This dipole also influences the electron affinity. In agreement with the band of a semiconductor with an electrolyte, the electrolyte can be visualized as possessing two distinct energy levels: an empty level as the oxidized level (represented by the most probable energy level $E_{\mathrm{ox}}^{\mathrm{O}}$ ) and a filled level as the reduced level (represented by the most probable energy level $E_{\mathrm{re}}^{\mathrm{O}}$ ).

Generally, band bending due to charge transfer at the interface can be of two types: (1) upward band bending and (2) downward band bending, depending on the type of material. In the case of an n-type semiconductor (the anode), the Fermi level is usually at higher energy (less negative) than the Fermi level of the electrolyte, and electrons try to move from the semiconductor (the anode) to the electrolyte to equilibrate the Fermi level. In this case, the Fermi level of the semiconductor decreases in energy until both Fermi levels overlap; hence, $E_{\mathrm{F}}$ shifts to lower energy, which results in upward band bending, as shown in Fig. 3a, and creates a depletion layer close to the surface of the anode/electrolyte interface. In the case of p-type (normally on the cathode side) semiconductors, the Fermi level normally exists at lower energy (near the VB and more negative) than that of the electrolyte, and its $E_{\mathrm{F}}$ shifts to higher energy (downward band bending) at the interface. A positive space charge region $\left(\mathrm{h}^{+}\right)$is therefore created near the surface of the anode interface due to electronic transformation in the electrolyte to achieve electronic equilibrium. A positive space charge means that fewer electrons are in this region. Hence, a charge accumulation/depletion region is formed at the cathode/electrolyte interface. Additionally, on the electrolyte side, when it is fully charged, the electrolyte interface will be left with non-absorbed ions with opposite charges, and they will form a Helmholtz double layer (Fig. 3a). (a)
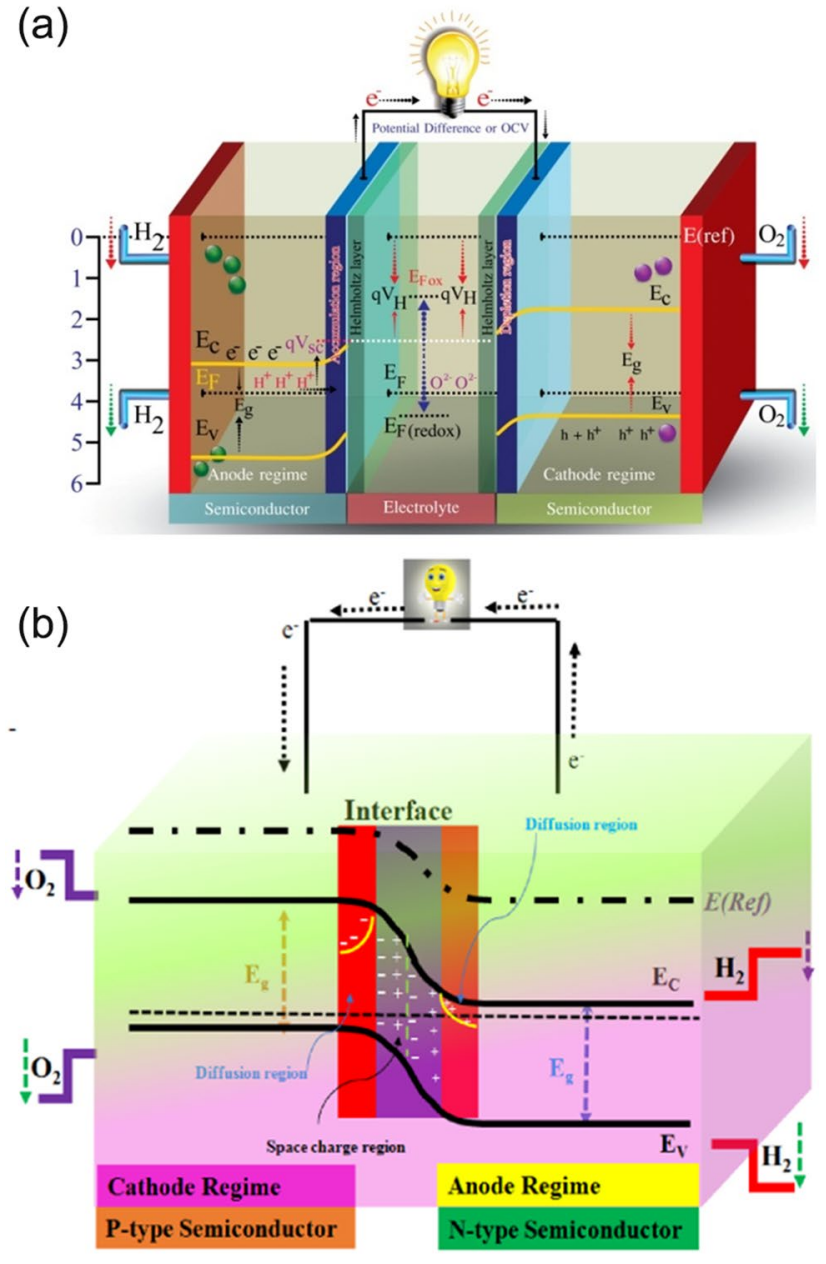

Fig. 3 a Schematic of the working principle and energy diagram at the SOFC electrode (semiconductor) interface with the electrolyte in which Fermi levels are in equilibrium positions, and $\mathbf{b}$ schematic of the working principle and energy diagram for an SOFC without an electrolyte

A space charge region (created due to a change in $E_{\mathrm{F}}$ position) can be expected on the semiconductor side due to the difference in electrostatic potential in the process, and its charge will be transferred to the electrolyte, leading to energy loss and band structure rearrangement (see Fig. 3a). The concentration of the charges in the space charge region depends on the potential difference between the semiconductor and the electrolyte. The potential drop in the space charge region is much more than that in the Helmholtz layer because the former spreads over a large area and exists due to ionization of the acceptor solid, while the latter is built up at the single-atom level away from the electrolyte surface. The inhomogeneous distribution of charges in the interfacial region establishes a BIEF that crosses over the electrode-electrolyte interface (EEI), which can also aid in ion or charge carrier crossing of the interface barrier. In other words, the created electric field produces a "built-in 
potential difference". Another significant aspect of such a built-in potential at the interface is to oppose the flow of electrons and holes across the junction, so it is denoted as the potential barrier to establish the device voltage. In practical devices, instead of using two interfaces (anode/electrolyte and cathode/electrolyte), a one-interface device (as shown in Fig. 3b), such as by joining an n-type semiconductor and a p-type semiconductor, can work efficiently (low space charge region) by creating a BIEF to block electron penetration while enabling high ionic transport. This advanced configuration should be employed to construct a device with one electrode by ohmic contact to reduce the polarization loss.

\section{Semiconductor Electrochemistry in Fuel Cells}

Based on the fundamentals of semiconductor electrochemistry briefly discussed in the above section, we further discuss both conventional ion-based electrolytes and semiconductorbased membranes for fuel cells, with an emphasis on how semiconductor-ionic conductors replace conventional ionic electrolytes, resulting in different scientific principles.

Generally, SOFC reactions can be expressed in KrögerVink notation as follows: in an $\mathrm{O}^{2-}$ conducting electrolyte, the cathode reaction is $0.5 \mathrm{O}_{2}+2 \mathrm{e}^{-}+\rightarrow \mathrm{O}_{\mathrm{O}}^{\mathrm{x}}$, and the anode reaction is $\mathrm{H}_{2}+\mathrm{O}_{\mathrm{O}}^{\mathrm{x}} \rightarrow \mathrm{H}_{2} \mathrm{O}+2 \mathrm{e}^{-}+V_{\mathrm{O}}^{*}$, where $V_{\mathrm{O}}^{*}$ is the oxygen ion vacancy and $\mathrm{O}_{\mathrm{O}}^{\mathrm{x}}$ is the lattice oxygen ion in the electrolyte.

In $\mathrm{H}^{+}$conducting fuel cells, the reaction at the fuel side (anode) is $\mathrm{H}_{2} \rightarrow 2 \mathrm{H}^{+}+2 \mathrm{e}^{-}$, and that at the air side (cathode) is $2 \mathrm{H}^{+}+\frac{1}{2} \mathrm{O}_{2}+2 \mathrm{e}^{-} \rightarrow \mathrm{H}_{2} \mathrm{O}$. In both cases, the overall cell reaction is $\mathrm{H}_{2}+\frac{1}{2} \mathrm{O}_{2} \rightarrow \mathrm{H}_{2} \mathrm{O}$. Both anode and cathode materials can now easily be conceptualized as semiconductors in a strongly reducing or oxidizing atmosphere. More importantly, electronic exchange with chemicals or electron/ hole transport is crucial to realize electrochemical reactions and current collection. However, semiconducting properties were not explicitly noted until they were addressed by K. Singh in 2013 (see also Fig. 1a) [3]. The electrical conduction behavior of the electrode material of SOFCs changes at different oxygen partial pressures, leading to electron or hole conduction in reducing or oxidizing atmospheres, respectively. A particular example is the perovskite oxide series that has been extensively developed and investigated as electrode materials for SOFCs [18-25]. They have been used as electrode materials to yield reduced material and cell fabrication costs and higher resistance to carbon deposition and sulfur poisoning due to amphiprotic electron and hole conduction under different oxygen partial pressures [26, 27].

\subsection{Electrolyte-based SOFCs}

Regarding the electrolyte materials in SOFCs, significant effort has been put in developing materials with higher ionic conductivity but limited electronic conduction in a fuel cell atmosphere. Indeed, a large number of new oxide ionic conductor materials have been developed and reported in the literature, such as doped ceria [28], $\mathrm{La}_{0.9} \mathrm{Sr}_{0.1} \mathrm{Ga}_{0.8} \mathrm{Mg}_{0.2} \mathrm{O}_{3}$ [29], $\mathrm{BaZr}_{0.1} \mathrm{Ce}_{0.7} \mathrm{Y}_{0.2-x} \mathrm{Yb}_{x} \mathrm{O}_{3-\delta}$ [30], $\mathrm{Ln}_{10}\left(\mathrm{SiO}_{4}\right)_{6} \mathrm{O}_{3}$ [31], calcium-doped $\mathrm{LaNbO}_{4}$ [32], $\mathrm{Na}_{0.5} \mathrm{Bi}_{0.5} \mathrm{TiO}_{3}$ [33], and $\mathrm{Sr}_{1-x} \mathrm{Na}_{x} \mathrm{SiO}_{3-0.5 x}$ [34]. Most of them show higher ionic conductivity than that of the state-of-the-art electrolyte YSZ, particularly for low-temperature operation. In addition, proton conductors for low-temperature (LT) SOFCs have recently stimulated worldwide interest and research input [23, 25, 35-38]. However, none of these materials can replace YSZ for industrial deployment yet due to the intrinsic issues with these materials, such as the high reactive activity with cell components and instability under fuel cell conditions. In addition, neither YSZ nor the newer generation of $\mathrm{O}^{2-}$ or $\mathrm{H}^{+}$conducting materials can meet the high ionic conductivity demand of $0.1 \mathrm{~S} \mathrm{~cm}^{-1}$ below $600^{\circ} \mathrm{C}$, the so-called LT range. The electrolyte material and resultant system challenges remain in SOFCs.

In parallel, another stream of LT SOFC research involves developing two-phase composite electrolytes that have better ionic conductivity than single-phase electrolytes, as discussed above for single $\mathrm{O}^{2-}$ or $\mathrm{H}^{+}$ion conducting electrolytes, which highly rely on the oxygen vacancy concentration of the oxide matrix. These composite electrolytes originate from ceria-salt composites [39], with a focus on ceria-carbonate composite systems [5, 40-48]. In addition, ceria-carbonate electrolytes have a unique characteristic of hybrid or dual $\mathrm{H}^{+}$and $\mathrm{O}^{2-}$ conduction [5, 48-60], which was even stable over $6000 \mathrm{~h}$ [61]. Figure 4 illustrates these three types of ion conducting electrolyte-based SOFC devices. In all these electrolyte-based electrode devices, semiconductors, commonly perovskite oxides, for example, $(\mathrm{La}, \mathrm{Sr})$ $(\mathrm{Co}, \mathrm{Fe}) \mathrm{O}_{3},(\mathrm{La}, \mathrm{Sr}) \mathrm{MnO}_{3},(\mathrm{La}, \mathrm{Sr}) \mathrm{CoO}_{3}$, and $(\mathrm{Ba}, \mathrm{Sr})(\mathrm{Co}, \mathrm{Fe})$ $\mathrm{O}_{3}[62-64,64,66]$, and transition metal oxides, e.g., $\mathrm{LiNiO}_{2}$ and $\mathrm{LiNiCoAlO}_{2}[67,68]$, are used as electrode materials, and they can be described in the semiconductor electrochemical way as discussed in Sect. 2. Another interesting report given by Kim et al. [69] presented the development of a hybrid solid oxide cell-based mixed $\mathrm{H}^{+}$and $\mathrm{O}^{2-}$ conductive $\mathrm{BaZr}_{0.1} \mathrm{Ce}_{0.7} \mathrm{Y}_{0.1} \mathrm{Yb}_{0.1} \mathrm{O}_{3-\delta}$ electrolyte for the simultaneous electrolysis of water at the anode and cathode; significantly improved the electrolysis cell performance and stable operation during $60 \mathrm{~h}$ of nonstop testing were achieved.

Different from classic heteroelement structural doping, the oxygen ionic conduction in doped ceria occurs through bulk diffusion via oxygen vacancies, while $\mathrm{Zhu}$ et al. [68, 70] recently reported that nondoped $\mathrm{CeO}_{2}$ itself acts as a 
super proton conductor under fuel cell conditions. The precipitated $\mathrm{CeO}_{2-x}$ materials treated at different temperatures (as-synthesized, 600 and $1000{ }^{\circ} \mathrm{C}$ ) all showed defective particle surfaces with many oxygen defects on the surface according to careful high-angle annular dark-field scanning transmission electron microscopy and electron energy loss spectroscopy analyses. The lower the treatment temperature, the higher the oxygen vacancy concentration is. In addition, a charge depletion layer is formed between the interface of core ceria (intrinsic-type semiconductor, $\mathrm{Ce}^{4+}$ ) and surface ceria (n-type semiconductor, $\mathrm{Ce}^{3+}$ ), which favors superionic conduction. Moreover, the ionic transport through ceria was determined to be a proton conduction contribution instead of an oxygen ion contribution by intentionally adding a pure proton conductor layer between the electrolyte and cathode. An isotopic effect study also supported the claims. Consequently, the constrained surface region of $\mathrm{CeO}_{2-\delta}$ is believed to build long-term proton shuttles, suggesting a new methodology for and understanding of the proton transport in general oxides and a promising electrolyte material for newgeneration proton ceramic fuel cells.

\subsection{Semiconductor Membrane Fuel Cells}

According to traditional knowledge, electrolytes with partial electronic conductivity will significantly reduce the cell voltage and system energy efficiency [71]. In 1992, Riess proposed the use of mixed ionic and electronic conductors (MIECs) to replace solid-state electrolytes to run SOFCs when the FC is operated close to its maximum power output [72]. More recently, a new research emphasis has been put on using semiconductor oxides, more specifically electronic insulating oxides under an applied fuel cell atmosphere, to substitute conventional ion conducting electrolytes for SOFCs. This research was initiated by the revolutionary inventions called a single-layer fuel cell (SLFC) and an EFFC. In these cases, one-layer semiconductor-ionic conductor composite components can replace the conventional three-layer components of the anode, electrolyte and cathode while providing functions that can make the fuel cell operate in the same way [73-77]. Such a single-layer material is made of a semiconductor-ionic mixed or heterostructure composite, which leads to the same fuel cell functionality and holds the potential for lower temperature and higher performance applications. Later, a series of semiconductor materials were shown as SLFCs in the same way, e.g., $\mathrm{La}_{0.9} \mathrm{Sr}_{0.1} \mathrm{InO}_{3-\delta}[78,79], \mathrm{Li}_{x} \mathrm{Al}_{0.5} \mathrm{Co}_{0.5} \mathrm{O}_{2}$ [80], $\mathrm{SmNiO}_{3}$ [16], $\mathrm{La}_{0.2} \mathrm{Sr}_{0.25} \mathrm{Ca}_{0.45} \mathrm{TiO}_{3}$ [81], $\mathrm{TiO}_{2}$ [82], $\mathrm{LiZnO}$ [83], and $\mathrm{Na}_{0.5} \mathrm{Bi}_{0.5} \mathrm{TiO}_{3}$ [33]. From a classic SOFC perspective, electronic conduction through the electrolyte/ membrane will cause significant losses in both cell voltage (open-circuit voltage, OCV) and energy efficiency, while for the semiconductor fuel cell, the fuel cell behavior is not influenced. Generally, the electrical conduction behavior of semiconducting materials is well recognized to be a function of the applied oxygen partial pressure, as seen from the aforementioned symmetric perovskite oxide electrode materials in SOFCs. Moreover, some materials show interesting electronic, pure ionic and hole conduction under low, intermediate and high oxygen partial pressure conditions at a certain temperature [78]. For example, the electrical conductivity of $\mathrm{La}_{0.9} \mathrm{Sr}_{0.1} \mathrm{InO}_{3-\delta}$ changes only slightly with oxygen partial pressures from $10^{-5}$ to $10^{-20}$ between 600 and $800{ }^{\circ} \mathrm{C}$, a typical ionic conduction behavior, while it exhibits typical p-type and n-type semiconducting behavior under higher and lower oxygen partial pressure conditions [78, 79]. The constructed SOFCs based on only the $\mathrm{La}_{0.9} \mathrm{Sr}_{0.1} \mathrm{InO}_{3-\delta}$ material, called SLFCs, gave an OCV of higher than $1.0 \mathrm{~V}$ and a maximum power output of $3 \mathrm{~mW} \bullet \mathrm{cm}^{-2}$ at $800{ }^{\circ} \mathrm{C}$. However, in such a single layer fuel cell, a functional layer of $\mathrm{La}_{0.9} \mathrm{Sr}_{0.1} \mathrm{InO}_{3-\delta}$ performing as an electrolyte layer remains, which is similar to that in the classic SOFC, its p-and n-type conduction behavior is utilized for electrode functionality.

Therefore, in semiconductor-based fuel cell devices, the working principles built on semiconductor and heterostructure membranes should differ from those of ion electrolyte membrane-based fuel cells. A technical illustration of the difference between classic and newly developed semiconductor-based SOFCs is shown in Fig. 5, which shows the SOFC based on the $\mathrm{O}^{2-}$ conducting electrolyte without
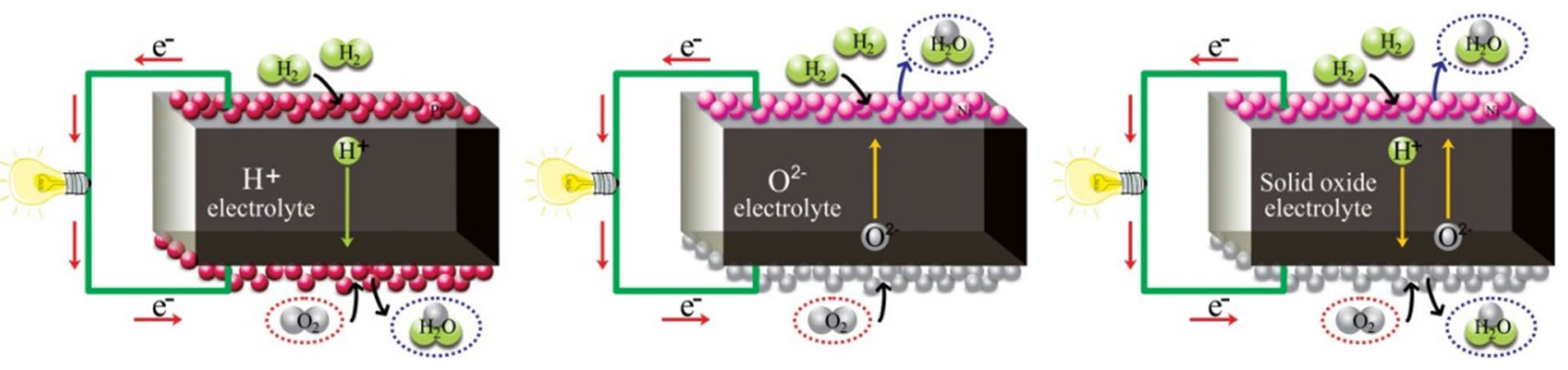

Fig. 4 Electrolyte-based SOFCs with $\mathrm{O}^{2-}, \mathrm{H}^{+}$or hybrid $\mathrm{H}^{+} / \mathrm{O}^{2-}$ conducting membranes 
electron passage. However, in Fig. 5b, the coexistence of both ions (e.g., the $\mathrm{O}^{2-}$ case) and electrons, which is commonly the case in semiconductors and their heterostructures, takes over the electrolyte. Surprisingly, the latter (Fig. 5b) can display even better performance than the electrolytebased SOFC. This is truly a new phenomenon, and therefore, the semiconductor electrochemistry of fuel cells shows high potential for further deployment. It is naturally introduced in term of semiconductors and physical principles in the following.

Different from the above case, recently, mixed ionic and electronic conducting single-phase oxides have also been transformed into ionic conductors with ionic transfer number close to unity under fuel cell conditions, more accurately by proton incorporation, according to the reports by Lan [80] and Zhou et al. [16]. As a typical LIB electrode, the layered structure $\mathrm{Li}_{x} \mathrm{Al}_{0.5} \mathrm{Co}_{0.5} \mathrm{O}_{2}$ (LCAO) can accommodate protons in the layer between two transition metal oxide layers or by replacing lithium ions (Fig. 6a). Therefore, the obtained proton-intercalated $\mathrm{Li}_{x} \mathrm{H}_{y} \mathrm{CoO}_{2}$ at the cathode leads to a change in the oxidation states of transition metal ions, which consequently relieves the electronic conduction of traditional semiconducting $\mathrm{LiCoO}_{2}$; the substitution of Co with $\mathrm{Al}$ also leads to suppressed electronic conduction in the materials, changing the semiconductor to a pure ionic conductor with an almost unity ionic transfer number.

Similarly, a distinguished work by Zhou et al. [16] reported that the highly electronically conducting perovskite oxide $\mathrm{SmNiO}_{3}$ (SNO) was transformed into a unitytransference ionic conductor under fuel cell conditions $\left(\mathrm{H}_{2}, \mathrm{Pt} / \mathrm{SNO} / \mathrm{Pt}\right.$, air, Fig. 6b). An in-depth investigation showed that when SNO is exposed to a hydrogen anode, hydrogen dissociates into protons and electrons accompanied by the reduction of $\mathrm{Ni}^{3+}$ cations in $\mathrm{SNO}$ to $\mathrm{Ni}^{2+}$. The proton incorporation into the SNO lattice forms $\mathrm{H}-\mathrm{SNO}$ because the concentration and potential gradient lead to

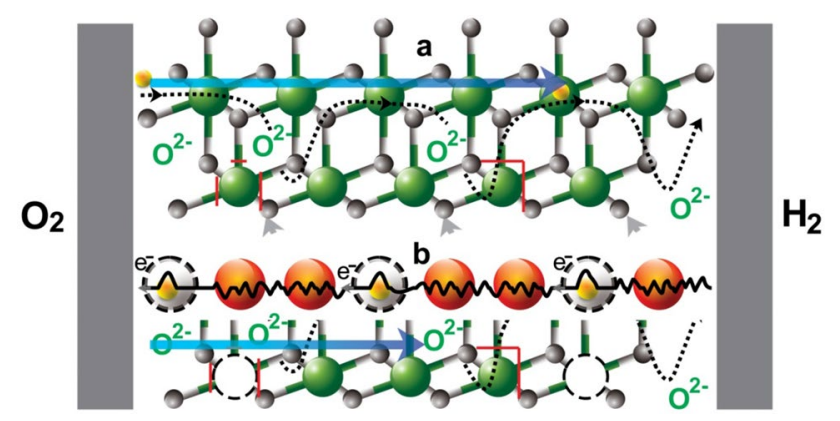

Fig. 5 a Conventional $\mathrm{O}^{2-}$ conduction based on oxygen vacancies in YSZ or ceria electrolyte, and $\mathbf{b}$ coexistence of electronic and ionic conduction in the semiconductor or its heterostructure material membranes filling-controlled Mott transitions such that electrons are no longer able to transport through the $E_{\mathrm{g}}^{2}$ manifold because of the large electronic bandgap. Such a transition enables hydrogenated SNO to provide the electrolyte functionality for SOFCs. Moreover, according to experimental measurements, the proton conductivity in $\mathrm{H}-\mathrm{SNO}$ is higher than that in well-known high proton conductivity $\mathrm{Ba}(\mathrm{Ce}, \mathrm{Zr}) \mathrm{O}_{3}$-based perovskite oxides at reduced temperatures. A micro-SOFC with optimal electrolyte thickness and an active $\mathrm{Pt}$ metal electrode gave a maximum power density of $225 \mathrm{~mW} \bullet \mathrm{cm}^{-2}$ at $525{ }^{\circ} \mathrm{C}$, which is comparable to the best value in the applied temperature range. Therefore, both LCAO and SNO materials eventually transform from high electron (hole) conductors to common proton conducting electrolyte-based fuel cells, i.e., the proton ceramic fuel cell (PCFC) process, even though the SOFC devices are initially constructed as a semiconductor device. Hydrogenation of oxides leads to wide electronic bandgap materials, which is an interesting approach to design and obtain new-generation electrolytes for SOFCs working at low temperatures [4].

Another work by Dong et al. [82] reported that thin film $\mathrm{TiO}_{2}$, a typical semiconductor, could be used as an electrolyte for LT SOFCs. SOFCs based on a $\mathrm{TiO}_{2}$ thin film were fabricated by a spin coating method on an electrode supporter, giving an OCV of $1.1 \mathrm{~V}$ and a maximum power output of $364 \mathrm{~mW} \bullet \mathrm{cm}^{-2}$ at $550{ }^{\circ} \mathrm{C}$. This certificates that typical semiconductors can be used as electrolytes for SOFCs. In this work, Dong proposed the use of the universal energy band principle instead of electronic conduction theory to evaluate the possible application of novel materials for fuel cell and photocatalysis applications. They proposed that the electronic conduction in electrolyte materials should not be blamed if the energy band diagram can be well aligned in a real fuel cell. Under a fuel cell atmosphere, $\mathrm{TiO}_{2}$ possesses a higher $\mathrm{CB}$ above the redox potential of $\mathrm{H}_{2} / \mathrm{H}^{+}$and a lower $\mathrm{VB}$ than the redox potential of $\mathrm{O}_{2} / \mathrm{O}^{2-}$, which can help effectively block electron transport through the electrolyte. When $\mathrm{TiO}_{2}$ is combined with the electrode material $\mathrm{LiNi}_{0.8} \mathrm{Co}_{0.15} \mathrm{Al}_{0.05} \mathrm{O}_{2}$, a LT highactivity symmetric electrode, the electrons produced at the anode cannot move to the $\mathrm{CB}$ of $\mathrm{TiO}_{2}$; therefore, they can only follow the external circuit of the cell and transfer to the cathode, realizing the fuel cell function. The nearly Nernst theoretical voltage and excellent LT power output verified the feasibility and correctness of the adopted approach. More recently, SOFCs using the pure $\mathrm{SrTiO}_{3}$ "electrolyte" delivered a peak power output of $620 \mathrm{~mW} \bullet$ $\mathrm{cm}^{-2}$ at $550{ }^{\circ} \mathrm{C}[81,84,85]$, while it is an intrinsic semiconductor and presents a high n-type electronic conductivity. Moreover, the ionic conductivity reached $0.24 \mathrm{~S} \bullet$ $\mathrm{cm}^{-1}$ at $550{ }^{\circ} \mathrm{C}$, which is higher than that of most current 
(a)

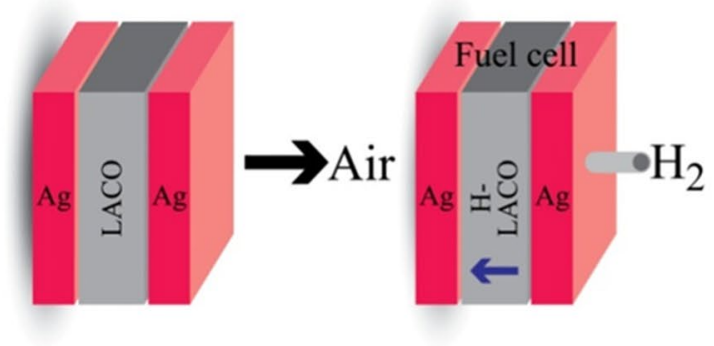

(b)

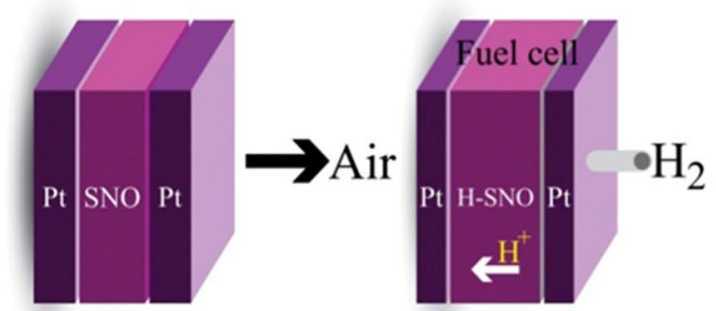

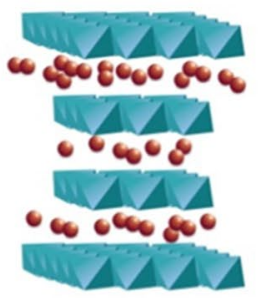

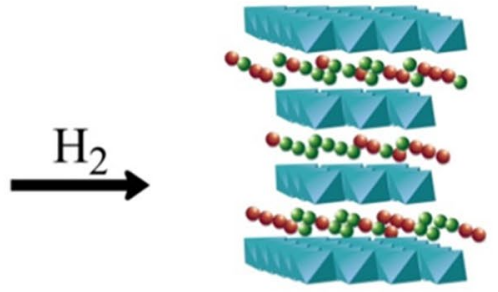

$\mathrm{Li}_{x} \mathrm{Al}_{0.5} \mathrm{Co}_{0.5} \mathrm{O}_{2}$

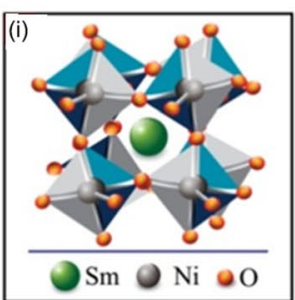

(iv) Electron itinerant

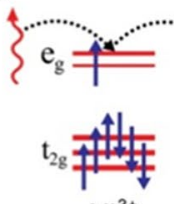

$\mathrm{Ni}^{3+}$
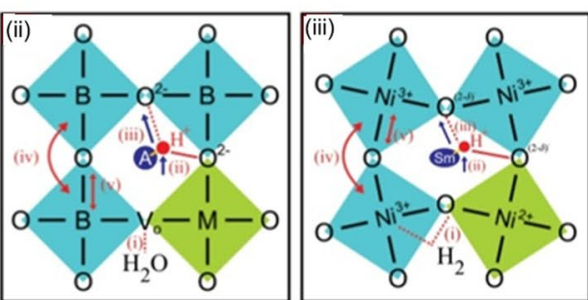

(V) Electron localized

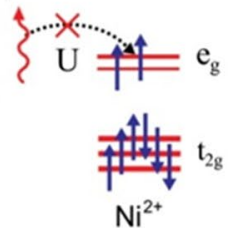

Fig. 6 Working principle of SLFCs operated based on existing SOFC science, i.e., ionic (in the case of $\mathrm{H}^{+}$conduction) electrolyte devices formed during in situ fuel cell operation, regardless of the construction of the semiconductor layer configuration. a For the LCAO case.

single-phase pure solid-state ionic conductive electrolyte materials. A deep examination of the material texture and morphology confirmed that a superhigh ionic conductivity layer with an amorphous structure is formed on the surface of $\mathrm{SrTiO}_{3}$ [85]. Regardless, the superior electrochemical activity suggests a new approach for LT SOFC applications.

\subsection{Semiconductor Heterostructure Materials}

Commonly, compared to the single-phase electrolyte drawback that it cannot meet all the strict requirements for reliable, robust and durable SOFCs, semiconductor heterostructures with one ionic material or another semiconductor phase incorporated can provide better performance, such as higher ionic conductivities, than conventional electrolytes and increase the triple-phase boundary for electrode reactions $[1,86]$. For example, bulk p-n heterostructure materials have been proposed to tune semiconductors to superionic conduction because the $\mathrm{p}$ and $\mathrm{n}$ materials can balance free electrons/holes, thus suppressing electron leakage and resulting in no net electrons [17, 67, 87-95]. Compositing p-type $\mathrm{LiZnO}$ with the ionic conductor doped ceria (n-type under fuel electrode conditions) for LT SOFCs has been
Reproduced with permission from Ref. [80]. Copyright 2014 WileyVCH. b For the SNO case. Reproduced with permission from Ref. [16]. Copyright 2016 Springer Nature

reported. Interestingly, this bulk hybrid electrolyte exhibits superionic conductivity $\left(>0.1 \mathrm{~S} \bullet \mathrm{cm}^{-1}\right.$ over $\left.300{ }^{\circ} \mathrm{C}\right)$ and excellent electrolytic performance $\left(400-630 \mathrm{~mW} \bullet \mathrm{cm}^{-2}\right)$ between 480 and $550^{\circ} \mathrm{C}$. Unexpectedly, the hybrid semiconductor shows net-electron-free transport in the electrolyte, as reflected by the sufficient $\mathrm{OCV}$ under $\mathrm{H}_{2}$ /air fuel cell conditions. Later, as demonstrated by Zhu et al. [77] and Wang et al. [89], fuel cells based on the planar/bulk n-type/p-type semiconducting heterostructure gave impressive fuel cell performance under $\mathrm{H}_{2} /$ air conditions. Wu et al. [96] synthesized a $\mathrm{ZnO} / \mathrm{SrTiO}_{3}$ semiconductor by a hydrothermal method and used it as a photocatalytic hydrogen production catalyst and a fuel cell "electrolyte layer". The photocatalytic cell based on this $\mathrm{n} / \mathrm{n}$-type semiconducting heterostructure gave a $\mathrm{H}_{2}$ production rate of $1317.44 \mu \mathrm{mol} \bullet \mathrm{g}^{-1}$ within $5 \mathrm{~h}$ under solar-light irradiation and an OCV of $1.14 \mathrm{~V}$, and SOFCs presented a maximum power density of $564 \mathrm{~mW} \bullet$ $\mathrm{cm}^{-2}$ at $550{ }^{\circ} \mathrm{C}$. In the interesting work by Cai et al. [97], they composited all the materials in a typical SOFC, such as a $\mathrm{Ni}(\mathrm{O})-\mathrm{YSZ}$ anode, a YSZ electrolyte and an LSM-YSZ cathode, to identify each component that could function as a semiconductor-ionic membrane for electrolyte functioning. They also made an 'all-components-in-one' fuel cell, and the complex hybrid heterostructure layer with the NCAL 
electrode displayed a three times higher device performance than the conventional YSZ electrolyte-based fuel cell under the same operating conditions (temperature and fuel/oxidant partial pressure). The "all-in-one" heterostructures appear to have much better ionic transport properties than existing ionic materials by creating a motorway for ionic transport along the semiconductor and ionic interfaces, which normally contain a space charge layer and present band bending and an induced BIEF, facilitating ionic transport/transfer, which cannot be manipulated by single-phase materials.

Moreover, an EFFC can be superior to traditional electrochemical fuel cells due to the physical removal of the conventional ionic electrolyte layer and two physical interfaces between the electrolyte and the electrodes (the anode/the cathode). In particular, in semiconductors and heterostructures, coupling interactions between charge carriers, electrons (holes) and ions impact ionic transport and redox reactions from the conventional macro-redox in three-layer devices to the nano-redox in single-layer configuration devices (as shown in Fig. 2f) as new-generation energy devices. These results suggest that semiconductor electrochemistry could play an important role in improving the fuel cell performance and developing new science and technology to continuously increase fuel cell R\&D [1, 2]. By integrating the band structure and alignment fundamentals into fuel cell design, many new energy devices/technologies jointly harnessing semiconductors and electrochemistry have been demonstrated with plentiful examples. In addition, band alignment can also make significant contributions to speed up the HOR and ORR by adjusting the reactant and intermediate phase absorption energies, thus lowering the required activation energy, which has been commonly demonstrated in the photochemical water splitting process and other related fields $[15,98]$. From a reaction product aspect, facilitating fuel cell functions for a reversible process via photochemical water splitting to $\mathrm{H}_{2}$ and $\mathrm{O}_{2}$ is desirable to generate $\mathrm{H}_{2} \mathrm{O}$ and simultaneously produce electricity. These new emerging trends of semiconductors and the associated methodologies have changed the fuel cell electrochemistry and brought new scenarios for fuel cell R\&D toward semiconductor-fuel cell science, which may pave the commercialization roadmap for SOFCs and impact other areas in chemistry, such as photocatalysis/electrolysis and batteries.

Without the ion conducting/electron insulating layer, a key question arises: how does such a device work? In fact, various semiconductors and heterostructures have been widely applied without by using the traditional anode/electrolyte/cathode structure based on multiple built-in junctions. These devices have been developed by introducing new functional semiconductor materials or a semiconductor with an ionic conductor to form heterostructures. Figure 7 presents an overview of these novel fuel cells based on threelayer, two-layer, and single-layer structures. A three-layer fuel cell device (Fig. 7a) employs a semiconductor (S) or a semiconductor heterostructure $\left(\mathrm{S}^{+}\right)$membrane instead of the sole ionically conductive electrolyte, but it can be tuned to an ion conducting electrolyte (function) via a semiconductor-ionic conductor transition in the fuel cell environment. This device has the three-layer configuration of the anode (n-semiconductor or metal)/S or $\mathrm{S}^{+} /$cathode (p-semiconductor). The abovementioned LCAO and SNO fuel cells belong to this type. This configuration may also include an electrolyte layer because the ionic conductor or wide bandgap semiconductor can be treated/tuned as an electrolyte [2]. Fig. $7 \mathrm{~b}$ illustrates the fuel cell device constructed by using only two layers, an anode and a cathode; refer to Fig. $7 \mathrm{~b}$ for a planar $\mathrm{p}-\mathrm{n}$ junction device. Conventional SOFC technology commonly uses a three-layer structure, two electrodes using a mixture of semiconductor oxides, e.g., $\mathrm{NiO}$ for the anode and perovskite oxide for the cathode, and an ionic electrolyte, e.g., doped ceria or zirconia, to enhance the ionic conductivity in the electrodes and effectively minimize the electrode polarization while enhancing the power output. The double-layer device was previously reported [77] and has been verified by other interesting research work. These devices were constructed by using typical SOFC components/layers in contact without an electrolyte between them. By removing the middle electrolyte layer, the fuel cell can still function due to the $\mathrm{p}-\mathrm{n}$ junction principle.

In the new semiconductor approach, as illustrated in Fig. $7 \mathrm{c}$, the configuration looks very similar to that of the SOFC electrode component of mixed electrolyte and electrode materials: all three layer materials of anode, electrolyte, and cathode (where the anode and the cathode could be the same material, leading to symmetrical fuel cells) can function within a single component, i.e., the "three-in-one" type device [99], outperforming the traditional three-layer fuel cell functions, thus stimulating significant industrial and fundamental research interest with remarkable and additional contributions to fuel cell science and technology. From a technical aspect, the bulk heterojunction (BHJ) requires delicate nanoengineering to tailor the $\mathrm{n}$ and $\mathrm{p}$ conducting properties at the nanolevel using heterostructure composite technology.

In later developments, metal-semiconductor-based Schottky junctions were discovered to have a significant impact on fuel cell performance [100]. The Schottky junction fuel cell device, as shown in Fig. 7d, is constructed using only one type of semiconductor, either n- or p-type (more commonly) or a semiconductor-ionic heterostructure composite, as reported [100, 101]. In this case, a Schottky barrier is formed between the anodic reduced metal/alloy surface and a single layer of the p-type (or n-type) semiconductor (Fig. 7d), thus preventing electrons from passing through the device internally. Moreover, by applying energy band design/alignment to design fuel cells as a new 

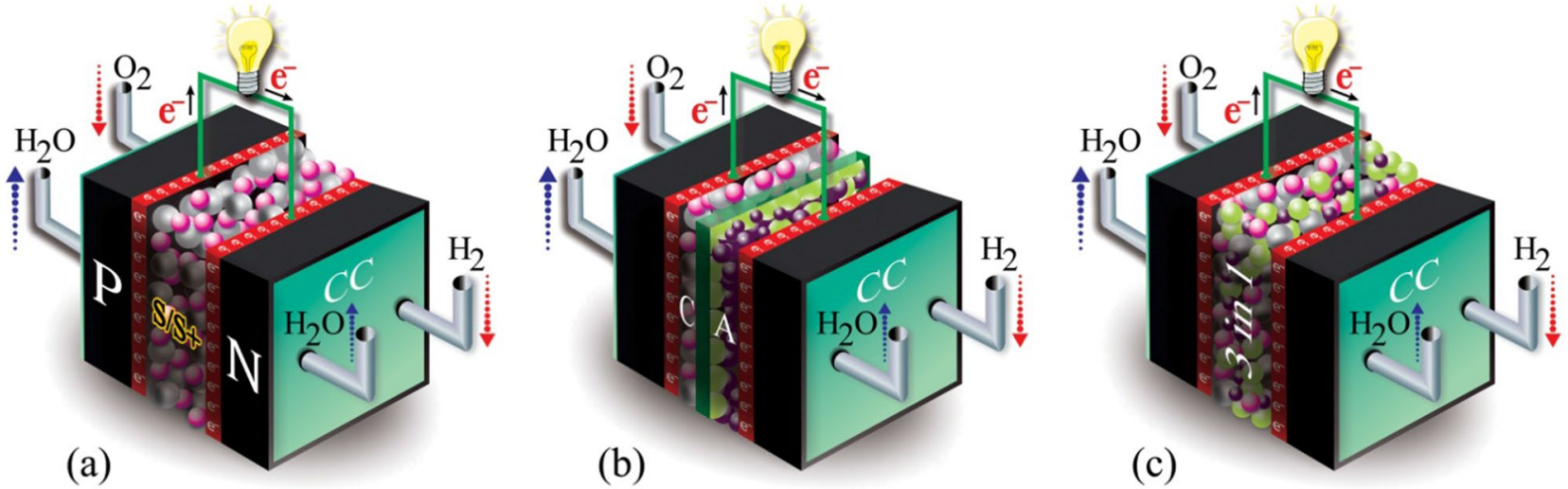

$\mathrm{CC}=$ Current collection

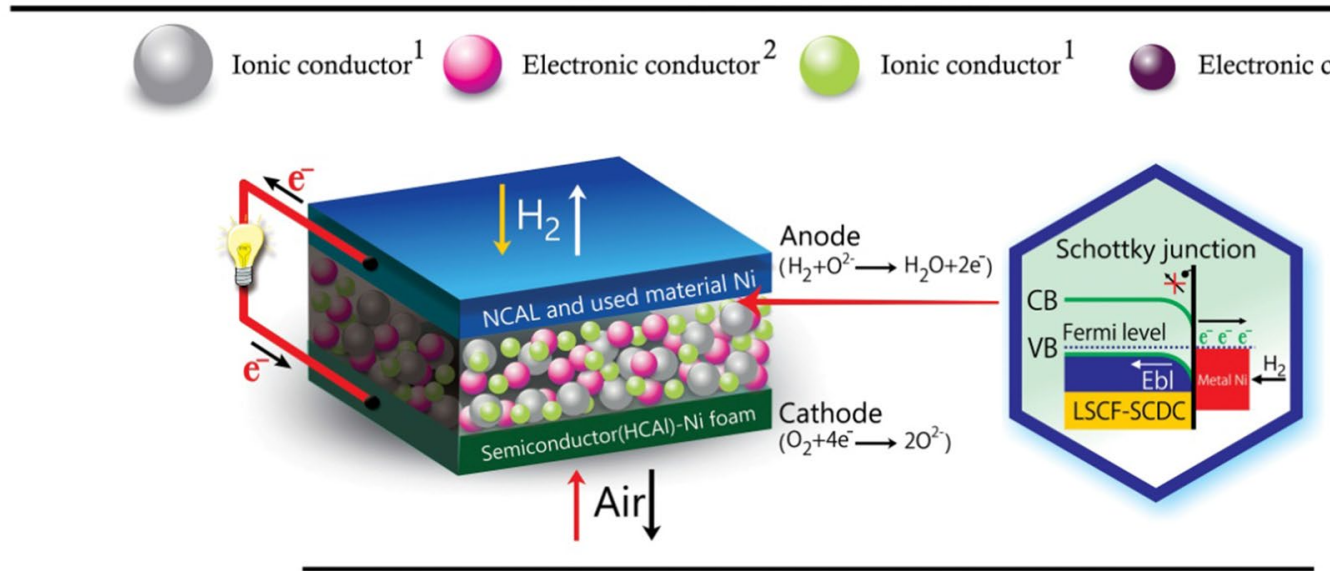

(d)

Semiconductor electrochemistry

Fig. 7 Schematic illustration of (a) a three-layer fuel cell device consisting of an n-semiconductor anode/semiconductor (S) or semiconductor heterostructure $\left(\mathrm{S}^{+}\right)$membrane/p-semiconductor cathode; (b) a two-layer fuel cell: A, anode; C, cathode; and (c) a 3-in-1 SLFC device. CC stands for current collection. All cases are considered with both $\mathrm{H}^{+}$and $\mathrm{O}^{2-}$ conduction; in the case of only one type of

fuel-to-electricity conversion technology, the performance can arguably surpass that of fuel cells [102]. The designed energy band and alignment based on PSC science can isolate the device (Fig. 8a, b), avoiding the electronic short-circuiting problem and simultaneously generating electricity with high power outputs $>1000 \mathrm{~mW} \bullet \mathrm{cm}^{-2}$ at $550{ }^{\circ} \mathrm{C}$. There is a unique charge separation mechanism, discovered by Zhu et al. [103], as shown in Fig. 8c.

This can be a general methodology for new conversion devices based on semiconductors and principles. In the latest research, Dong et al. [82] also used the same strategy to construct a fuel cell with $\mathrm{TiO}_{2}$ as the electrolyte. They claimed that electronic conduction in electrolyte materials should not be blamed if the energy band diagram can be well aligned in a real fuel cell. In the fuel cell, the CB of the electrolyte, either a pure ionic conductor or a semiconductor, should be higher than the redox potential of $\mathrm{H}_{2} / \mathrm{H}^{+}$; therefore, the ions, either $\mathrm{H}^{+}$or $\mathrm{O}^{2-}$, the corresponding $\mathrm{H}_{2} \mathrm{O}$ formation is only on one side, the former in the cathode $\left(\mathrm{O}_{2}\right.$, which can be air) and the latter in the anode. Reproduced with permission from Ref. [77]. Copyright 2011 RSC. (d) Fuel cell constructed by a Schottky junction device, in which the Schottky junction barrier is caused by band bending at the metal/semiconductor (electrolyte) interface

electrons cannot jump to the $\mathrm{CB}$ of the electrolyte, or are blocked by the electrolyte layer. $\mathrm{TiO}_{2}$ is a typical semiconductor with great application potential in photovoltaics and photoelectrochemistry [104-108]. At first glance, the use of $\mathrm{TiO}_{2}$ will cause the short-circuiting issue in fuel cell conditions. This does not happen in this fuel cell case since $\mathrm{TiO}_{2}$ possesses a higher $\mathrm{CB}$ above the redox potential of $\mathrm{H}_{2} /$ $\mathrm{H}^{+}$and a lower VB than the redox potential of $\mathrm{O}_{2} / \mathrm{O}^{2-}[98$, $105,109,110]$, which can help effectively block electron transport through the electrolyte. When combined with the advanced NCAL symmetric electrode for demo-SOFCs, the reduced electrode materials in the anode have a lower $\mathrm{CB}$ than the redox potential of $\mathrm{H}_{2} / \mathrm{H}^{+}$and a higher $\mathrm{VB}$ than the redox potential of $\mathrm{O}_{2} / \mathrm{O}^{2-}$. The electrons and holes can easily move to and be collected in the electrode. Such a fuel cell device has been successful demonstrated, delivering $1.10 \mathrm{~V}$ (OCV) and $364 \mathrm{~mW} \mathrm{~cm}^{-2}$ at $550{ }^{\circ} \mathrm{C}$ under hydrogen/air 
Fig. 8 a Nanoparticle contacts between the LSCF and Sm and Ca co-doped Ceria (SCDC), b energy diagram of the $\mathrm{p}-\mathrm{n} \mathrm{BHJ}$ for charge separation on the $\mathrm{H}_{2}$ contact side at the particle level, and $\mathbf{c}$ energy band diagram at the device level. Reproduced with permission from Ref. [103]. Copyright 2017 Elsevier

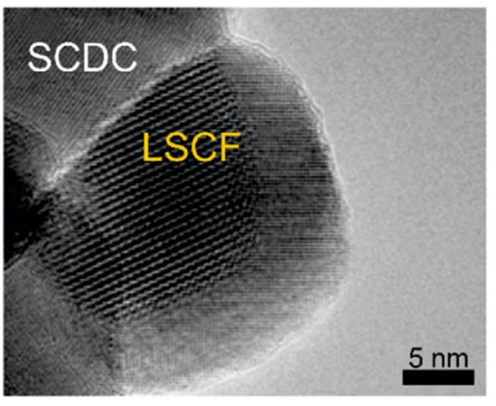

(a)

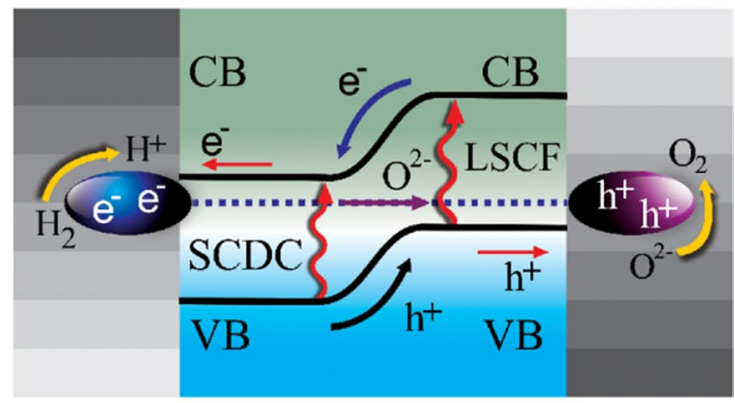

(b)

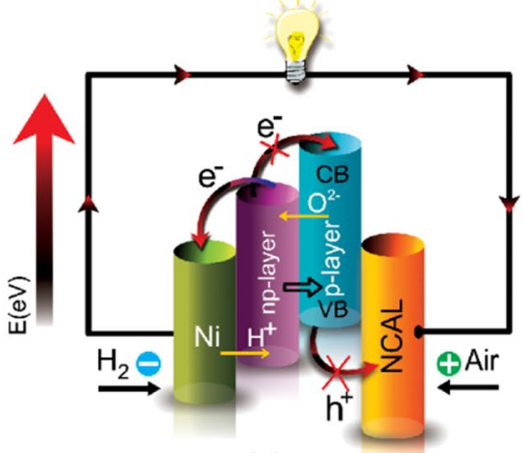

(c)

conditions. The nearly Nernst theoretical voltage and excellent power output have verified the proposed methodology. Electronic conduction in electrolytes could be well managed by properly choosing the electrode material based on the energy band diagram method $[111,112]$. More details will be further discussed in Sect. 5 .

To this end, a summary of the developed semiconductor and/or heterostructure material-based fuel cells and their corresponding electrical properties, including ionic conductivity and fuel cell electrochemical performance, is presented in Table 1. The ionic conductivities of semiconductor or heterostructure materials are much higher than those of single-phase oxide ion conducting electrolytes, which enables superior fuel cell electrochemical performance at low temperatures. Semiconductor-based fuel cells may suggest an alternative promising approach to develop next-generation SOFCs or PCFCs.

\section{Semiconductors and Semiconductor Electrochemistry in Batteries}

\subsection{LIB as a Typical System}

Extensive examples of employing semiconductor bands and physics in electrochemistry can be widely found. One of the featured fields is the rechargeable batteries or secondary batteries, such as LIBs, Na-ion batteries, and $\mathrm{Zn}$ - and Mg-ion batteries, which reversibly convert electrical and chemical energy via redox reactions, thus storing electrical energy as a chemical potential in their electrodes $[122,123]$. Metal ions are reversibly transported between the anode and cathode and through the electrolyte, releasing or storing energy. Generally, the specific capacity of electrodes and the working voltage of the battery determine the energy density of these devices, i.e., the differential chemical potentials between the cathode and the anode. In these typical electrochemical devices, semiconductor properties and band theories provide a new comprehensive understanding of the scientific principles for improving the electrochemical reaction kinetics to increase the rate performance. Taking the LIB as a typical system, Fig. 9 shows an example of understanding the lithium battery electrochemistry and cathode (positive electrode) materials from the semiconductor band structure and physics (Fig. 9a). The $\mathrm{LiCoO}_{2}$ positive electrode (cathode) energy as a function of the density of states, being relevant to the Fermi level of $\mathrm{Co}^{4+/ 3+}$ redox couples, is presented in the device energy level diagram with respect to the highest occupied molecular orbital (HOMO) and the lowest unoccupied molecular orbital (LUMO) of the liquid electrolyte, as shown in Fig. 9b [124]. The battery voltage, i.e., the OCV $V_{\text {OC }}$ can be expressed as $V_{\text {oc }}=\left(\mu_{\mathrm{c}}-\mu_{\mathrm{a}}\right) / \mathrm{e}$, where e is the magnitude of the electronic charge and the difference in chemical potential between the anode (a) and the cathode (c).

Normally, this working voltage is also determined by the electrochemical window of the electrolyte (see Fig. 9b), which is controlled by the energy gap between the HOMO 
Table 1 Electrical properties of the applied semiconductor-based fuel cells

\begin{tabular}{|c|c|c|c|c|c|}
\hline Number & Semiconductor materials & Fuel cell configuration & Ionic conductivity & $\begin{array}{l}\text { Fuel cell electrochemical } \\
\text { performance }\end{array}$ & References \\
\hline 1 & $\mathrm{La}_{0.9} \mathrm{Sr}_{0.1} \mathrm{InO}_{3-\delta}$ & $\mathrm{Pt} / \mathrm{La}_{0.9} \mathrm{Sr}_{0.1} \mathrm{InO}_{3-\delta} / \mathrm{Pt}$ & $\begin{array}{l}7.6 \times 10^{-3} \mathrm{~S} \bullet \\
\mathrm{cm}^{-1} @ 900{ }^{\circ} \mathrm{C}\end{array}$ & $3 \mathrm{~mW} \bullet \mathrm{cm}^{-2}$ at $800{ }^{\circ} \mathrm{C}$ & {$[78,79]$} \\
\hline 2 & $\mathrm{Li}_{x} \mathrm{Al}_{0.5} \mathrm{Co}_{0.5} \mathrm{O}_{2}$ & $\begin{array}{l}\mathrm{Ag} / \mathrm{Li}_{x} \mathrm{Al}_{0.5} \mathrm{Co}_{0.5} \mathrm{O}_{2}(0.79 \mathrm{~mm}) / \\
\mathrm{Ag}\end{array}$ & $0.1 \mathrm{~S} \bullet \mathrm{cm}^{-1}$ at $500{ }^{\circ} \mathrm{C}$ & $173 \mathrm{~mW} \bullet \mathrm{cm}^{-2} @ 525^{\circ} \mathrm{C}$ & {$[80]$} \\
\hline 3 & $\mathrm{SmNiO}_{3}$ & $\mathrm{Pt} / \mathrm{SmNiO}_{3} / \mathrm{Pt}$ & $\begin{array}{l}2.17 \mathrm{E}-3 \mathrm{~S} \bullet \\
\mathrm{cm}^{-1} @ 500{ }^{\circ} \mathrm{C}\end{array}$ & $225 \mathrm{~mW} \bullet \mathrm{cm}^{-2}$ at $500{ }^{\circ} \mathrm{C}$ & {$[16]$} \\
\hline 4 & $\mathrm{La}_{0.2} \mathrm{Sr}_{0.25} \mathrm{Ca}_{0.45} \mathrm{TiO}_{3}-\mathrm{SDC}$ & $\mathrm{Ni} / \mathrm{LSCT}-\mathrm{SDC} / \mathrm{NCL}$ & - & $175 \mathrm{~mW} \bullet \mathrm{cm}^{-2}$ at $550{ }^{\circ} \mathrm{C}$ & [81] \\
\hline 5 & $\mathrm{TiO}_{2}$ & $\mathrm{NCAL} / \mathrm{TiO}_{2} / \mathrm{NCAL}$ & - & $364 \mathrm{~mW} \bullet \mathrm{cm}^{-2}$ at $550^{\circ} \mathrm{C}$ & {$[82]$} \\
\hline 6 & SDC-LiZnO & $\mathrm{Ni} / \mathrm{SDC}-\mathrm{LiZnO} / \mathrm{LiNiO}$ & $\begin{array}{l}>0.1 \mathrm{~S} \bullet \mathrm{cm}^{-1} \text { over } \\
300^{\circ} \mathrm{C}\end{array}$ & $\begin{array}{l}400-630 \mathrm{~mW} \bullet \mathrm{cm}^{-2} \text { at } \\
\quad 480-550^{\circ} \mathrm{C}\end{array}$ & [17] \\
\hline 6 & $\mathrm{LiZnO}$ & $\begin{array}{l}\text { NCAL-pasted } \mathrm{Ni} / \mathrm{LiZnO} / \\
\text { NCAL-pasted } \mathrm{Ni}\end{array}$ & $\begin{array}{l}0.028-0.087 \mathrm{~S} \bullet \mathrm{cm}^{-1} \text { at } \\
550{ }^{\circ} \mathrm{C}\end{array}$ & $\begin{array}{l}138-443 \mathrm{~mW} \bullet \mathrm{cm}^{-2} \text { at } \\
425-5500^{\circ} \mathrm{C}\end{array}$ & {$[83]$} \\
\hline 7 & $\mathrm{Na}_{0.5} \mathrm{Bi}_{0.5} \mathrm{TiO}_{3}$ & - & $\sim 0.01 \mathrm{~S} \bullet \mathrm{cm}^{-1}$ at $600{ }^{\circ} \mathrm{C}$ & - & {$[33]$} \\
\hline 8 & Core-shell $\mathrm{CeO}_{2}-\mathrm{CeO}_{2-x}$ & $\begin{array}{l}\mathrm{Ni}-\mathrm{NCAL} / \mathrm{CeO}_{2}-\mathrm{CeO}_{2-x} / \mathrm{NCAL}- \\
\mathrm{Ni}\end{array}$ & $0.16 \mathrm{~S} \bullet \mathrm{cm}^{-1} @ 520^{\circ} \mathrm{C}$ & $\begin{array}{l}697 \mathrm{~mW} \bullet \mathrm{cm}^{-2} @ \\
520^{\circ} \mathrm{C}\end{array}$ & [68] \\
\hline 9 & BZCFY-ZnO & $\begin{array}{l}\text { NCAL-Ni/BZFCY-ZnO/NCAL- } \\
\mathrm{Ni}\end{array}$ & $\begin{array}{l}0.07 \text { to } 0.20 \mathrm{~S} \bullet \mathrm{cm}^{-1} \text { at } \\
\quad 400-500^{\circ} \mathrm{C}\end{array}$ & $\begin{array}{l}248-643 \mathrm{~mW} \bullet \mathrm{cm}^{-2} \text { at } \\
400-500{ }^{\circ} \mathrm{C}\end{array}$ & [67] \\
\hline 10 & LSCF-SDC & $\begin{array}{l}\mathrm{Ag} / \mathrm{NCAL} / \mathrm{LSCF}-\mathrm{SCDC} / \mathrm{NCAL} / \\
\mathrm{Ag}\end{array}$ & - & $\begin{array}{l}1080 \mathrm{~mW} \bullet \mathrm{cm}^{-2} \text { at } \\
550{ }^{\circ} \mathrm{C}\end{array}$ & {$[102,103]$} \\
\hline 11 & $3 \mathrm{C}-\mathrm{SiC} / \mathrm{ZnO}$ & NCAL/3C-SiC-ZnO/NCAL & $0.12 \mathrm{~S} \bullet \mathrm{cm}^{-1}$ & $270 \mathrm{~mW} \bullet \mathrm{cm}^{-2}$ at $550{ }^{\circ} \mathrm{C}$ & [113] \\
\hline 12 & $\begin{array}{l}\mathrm{SrFe}_{0.75} \mathrm{Ti}_{0.25} \mathrm{O}_{3-\delta^{-}} \\
\mathrm{Sm}_{0.25} \mathrm{Ce}_{0.75} \mathrm{O}_{2-\delta}\end{array}$ & $\begin{array}{c}\mathrm{NCAL} / \mathrm{SrFe}_{0.75} \mathrm{Ti}_{0.25} \mathrm{O}_{3-\delta} \\
\mathrm{Sm}_{0.25} \mathrm{Ce}_{0.75} \mathrm{O}_{2-\delta} / \mathrm{NCAL}\end{array}$ & $0.1 \mathrm{~S} \bullet \mathrm{cm}^{-1}$ at $520^{\circ} \mathrm{C}$ & $920 \mathrm{~mW} \bullet \mathrm{cm}^{-2}$ at $520^{\circ} \mathrm{C}$ & [114] \\
\hline 13 & $\begin{array}{l}\mathrm{La}_{0.65} \mathrm{Sr}_{0.3} \mathrm{Ce}_{0.05} \mathrm{Cr}_{0.5} \mathrm{Fe}_{0.5} \mathrm{O}_{3-\delta^{-}} \\
\quad \text { SDC }\end{array}$ & $\begin{array}{l}\text { NCAL/ } \\
\mathrm{La}_{0.65} \mathrm{Sr}_{0.3} \mathrm{Ce}_{0.05} \mathrm{Cr}_{0.5} \mathrm{Fe}_{0.5} \mathrm{O}_{3-\delta^{-}} \\
\text {SDC/NCAL }\end{array}$ & - & $837 \mathrm{~mW} \bullet \mathrm{cm}^{-2}$ at $550{ }^{\circ} \mathrm{C}$ & [115] \\
\hline 14 & $\begin{array}{l}\text { Nanocrystalline structure } \\
\mathrm{Gd}_{0.1} \mathrm{Ce}_{0.9} \mathrm{O}_{2}\end{array}$ & $\begin{array}{l}\text { NCAL/0.5 mm Gd } \mathrm{me}_{0.1} \mathrm{Ce}_{0.9} \mathrm{O}_{2} / \\
\text { NCAL }\end{array}$ & $0.37 \mathrm{~S} \bullet \mathrm{cm}^{-1}$ at $520^{\circ} \mathrm{C}$ & $591.8 \mathrm{~cm}^{-2}$ at $550{ }^{\circ} \mathrm{C}$ & [116] \\
\hline 15 & $\mathrm{SrTiO}_{3}$ & $\mathrm{NCAL} / \mathrm{SrTiO}_{3}(\mathrm{STO}) / \mathrm{NCAL}-\mathrm{Ni}$ & $\begin{array}{l}0.16-0.24 \mathrm{~S} \bullet \mathrm{cm}^{-1} \text { at } \\
450-550{ }^{\circ} \mathrm{C}\end{array}$ & $\begin{array}{l}0.31-0.62 \mathrm{~W} \bullet \mathrm{cm}^{-2} \text { at } \\
450-550{ }^{\circ} \mathrm{C}\end{array}$ & {$[84,85]$} \\
\hline 16 & $\mathrm{Ce}_{0.8} \mathrm{Sm}_{0.2} \mathrm{O}_{2-\delta}$ and $\mathrm{SrTiO}_{3}$ & NCAL-Ni/SDC-STO/NCAL-Ni & $\begin{array}{l}0.05-0.14 \mathrm{~S} \bullet \mathrm{cm}^{-1} \text { at } \\
450-550{ }^{\circ} \mathrm{C}\end{array}$ & $\begin{array}{l}1.1 \mathrm{~V} \\
892 \mathrm{~mW} \bullet \mathrm{cm}^{-2}\end{array}$ & {$[93]$} \\
\hline 17 & $\begin{array}{l}\text { Natural hematite ore compos- } \\
\text { ited with } \mathrm{ZnO}\end{array}$ & NCAL-Ni/composite/NCAL-Ni & - & $580 \mathrm{~mW} \bullet \mathrm{cm}^{-2}$ at $550{ }^{\circ} \mathrm{C}$ & [117] \\
\hline 18 & $\mathrm{La} / \mathrm{Pr}$ codoped $\mathrm{CeO}_{2}-\mathrm{ZnO}$ & NCAL-Ni/LCP-ZnO/NCAL-Ni & $\begin{array}{l}0.08-0.29 \mathrm{~S} \bullet \mathrm{cm}^{-1} \text { at } \\
475-550{ }^{\circ} \mathrm{C}\end{array}$ & $1055 \mathrm{~mW} \bullet \mathrm{cm}^{-2}$ at $550^{\circ}$ & [118] \\
\hline 20 & $\mathrm{La}_{0.25} \mathrm{Sr}_{0.75} \mathrm{TiO}_{3}$ & $\begin{array}{l}\text { NCAL-Ni/La }{ }_{0.25} \mathrm{Sr}_{0.75} \mathrm{TiO}_{3} / \\
\text { NCAL-Ni }\end{array}$ & $0.221 \mathrm{~S} \bullet \mathrm{cm}^{-1}$ at $550{ }^{\circ} \mathrm{C}$ & $\begin{array}{l}908.2 \mathrm{~mW} \bullet \mathrm{cm}^{-2} \text { at } \\
5500^{\circ} \mathrm{C}\end{array}$ & [84] \\
\hline 21 & NiO-YSZ-LSCF & $\begin{array}{l}\text { NCAL-Ni/NiO-YSZ-LSCF/ } \\
\text { NCAL-Ni }\end{array}$ & - & $\begin{array}{l}1055 \mathrm{~mW} \bullet \mathrm{cm}^{-2} \text { at } \\
550{ }^{\circ} \mathrm{C} \\
\text { OCV: } 1.04 \mathrm{~V}\end{array}$ & [97] \\
\hline 22 & $\begin{array}{l}\text { Hematite/LaCePrO }{ }_{x}^{-} \\
\mathrm{La}_{0.6} \mathrm{Sr}_{0.4} \mathrm{Co}_{0.2} \mathrm{Fe}_{0.8} \mathrm{O}_{3-\delta}\end{array}$ & $\begin{array}{l}\text { NCAL-Ni/hematite/LaCePr } \\
\mathrm{O}_{x-} \mathrm{La}_{0.6} \mathrm{Sr}_{0.4} \mathrm{Co}_{0.2} \mathrm{Fe}_{0.8} \mathrm{O}_{3-\delta} l \\
\text { NCAL-Ni }\end{array}$ & $0.153 \mathrm{~S} \bullet \mathrm{cm}^{-1}$ at $600^{\circ} \mathrm{C}$ & $\begin{array}{l}303-662 \mathrm{~mW} \bullet \mathrm{cm}^{-2} \text { at } \\
500-600{ }^{\circ} \mathrm{C}\end{array}$ & [119] \\
\hline 23 & $\begin{array}{l}\text { Hematite- } \\
\qquad \mathrm{La}_{0.6} \mathrm{Sr}_{0.4} \mathrm{Co}_{0.2} \mathrm{Fe}_{0.8} \mathrm{O}_{3-\delta}\end{array}$ & NCAL-Ni/composite/NCAL-Ni & $\begin{array}{l}0.026 \text { to } 0.084 \mathrm{~S} \bullet \mathrm{cm}^{-1} \text { at } \\
400-600{ }^{\circ} \mathrm{C}\end{array}$ & $467 \mathrm{~mW} \bullet \mathrm{cm}^{-2}$ at $600{ }^{\circ} \mathrm{C}$ & {$[120]$} \\
\hline 24 & $\begin{array}{l}\mathrm{Ba}_{0.5} \mathrm{Sr}_{0.5} \mathrm{Co}_{0.8} \mathrm{Fe}_{0.2} \mathrm{O}_{3-\delta^{-}} \\
\mathrm{Sm}_{0.2} \mathrm{Ce}_{0.8} \mathrm{O}_{1.9}\end{array}$ & NCAL-Ni/composite/NCAL-Ni & - & $655 \mathrm{~mW} \bullet \mathrm{cm}^{-2}$ at $550{ }^{\circ} \mathrm{C}$ & {$[101]$} \\
\hline 25 & 3(H-PSCFN)-7LNSDC & $\mathrm{Ag} / 3$ (H-PSCFN)-7LNSDC/Ag & - & $\begin{array}{l}161.80 \mathrm{~mW} \bullet \mathrm{cm}^{-2} \text { at } \\
600{ }^{\circ} \mathrm{C}\end{array}$ & {$[90]$} \\
\hline 26 & $\begin{array}{l}\mathrm{LiNiCuZn}(\mathrm{Fe}) \text {-oxide-NKSDC } \\
\text { mixture/BSCF-SDC }\end{array}$ & $\begin{array}{l}\mathrm{Ag} / \mathrm{LiNiCuZn}(\mathrm{Fe}) \text {-oxide- } \\
\mathrm{NKSDC} \text { mixture/BSCF-SDC/ } \\
\mathrm{Ag}\end{array}$ & - & $600 \mathrm{~mW} \bullet \mathrm{cm}^{-2}$ at $550{ }^{\circ} \mathrm{C}$ & [77] \\
\hline 27 & $\begin{array}{l}\mathrm{LiNi}_{0.8} \mathrm{Co}_{0.15} \mathrm{Al}_{0.05} \mathrm{O}_{2} / \text { terbium- } \\
\text { doped ceria }\end{array}$ & $\begin{array}{r}\mathrm{Ag} / \mathrm{LiNi}{ }_{0.8} \mathrm{Co}_{0.15} \mathrm{Al}_{0.05} \mathrm{O}_{2} / \\
\text { terbium-doped ceria/Ag }\end{array}$ & - & $230 \mathrm{~mW} \bullet \mathrm{cm}^{-2}$ at $500{ }^{\circ} \mathrm{C}$ & [89] \\
\hline
\end{tabular}


Table 1 (continued)

\begin{tabular}{lllll}
\hline Number & Semiconductor materials & Fuel cell configuration & Ionic conductivity & $\begin{array}{l}\text { Fuel cell electrochemical } \\
\text { performance }\end{array}$ \\
\hline 28 & $\mathrm{La}_{0.6} \mathrm{Sr}_{0.4} \mathrm{Co}_{0.2} \mathrm{Fe}_{0.8} \mathrm{O}_{3-\delta^{-}}$ & NCAL-Ni/composite/NCAL-Ni & $0.188 \mathrm{~S} \bullet \mathrm{cm}^{-1}$ at $600{ }^{\circ} \mathrm{C}$ & $814 \mathrm{~mW}^{\circ} \mathrm{cm}^{-2}$ \\
& $\mathrm{Ca}_{0.04} \mathrm{Ce}_{0.80} \mathrm{Sm}_{0.16} \mathrm{O}_{2-\delta}$ & & $0.039 \mathrm{~S} \mathrm{~cm}$ cm $^{-1}$ at $600{ }^{\circ} \mathrm{C}$ & {$[121]$} \\
$\mathrm{Ca}_{0.04} \mathrm{Ce}_{0.80} \mathrm{Sm}_{0.16} \mathrm{O}_{2-\delta}$ & & & \\
\hline
\end{tabular}

*NCAL: $\mathrm{Ni}_{0.8} \mathrm{Co}_{0.15} \mathrm{Al}_{0.05} \mathrm{LiO}_{2} ; \mathrm{SDC}: \mathrm{Sm}_{0.2} \mathrm{Ce}_{0.8} \mathrm{O}_{2}$

Fig. 9 a Schematic energy level diagram for a lithium cell; $\mathbf{b}$ with $\mathrm{LiCoO}_{2}$ as the cathode and lithium as the anode, illustrating the origin of Voc and relative energy positions with respect to the HOMO and the LUMO of the liquid electrolyte. The Fermi level of the lithium anode is drawn above the LUMO of the electrolyte, indicating that reduction of the electrolyte is usually observed. Note that the Fermi level of the cathode shifts downward during deintercalation. $\mathbf{c}$ Electronic band structure of $\mathrm{LiCoO}_{2}(\mathrm{Li}=1$, left $)$,

$\mathrm{Li}_{0.5} \mathrm{CoO}_{2}(\mathrm{Li}=0.5$, middle $)$ and $\mathrm{CoO}_{2}(\mathrm{Li}=0$, right $)$, as deduced from DFT calculations and experimental measurements. Reproduced with permission from Ref. [126]

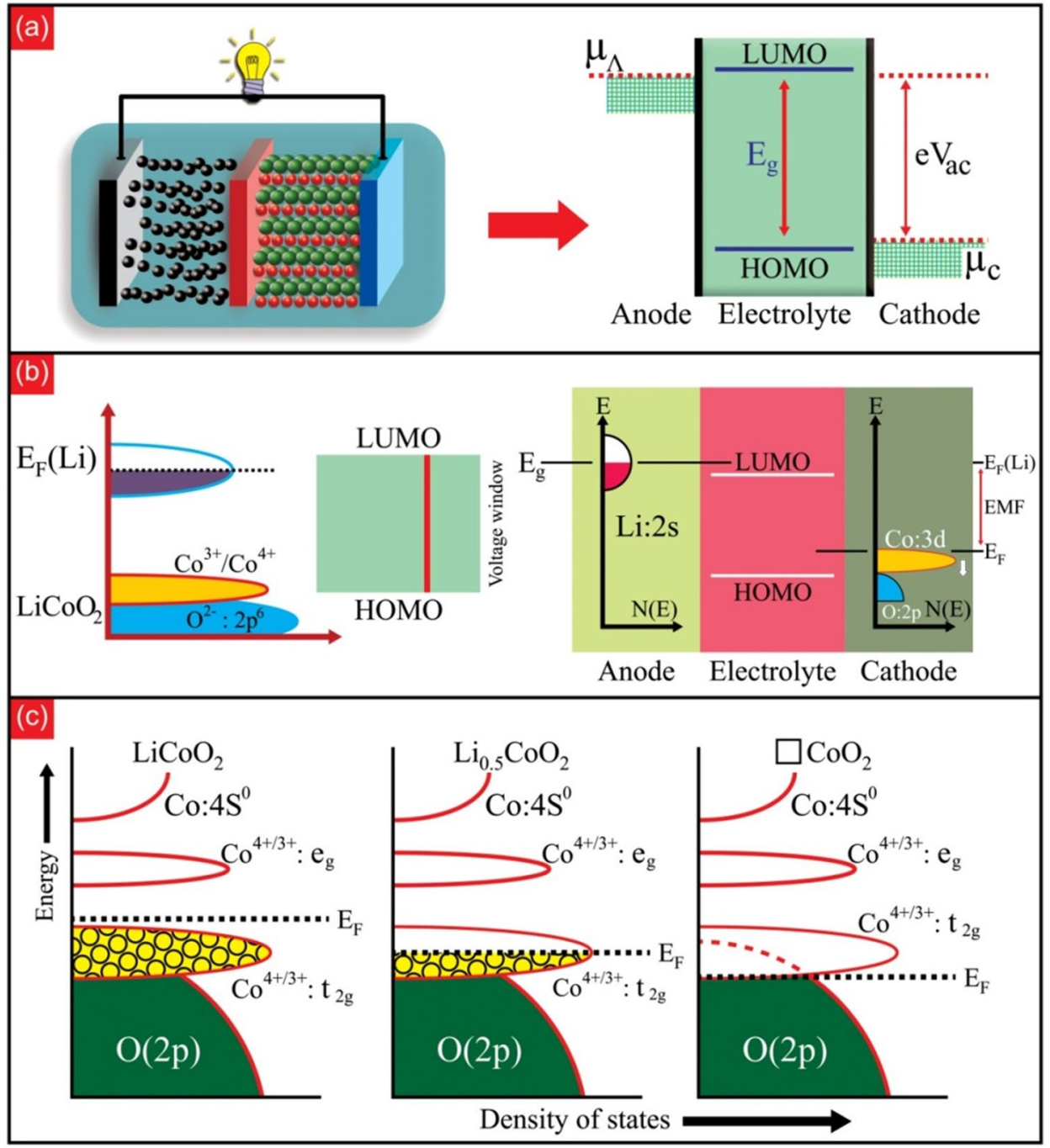

and the LUMO. To work properly, the anode and cathode materials must follow the rule that $\mu_{\mathrm{a}}$ is below the LUMO and $\mu_{\mathrm{c}}$ is above the HOMO; otherwise, the electrolyte will be reduced on the anode surface or oxidized in the cathode zone, forming a passivating solid electrolyte interphase (SEI) film [125]. From a physical point of view, one may relate the cell voltage to the difference in the (electro)chemical potential of the electrons between the cathode and anode, as given by the position of their Fermi levels (see Fig. 9a). However, we should keep in mind that the Fermi level (electron chemical potential) of (single) electrode materials in the discussion of electrode potentials is not exact but quite often provides reasonable accuracy and results.

In Ensling's work, the authors highlighted the significance of the (partially) covalent character of the device capacity and stability as well as electrode kinetics after investigating the electronic structure of the $\mathrm{LiCoO}_{2}$ cathode materials. Figure 9c presents three typical structures of $\mathrm{LiCoO}_{2}(\mathrm{Li}=1$, left $), \mathrm{Li}_{0.5} \mathrm{CoO}_{2}(\mathrm{Li}=0.5$, middle $)$ and $\mathrm{CoO}_{2}$ $\left(\mathrm{Li}=0\right.$, right) after $\mathrm{Li}^{+}$removal from the $\mathrm{LiCoO}_{2}$ structure 


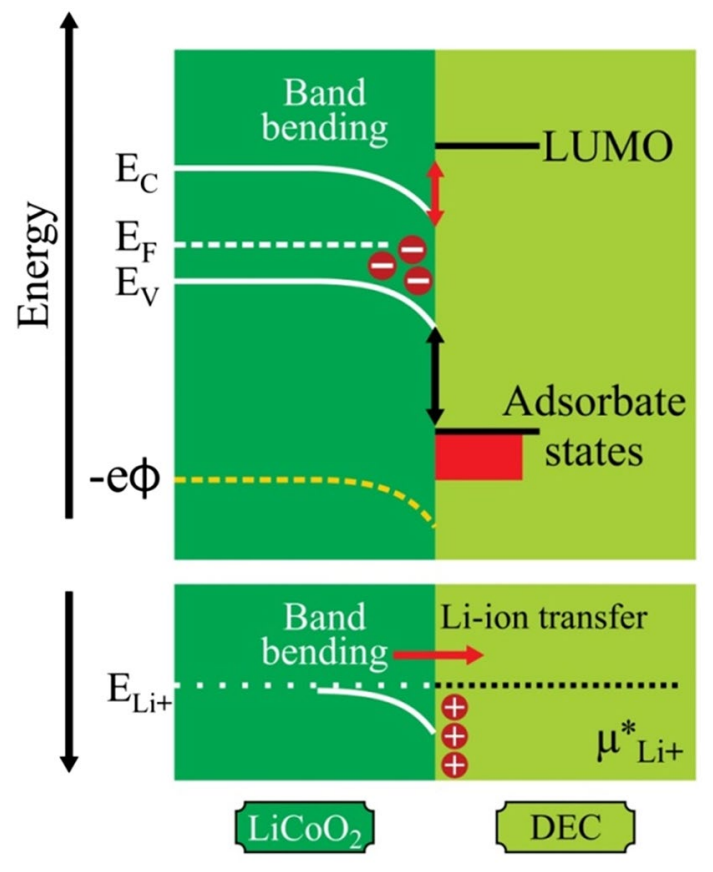

Fig. 10 Electron and ion energy level diagram of the $\mathrm{LiCoO}_{2} / \mathrm{DEC}$ interface established from LT adsorption of DEC (alkyl carbonate solvent) electrolyte. DEC: diethyl carbonate. Note that the Li-ion levels are deduced from theoretical considerations. Reprinted with permission from Ref. [130]. Copyright 2014 ACS

with different electronic bands, along with the differences in the chemical instability with respect to oxygen loss due to the overlapping of the $\mathrm{Co}^{4+/ 3+}: t_{2 \mathrm{~g}}$ band with the $\mathrm{O} 2 \mathrm{p}$ orbitals. The changes within the structure and occupation of the density of states (DOS) of $\mathrm{Li}_{x} \mathrm{CoO}_{2}$ during deintercalation are schematically summarized. The Fermi level (EF) reaches a critical value when the $\mathrm{Co} 3 \mathrm{~d}$ states $\left(\mathrm{Co}^{4+/ 3+}\right.$ couple) cross the top of the $\mathrm{O} 2 \mathrm{p}$ bands, which is accompanied by hole transfer to the $\mathrm{O} 2 \mathrm{p}$ states. A significant number of electrons can be removed from the $\mathrm{O} 2 \mathrm{p}$ band, leading to oxidation of Co ions and/or formation of oxygen vacancies, which is not favored for cathodic durability. Therefore, the proximity in energy of the $t_{2 \mathrm{~g}}$ and $\mathrm{O} 2 \mathrm{p}$ bands determines the intrinsic voltage limit for the $\mathrm{LiCoO}_{2}$ cathode material [126]. The loss of oxygen from the lattice in the $\mathrm{Li}_{1-x} \mathrm{CoO}_{2}$ system may explain the limited capacity $\left(140 \mathrm{mAh} \bullet \mathrm{g}^{-1}\right)$, which is significantly lower than the theoretical value. Therefore, investigating the metastable character of partially deintercalated semiconductors of $\mathrm{Li}_{x} \mathrm{CoO}_{2}$ is very important for the device process kinetics and durability, where the band structure plays an important role.

In the LIB field, further improvements in electrodes and cells are generally limited by an incomplete understanding of the interfaces, involved charge transfer, charge compensation, and chemical reaction processes. Much attention has been paid in the past to the electric potential gradient at the interface, although double (dipole) layers can have a significant impact on the energy level (mis)alignment [127]. Additionally, for ionic phases with low charge carrier concentrations, diffuse charge layers (space charge layers) are encountered at interfaces [128], which induce band bending and related charge carrier concentration changes that have a significant impact on the charge transfer rate and interface stability. Figure 10 shows an energy level diagram for the $\mathrm{LiCoO}_{2}$ /diethyl carbonate (DEC) (alkyl carbonate solvent) electrolyte interface with a focus on the formation of the electrochemical double layer. $\mathrm{Li}$ ions are generally aligned with the ionic electrochemical potential of $\mathrm{Li}^{+}$in the two phases (the chemical potential of Li ions is initially very low in the DEC adsorbate phase). According to theoretical considerations, the Li-ion energy level is bent in the opposite direction to the electron energy levels due to the opposite charge of the ion. With such an energy level diagram, the interface and its kinetic properties can be understood, as it contains energy level offsets as well as any charge carrier concentration changes, as evidenced by band bending [129].

\subsubsection{Band Theory for Tuning from Semiconducting to lon Conducting Electrolytes}

Currently, efforts are mainly devoted to the development of new solid-state electrolytes, such as oxide and sulfide, to increase the energy density and safety of lithium batteries. However, the ionic conductivity in solid-state ionic electrolytes is much lower than that in liquid electrolytes. The traditional design of ionic conductors is primarily based on substitutional doping of dissimilar valence cations into the unit lattice of the structure, resulting in inherent limits on the dopant concentration and thereby ionic conductivity. Recently, a very interesting example of applying semiconductors and electronic states to batteries is the strongly correlated perovskite $\mathrm{SmNiO}_{3}(\mathrm{SNO})$, which shows applicable lithium ion conductivity at room temperature. SNO has a metal conduction nature and can be electrochemically transformed by $\mathrm{Li}^{+}$injection from an electronic conductor to an electronic insulator and a superior $\mathrm{Li}^{+}$conductor as the electrolyte for a LIB [131]. Based on extensive experimental and theoretical calculations [131], $\mathrm{Li}^{+}$ion shuttling and simultaneous suppression of electronic transport via the Mott transition are induced in such a system, which provides an alternative approach to develop novel LIBs or other energy devices.

Figure 11a-c shows that a large amount of mobile $\mathrm{Li}^{+}$can be found in an electrochemically lithiated $\mathrm{SmNiO}_{3}(\mathrm{Li}-\mathrm{SNO})$ system, which is located in interstitial sites of the perovskite, approaching one dopant ion per unit cell, accompanied by significant lattice expansion. Such interstitially inserted $\mathrm{Li}^{+}$ions can facilitate fast $\mathrm{Li}^{+}$conduction associated with a lower activation energy in comparison with the structural 
case. Figure $11 \mathrm{~b}$ presents a design principle for solid-state $\mathrm{Li}^{+}$conductors based on SNO. Pristine SNO is a narrow gap semiconductor after lithiation, i.e., the lithium-doped/ inserted thin film SNO (Li-SNO), then transforms into an insulator, with a gap of approximately $3 \mathrm{eV}$ (Fig. 11c). First-principles density functional theory (DFT) calculations showed that the pristine SNO exhibits a monoclinic cell without distortion, while with lithium entering SNO, $\mathrm{Ni}^{3+}$ is converted to $\mathrm{Ni}^{2+}$, resulting in a much different total DOS (Fig. 11d).

The $\mathrm{Li}^{+}$-inserted $\mathrm{Li}$-SNO has an expanded structure that allows for a 3D interconnected $\mathrm{Li}^{+}$diffusion channel, and the interstitial $\mathrm{Li}^{+}$is weakly bonded with oxygen ions, therefore exhibiting fast $\mathrm{Li}^{+}$conduction behavior. Accompanying this transition, the pristine SNO shows insulation due to suppression of electron transport in $\mathrm{SNO}$. The $\mathrm{Li}^{+}$conductivity was determined to be $3.1 \times 10^{-3} \mathrm{~S} \cdot \mathrm{cm}^{-1}$ at room temperature with an activation barrier of $\sim 0.24 \mathrm{eV}$. The corresponding LiSNO battery demonstrated LIB capacity and good lithiation and delithiation cycle life with average coulombic efficiency of $96.8 \%$. This work provides evidence for ion shuttling in the lattice and atomistic pathways [132-134]. Moreover, this strategy can be extended to other ions, such as $\mathrm{Na}^{+}$, demonstrating the generality of the approach.

A theoretical design of the $\mathrm{Li}^{+}$conductor could be based on wide bandgap semiconductors. Wide bandgap semiconductors, especially dielectric materials, can potentially be used as electrolytes because of their large bandgap, which precludes the possibility of electrons being excited from the VB to the CB by thermal means. In addition, under electric field conditions, the electric dipole component in the dielectric materials can be adjusted, which may further affect the ionic transport properties [135-138]. $\mathrm{Li}^{+}$and $\mathrm{Na}^{+}$ions are large enough to form bent O-A-O symmetric bonds in some condensates of larger anion clusters with electric dipole moments, as illustrated in Fig. 12 for Na glass. The high-frequency dielectric constant is important because it represents the intrinsic property of the material and is directly related to the DC conductivity. Accompanying this electric dipole component, the electric dipole component of the electrolyte interface charge is increased by dipole coalescence. Using dielectric materials in the electrolyte may produce a very
Fig. 11 Strongly correlated nickelate as the ionic conductor in a LIB. a Electronic configuration of pristine $\mathrm{SmNiO}_{3}$ (SNO), a narrow gap semiconductor, at room temperature. $\mathbf{b}$ Self-designed electrochemical cell for lithiation of SNO. c Electronic configuration of lithiated SNO (Li-SNO). Electron filling leads to a large on-site Coulomb interaction, suppressing the electronic conduction pathway. $\mathrm{Li}^{+}$occupies multiple interstitial sites of the unit cell. Electron localization-induced perovskite lattice expansion facilitates $\mathrm{Li}^{+}$interstitial transport, which enables Li-SNO to be a potential lithium-ion conductor. d First-principles simulation of the total DOS for Li-SNO with $0-1$ intercalated $\mathrm{Li} / \mathrm{SNO}$ (gray). The projected DOS (PDOS) of the unoccupied Ni $E_{\mathrm{g}}$ states are shown in color. The lighter hues indicate $E_{\mathrm{g}}$ states of $\mathrm{Ni}^{3+}$, and the darker hues indicate those of $\mathrm{Ni}^{2+}$ including the newly occupied $E_{\mathrm{g}}$ states due to the localization of the added electron from the intercalated lithium below the Fermi energy. Reproduced with permission from Ref. [131] Copyright 2018 National Academy of Sciences
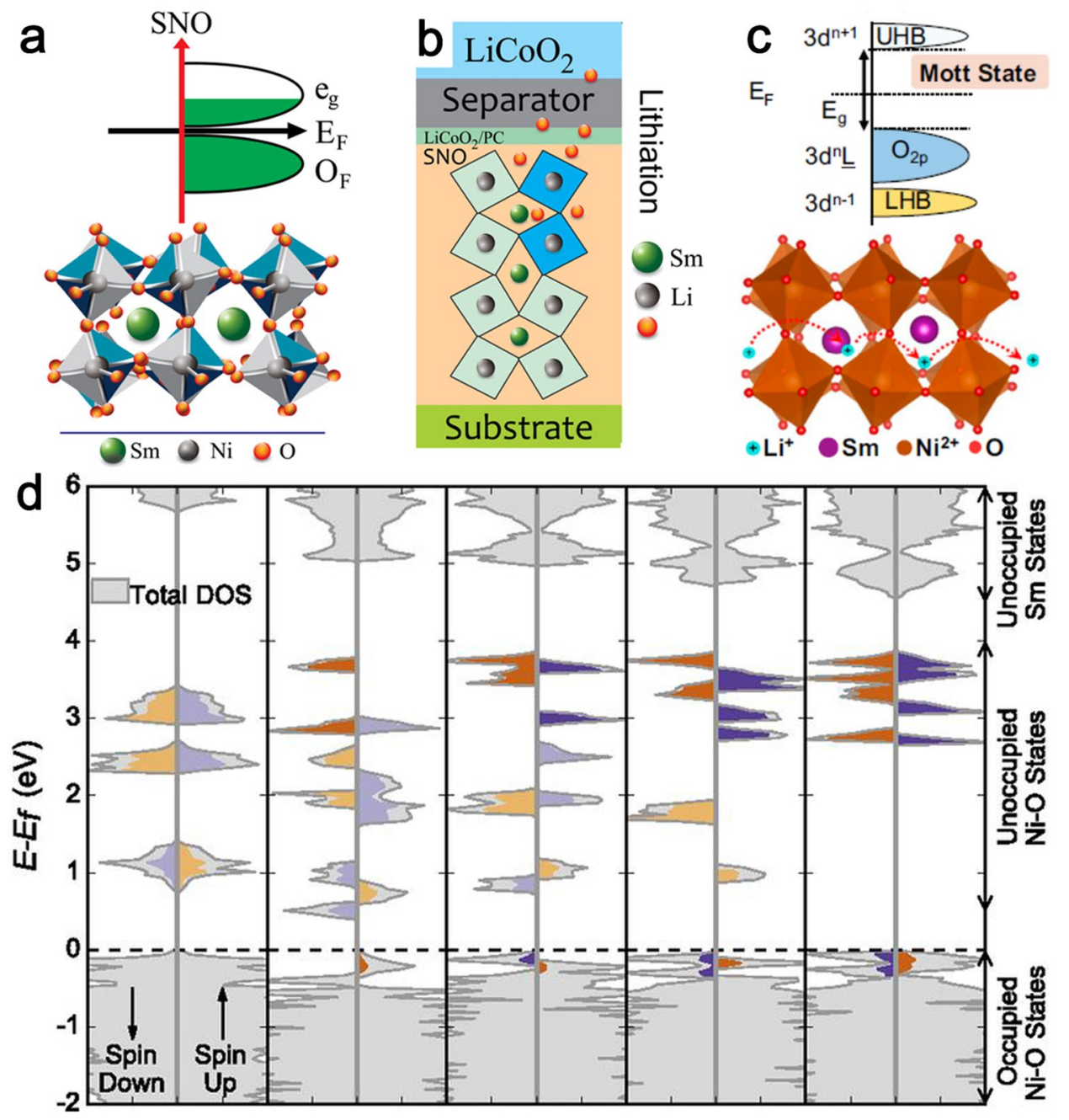
large energy gap window that makes it stable upon contact with both an alkali-metal anode and a high-voltage cathode without the formation of an SEI. The glass also contains electric dipoles that have a large dielectric constant. The Goodenough group applied dielectric materials as electrolytes for $\mathrm{Li}^{+}$and $\mathrm{Na}^{+}$batteries. For example, the $\mathrm{Li}^{+}$and $\mathrm{Na}^{+}$glass electrolytes $\mathrm{A}_{2.99} \mathrm{Ba}_{0.005} \mathrm{O}_{1+x} \mathrm{Cl}_{1-2 x}$ with $\mathrm{A}=\mathrm{Li}$ or $\mathrm{Na}$ were reported [128-131]. Bragg and Goodenough et al. [128] reported that the dipoles are oriented under an applied electric field and aligned parallel to the field axis, which enables solid glass electrolytes $\mathrm{A}_{2.99} \mathrm{Ba}_{0.005} \mathrm{O}_{1+x} \mathrm{Cl}_{1-2 x}$ with $\mathrm{A}=\mathrm{Li}$ or $\mathrm{Na}$ to yield an ionic conductivity $\sigma_{\mathrm{i}}>10^{-2} \mathrm{~S} \bullet$ $\mathrm{cm}^{-1}$ and a very large dielectric constant, which is extremely important to develop safe rechargeable batteries of high energy density and long cycle life.

\subsubsection{Role of the BIEF in Batteries}

One of the most exciting characteristics of semiconductor and energy band theories in the battery field is that the band alignment of different battery components or compositions that induces a BIEF or alters the local electric field (LEF) can significantly improve the electrochemical performance of the device, including promotion of ion transport, increase of the cycle life and high-speed discharge-charge cycle, and enlargement of the battery capacity.

To speed up electrode $\mathrm{Li}$ intercalation at high charge-discharge rates and promote the $\mathrm{Li}^{+}$ion diffusion process, a $\mathrm{BIEF}$ at the semiconductor particle (material) level has been reported. A typical example is reported by Xia et al. [11] for a $\mathrm{TiO}_{2}$-based electrode, as shown in Fig. 13. In comparison to bulk $\mathrm{TiO}_{2}$ (Fig. 13a) and nanocrystal $\mathrm{TiO}_{2}$ (Fig. 13b), Fig. 13c shows a structure consisting of a nanocrystalline stoichiometric core of an intrinsic-type $\mathrm{TiO}_{2}$ semiconductor and an amorphized nonstoichiometric outer layer $\mathrm{TiO}_{2-d}$ n-type shell. Such a structure creates an i-n heterostructure [11] with the BIEF direction from the outer layer to the core, which is expected to promote $\mathrm{Li}^{+}$diffusion during the lithium discharge process, i.e., help $\mathrm{Li}^{+}$insertion (Fig. 13d). Once $\mathrm{Li}^{+}$has been fully inserted or discharged into the $\mathrm{TiO}_{2}$ nanocrystal, the core will become $\mathrm{Li}_{y} \mathrm{TiO}_{2}$, turning into an intrinsic semiconductor. In contrast, the disordered layer
Fig. 12 Ab initio molecular dynamics calculations showing electric dipoles with a ratio of elementary dipoles to several unaligned clusters of 7:1 at $100{ }^{\circ} \mathrm{C}$. a Box containing 81 $\mathrm{Na}^{+}, 7 \mathrm{Cl}^{-}$and $37 \mathrm{O}^{2-}$ ions. b Elementary dipoles and clusters. c Chain segments calculated before and proposed after alignment. Reproduced with permission from Ref. [139]. Copyright 2016 ECS a

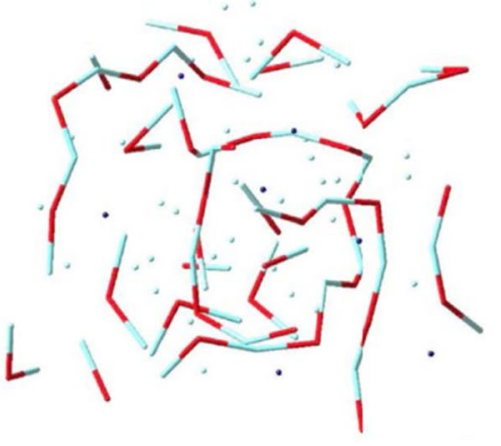

b

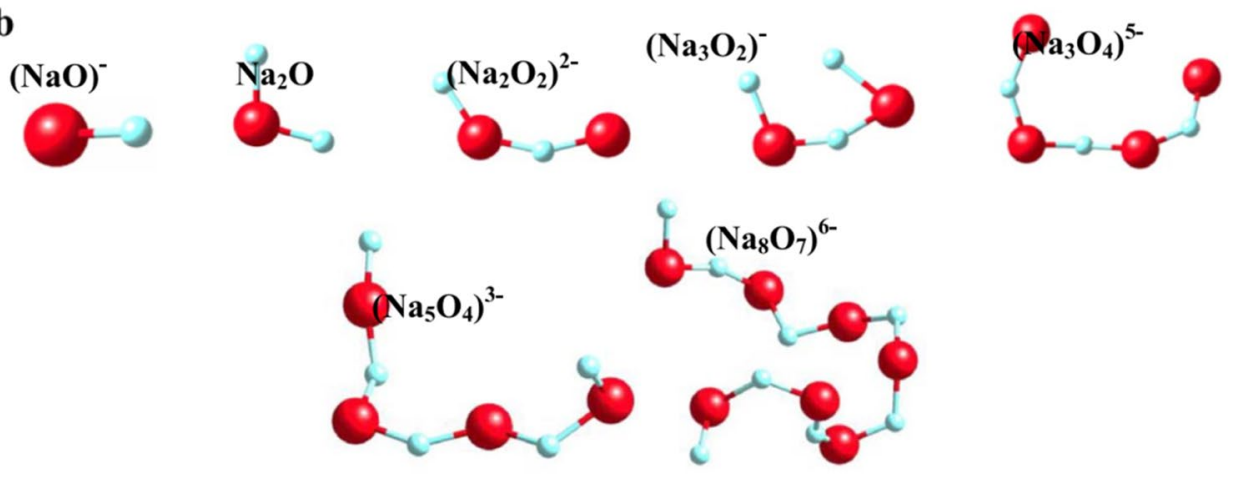

c

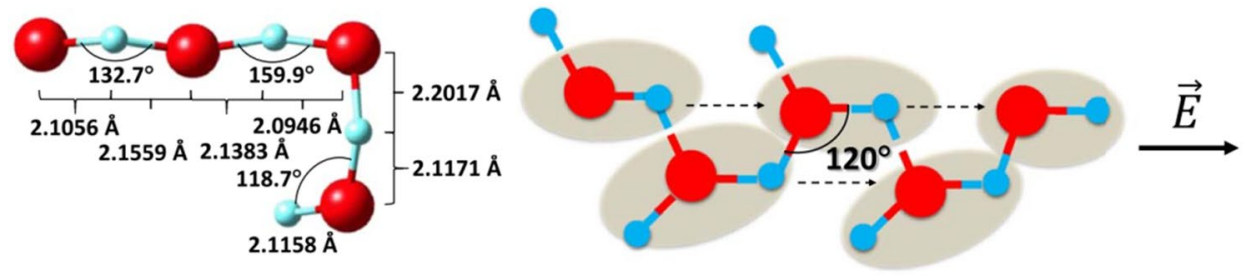


takes up much less $\mathrm{Li}^{+}$due to the existence of oxygen vacancies and becomes $\mathrm{Li}_{y-2 x-r} \mathrm{TiO}_{2-d}$, corresponding to a relative p-type semiconductor compared with $\mathrm{Li}_{y} \mathrm{TiO}_{2}$. Therefore, a new i-p heterostructure and a BIEF will be formed at the core/shell interface; thus, the new BIEF directed from the disordered layer to the crystalline core facilitates $\mathrm{Li}^{+}$ transport from the core to the shell, i.e., helps $\mathrm{Li}^{+}$extraction in the charging process (Fig. 13e). In the end, with the assistance of the in situ formed i-n and i-p heterostructure and BIEFs, a higher ionic diffusion capability is obtained during the $\mathrm{Li}^{+}$ion insertion/extraction process, increasing the rate performance.

Another interesting case is reported by Yan et al. [140] based on carbon-doped $\mathrm{Co}_{3} \mathrm{O}_{4}$ nanocrystals for superior Liion storage. The imbalanced charge distribution emerging from the carbon-dopant can induce an LEF to greatly facilitate charge transfer within unique sub-10 nm nanocrystalassembled $\mathrm{Co}_{3} \mathrm{O}_{4}$ hollow nanotubes (HNTs). The resulting carbon-doped $\mathrm{Co}_{3} \mathrm{O}_{4}$ HNT-based electrodes demonstrated an excellent reversible capacity of $950 \mathrm{mAh} \bullet \mathrm{g}^{-1}$ at 0.5 $\mathrm{A} \bullet \mathrm{g}^{-1}$ after 300 cycles and superior rate performance of the full battery with $853 \mathrm{mAh} \bullet \mathrm{g}^{-1}$ at $10 \mathrm{~A} \bullet \mathrm{g}^{-1}$. Zheng et al. [12] also reported that the LEF effect can be built at atomic interfaces on ultrathin $\mathrm{Bi}_{2} \mathrm{MoO}_{6}(\mathrm{BMO})$ nanosheets (Fig. 14a-c). The unbalanced charge distribution between the $\left[\mathrm{Bi}_{2} \mathrm{O}_{2}\right]^{2+}$ and $\left[\mathrm{MoO}_{4}\right]^{2-}$ layers induces an interfacial electric field at the interfaces, while the lopsided charge distribution around oxygen vacancies results in a local inplane electric field, thus promoting ion diffusion/electron transport. Additionally, the 2D ultrathin construction can provide interconnected charge migration paths formed on the open surfaces, which could facilitate the charge transfer process in the BMO sheets. Therefore, both the in-plane and interfacial electric fields, as illustrated in Fig. 14d, induced by atomic-level engineering (Fig. 14e) can cause an unbalanced charge distribution within the crystal and induce a

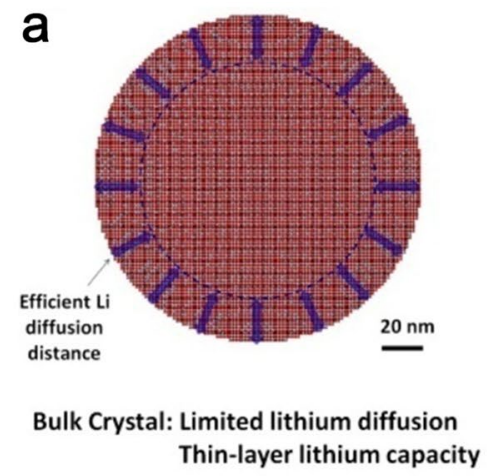

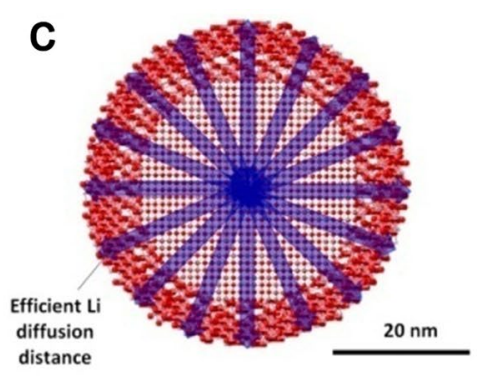

Surface-Amorphized Nanocrystal:
Improved lithium diffusion
Full lithium capacity

Surface-Amorphized Nanocrystal:
Improved lithium diffusion
Full lithium capacity

Surface-Amorphized Nanocrystal:
Improved lithium diffusion
Full lithium capacity d
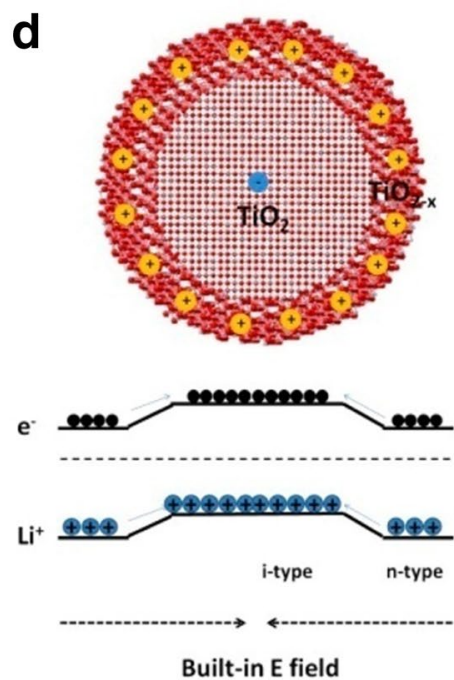

Lithium and electron insertion Near-full lithium capacity
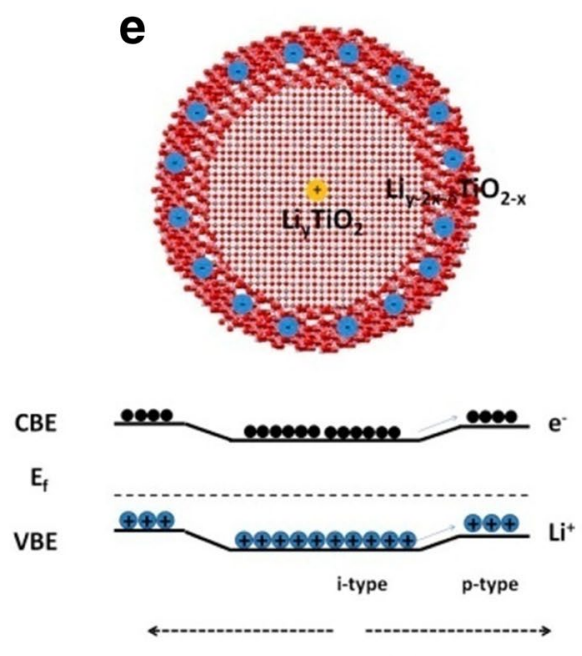

Built-in E field

Lithium and electron exaction
Fig. 13 Comparison of charge diffusion in electrode materials made of a bulk crystals, b nanocrystals, and $\mathbf{c}$ surface-amorphized nanocrystals, and illustration of the facilitation of charge transport under a BIEF during discharge (d) and charge (e) processes. The length and width of the arrows illustrate the relative penetration depth and the charge transfer/transport coefficients of the lithium ion in the material, respectively. Reproduced with permission from Ref. [11]. Copyright 2013 ACS 

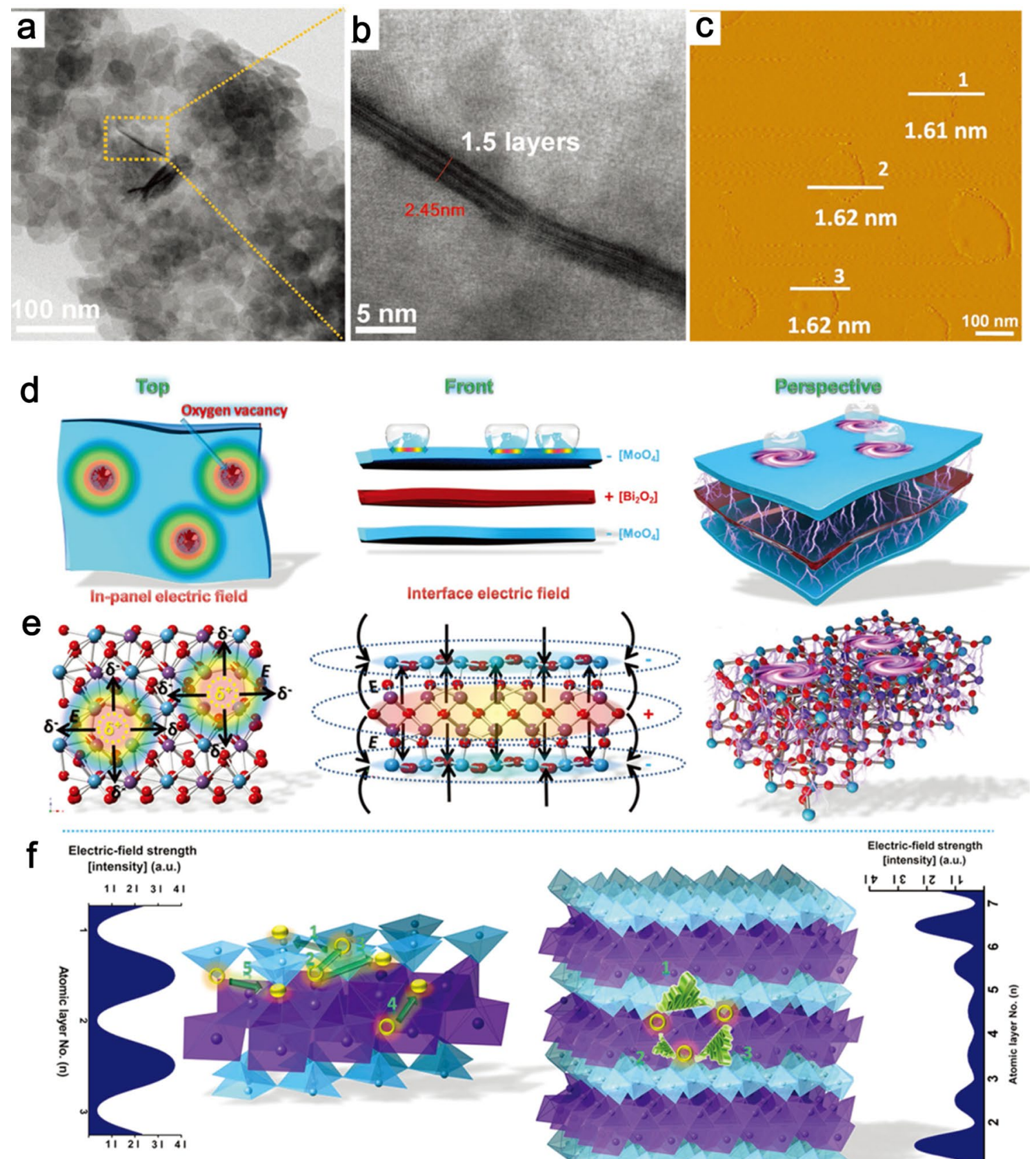

Rapid migration path

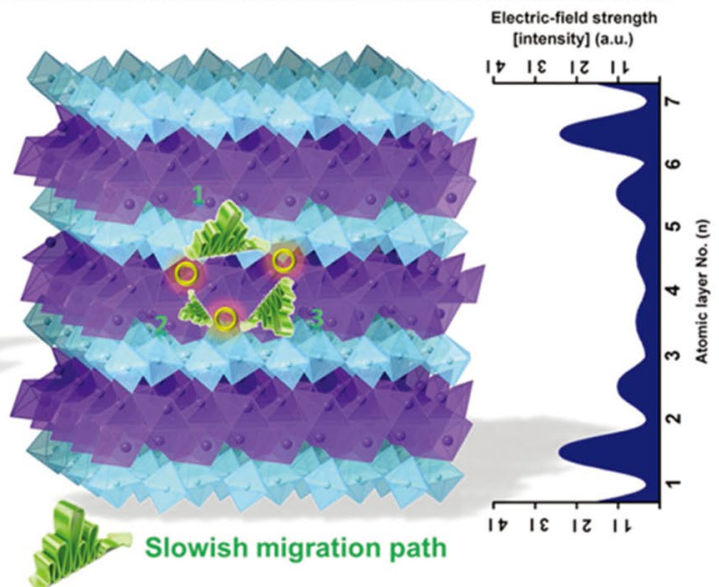

Fig. 14 Morphology of obtained BMO sheets. a TEM image, b enlarged high-resolution TEM image, and $\mathbf{c}$ atomic force microscopy (AFM) image with corresponding height. d Schematic diagram of the induced in-panel electric field and the interface electric field within the BMO sheets viewed in different directions. e Electric field distribution and corresponding crystal structure of the BMO sheets in

(d). f Relationship between the electric field, migration paths, and $\mathrm{Li}$ transfer kinetics in BMO sheets and bulk BMO. d-f Summary of the enhanced high rate capacity mechanism of the BMO sheets for Li-ion storage. Reproduced with permission from Ref. [12]. Copyright 2017 Wiley-VCH

BIEF, which can significantly boost the lithium-ion transfer dynamics. Impressively, the lithium battery using the BMO nanosheet electrode shows a long-term cycling performance at $2000 \mathrm{~mA} \bullet \mathrm{g}^{-1}$. A possible mechanism for the improvement in lithium storage in atomically thin BMO nanosheets is proposed as shown in Fig. 14f.

In addition to LIBs, the construction of a BIEF/LEF has also been demonstrated to be very effective in developing 
(a) Sodiation
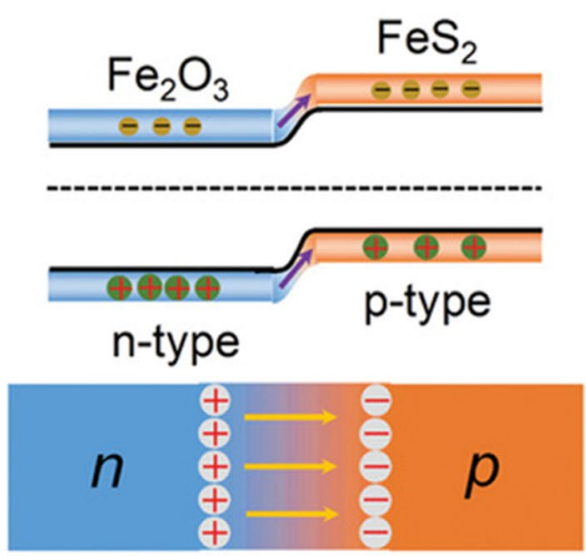

Built-in electric field

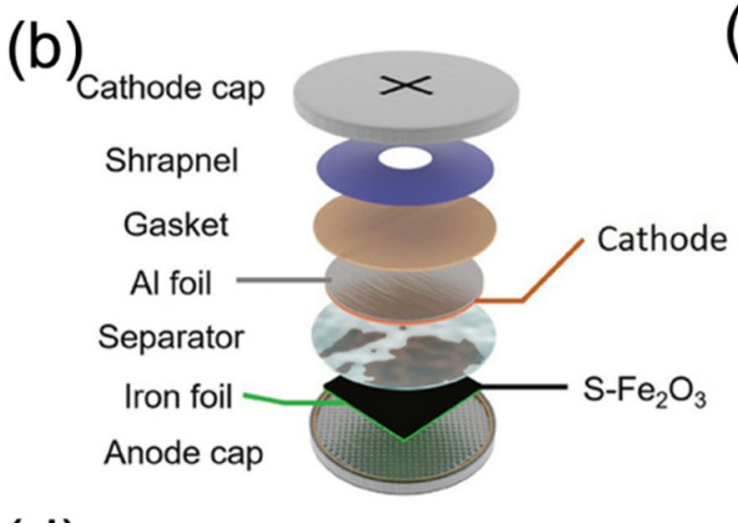

Fig. 15 a Schematic of the formation of a BIEF and $\mathrm{Na}^{+}$storage mechanism upon discharge and recharge, and electrochemical performance of the full cell of $\mathrm{Fe}_{2} \mathrm{O}_{3} / \mathrm{Na}_{0.67}\left(\mathrm{Mn}_{0.67} \mathrm{Ni}_{0.23} \mathrm{Mg}_{0.1}\right) \mathrm{O}_{2}$. b Schematic of the coin-type full cell. $\mathbf{c}$ Initial galvanostatic profiles of the

high-performance sodium-ion batteries [141, 142]. Ni et al. [141] found that a BIEF can reduce the activation energy and accelerate charge transport significantly based on the synergy of the ordered architecture of iron oxide-based nanotube arrays and a BIEF. Figure 15a schematically illustrates such a material system and the BIEF-related mechanism. A BIEF spontaneously develops at the heterogeneous interface of $\mathrm{n}-\mathrm{Fe}_{2} \mathrm{O}_{3}$ and $\mathrm{p}-\mathrm{FeS}_{2}$, as verified by Kelvin probe force microscopy measurements across the heterointerface. Upon discharge (sodiation), the BIEF that has an n-to-p direction will push $\mathrm{Na}^{+}$ions from $\mathrm{Fe}_{2} \mathrm{O}_{3}$ to neighboring $\mathrm{FeS}_{2}$, leading to enhanced transport kinetics. Then, for recharging, desodiation grows relatively $\mathrm{Na}^{+}$-rich $\mathrm{FeS}_{2}$ domains and $\mathrm{Na}^{+}$-deficient $\mathrm{Fe}_{2} \mathrm{O}_{3}$ domains, yielding a new BIEF with an electric field direction from $\mathrm{FeS}_{2}$ to $\mathrm{Fe}_{2} \mathrm{O}_{3}$ due to the potential difference. Therefore, the $\mathrm{Na}^{+}$diffusion kinetics can be boosted in such an $\mathrm{S}-\mathrm{Fe}_{2} \mathrm{O}_{3}$ system in both sodiation

\section{Desodiation}
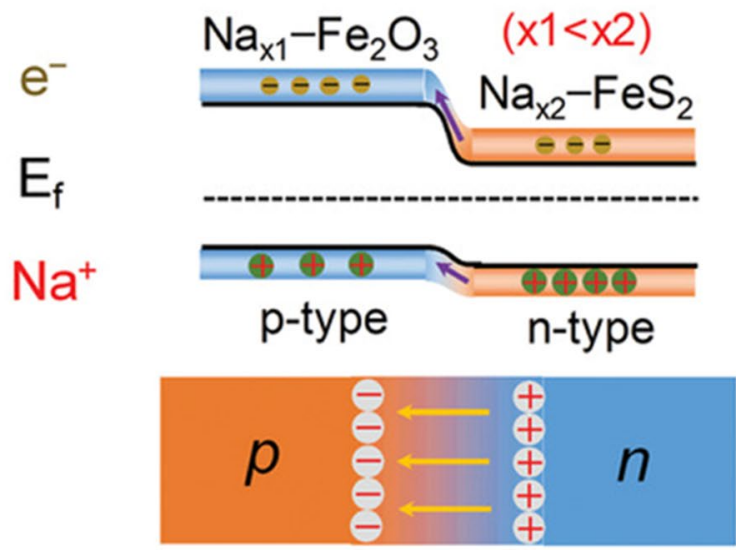

Built-in electric field

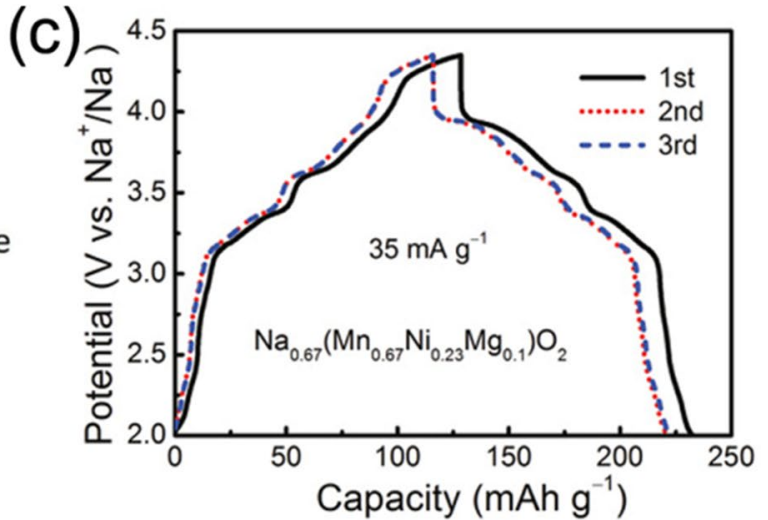

S-Fe $\mathrm{O}_{3} / \mathrm{Na}_{0.67}\left(\mathrm{Mn}_{0.67} \mathrm{Ni}_{0.23} \mathrm{Mg}_{0.1}\right) \mathrm{O}_{2}$ full cell at a rate of $0.2 \mathrm{~A} \mathrm{~g}^{-1}$ (based on the anode mass). Reproduced with permission from ref. [141]. Copyright 2019 Wiley-VCH

and desodiation states. More specifically, $\mathrm{S}-\mathrm{Fe}_{2} \mathrm{O}_{3}$ exhibits a high initial current efficiency of $83 \%$. The assembled $\mathrm{S}-\mathrm{Fe}_{2} \mathrm{O}_{3} / / \mathrm{Na}_{0.67}\left(\mathrm{Mn}_{0.67} \mathrm{Ni}_{0.23} \mathrm{Mg}_{0.1}\right) \mathrm{O}_{2}$ battery shown in Fig. $15 \mathrm{~b}$ afforded a reversible capacity of approximately 500 $\mathrm{mAh} \bullet \mathrm{g}^{-1}$ (based on anode mass) and an average voltage of $2.5 \mathrm{~V}$ (Fig. 15c), leading to a specific energy of $160 \mathrm{Wh} \bullet$ $\mathrm{kg}^{-1}$ (based on both active materials) at a power density of $60 \mathrm{~W} \bullet \mathrm{kg}^{-1}$. The energy remained at $142 \mathrm{Wh} \bullet \mathrm{kg}^{-1}$ under a specific power of $330 \mathrm{~W} \bullet \mathrm{kg}^{-1}$, which is comparable to that of commercial $\mathrm{LiFePO}_{4}$ batteries. Similar promotion effects were also observed in $\mathrm{Bi}_{2} \mathrm{~S}_{3}-\mathrm{Bi}_{2} \mathrm{O}_{3}$ [142] for Na-ion batteries and in C@N-C@N P-C graded heterostructures for aluminum-ion batteries (AIBs) [143]. Such a design also serves as a perfect platform for exploring the underlying correlation of the BIEF and the electrochemical performance of secondary batteries. 


\subsection{Coupled Energy Conversion and Storage Technologies with Semiconductors}

The application of semiconductors to new energy conversion and storage has been widely reported. Coupling devices through the joining principle is an emergent frontier. Here, two typical examples of designing fuel cells by combining the approaches of solar cell coupling and using photoelectrolysis principles to design semiconductor-ionic fuel cell (SIFC) devices are reviewed. Figure 16a-c illustrates the band design of a fuel cell based on the PSC principle with the band structure and alignment as a new fuel-to-electricity conversion approach [102]. Similar to the PSC, we used electron and hole transport layers (ETL and HTL) and a semiconductor-ionic LSCF-SCDC material layer sandwiched between the ETL and HTL (Fig. 16b, c). Such a novel system consists of an LSCF-SCDC functional layer (Fig. 16d). The electrochemical performance was compared for a conventional 3-layer fuel cell, the type-I cell with an ETL and an HTL similar to a solar cell, and a type-II symmetrical heterojunction device (Fig. 16e). The latter two cells showed much-improved fuel cell performance over the conventional 3-layer fuel cell. In particular, the type-II cell provided a peak power density of $1080 \mathrm{~mW} \bullet \mathrm{cm}^{-2}$ at $550{ }^{\circ} \mathrm{C}$ with hydrogen fuel/air oxidant. The outstanding electrochemical performance, we believe, is ascribed to the much-improved ionic conductivity of the LSCF-SCDC layer, i.e., $0.188 \mathrm{~S} \bullet \mathrm{cm}^{-1}$ ( 4 times higher than that of the individual SCDC electrolyte at $600^{\circ} \mathrm{C}$ ) because of the enriched oxygen at the interface of LSCF and SCDC [121]. This work highlighted exploring wide bandgap semiconductors and energy band design for new-generation fuel-to-electricity conversion. Well-aligned energy bands can be designed and realized by unique semiconductor-ionic materials from anode n-type conducting to cathode p-type conducting materials with junction formation incorporated with ionic functions to maintain fuel cell electrochemical reactions, all were integrated into one device [113, 122, 123]. The key issue in such a semiconductor-ionic device is that there must be a charge separation mechanism to prevent the electrons and holes from passing through the device internally and forming an electron short-circuiting problem [103].

In another case, fuel cell devices based on energy band alignment were experimentally demonstrated to show no $\mathrm{e}^{-} / \mathrm{h}^{+}$flow causing short circuiting based on a $\mathrm{TiO}_{2}$ functional layer as the electrolyte (Fig. 17) [82], in which a $\mathrm{TiO}_{2}$ thin film was deposited on the p-conducting semiconductor NCAL $\left(\mathrm{LiNi}_{0.8} \mathrm{Co}_{0.15} \mathrm{Al}_{0.05} \mathrm{O}_{2}\right)$ ceramic substrate, with another NCAL thin electrode on top completing the fuel cell construction (Fig. 17a, b). As a wide bandgap semiconductor, $\mathrm{TiO}_{2}$ is suggested to hold the capability to suppress electron and hole conduction through the bulk (Fig. 17c), as reflected by an OCV close to the theoretical value based on the Nernst equation (Fig. 17d), and the cell gave a peak
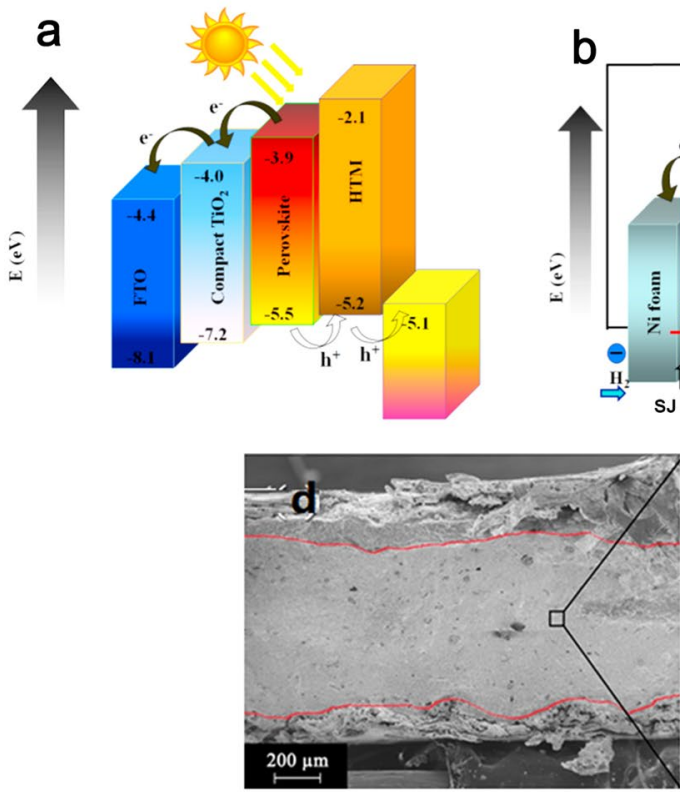

Fig. 16 Energy level diagram of a a perovskite-type solar cell, b a fuel-to-electricity conversion device (fuel cell) inspired by the PSC structure (type I) and c a symmetrical fuel-to-electricity conversion device (type II) with an in situ formed Schottky junction. d Crosssectional SEM image of the type-II device and close-up view of the
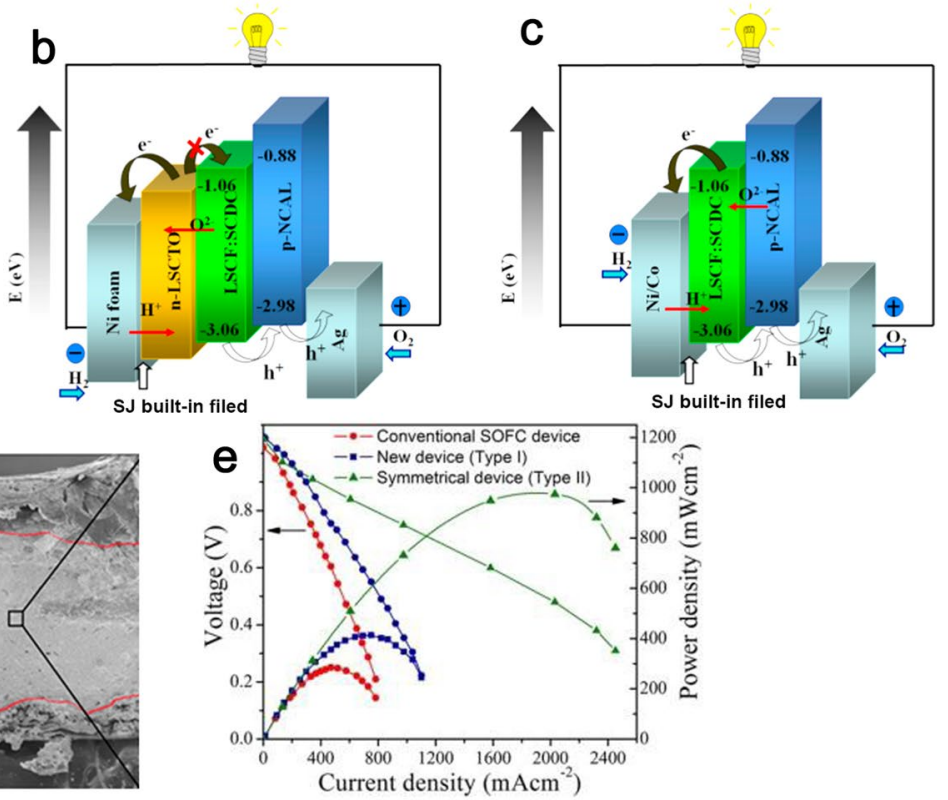

LSCF-SCDC functional layer. e Device electrochemical performance comparison of the conventional 3-layer fuel cell, the type-I fuel-toelectricity device with an ETL and an HTL, and the type-II symmetrical heterojunction fuel-to-electricity device. Reproduced with permission from ref. [102]. Copyright 2016 Elsevier 


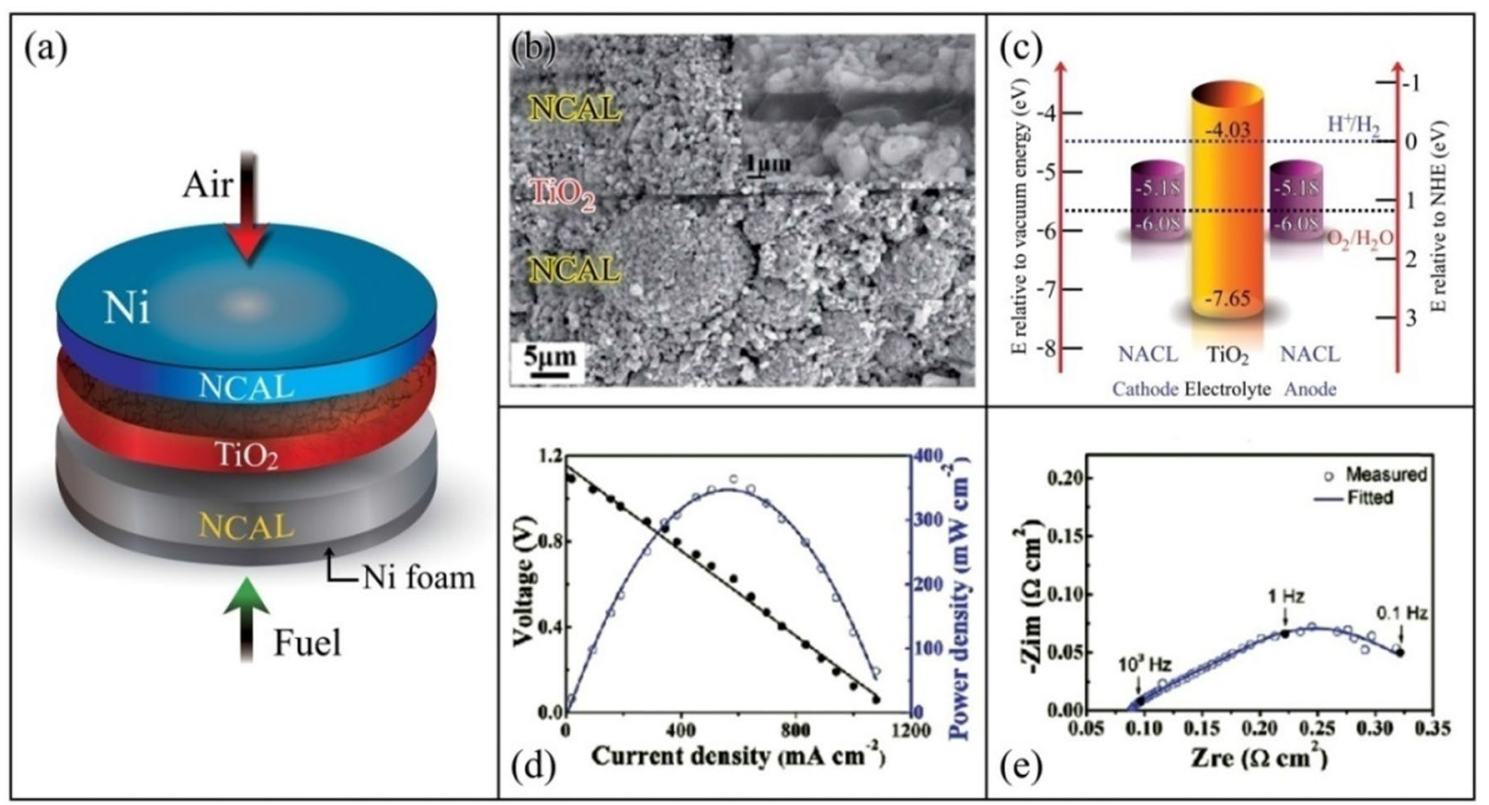

Fig. 17 a Construction of the fuel cell device using a $\mathrm{TiO}_{2}$ electrolyte functional layer; b SEM images of the cell configuration of the $\mathrm{TiO}_{2}$ electrolyte-based fuel cell device, $\mathbf{c}$ energy band diagram of the resulting thin film $\mathrm{TiO}_{2}$ electrolyte fuel cell with NCAL electrodes; d,

power output larger than $300 \mathrm{~mW} \bullet \mathrm{cm}^{-2}$ at $550{ }^{\circ} \mathrm{C}$ and an impressive electrochemical impedance value (Fig. 17e). This fundamental understanding and scientific design are important and naturally related to the photoelectrolysis and photocatalysis fields. The $\mathrm{TiO}_{2}$ fuel cell provides for the first time, from the detailed band parameters relevant to the photo-water splitting process and the products, the view that the photo-water electrolysis process, $\mathrm{H}_{2} \mathrm{O}=\mathrm{H}_{2}+\mathrm{O}_{2}$, is the reverse process to that in a fuel cell: $\mathrm{H}_{2}+\mathrm{O}_{2}=\mathrm{H}_{2} \mathrm{O}$. Compared to photocatalyst $\mathrm{TiO}_{2}$ water splitting, there are some similarities in the $\mathrm{TiO}_{2}$ electrolyte fuel cell band structure and alignment. Therefore, a new and universal design for $\mathrm{TiO}_{2}$ electrolyte or other semiconductor-based fuel cells from the band structure and alignment in comparison with the $\mathrm{TiO}_{2}$ photo-water splitting process is shown in Fig. 18, in which the electrolyte layer is extended from a typical electronic conductor to a wide bandgap semiconductor, providing the specific requirement mentioned in the following paragraph. According to energy band theory, to adjust the carrier transport behavior in a device, materials with different energy band structures should be carefully designed. For example, in a PEC water splitting device [15, 144], the Fermi level of the metal counter electrode must be higher than the redox potential of $\mathrm{H}^{+} / \mathrm{H}_{2}$, while the VB level of the semiconductor photoanode must be lower than the redox potential of $\mathrm{H}_{2} \mathrm{O} / \mathrm{O}_{2}$ (Fig. 18a). The fuel cell reaction product can be regarded as a reverse product of water splitting. In a typical fuel cell, electrons are generated at the anode/ e electrochemical performance of a proof-of-concept of the fuel cell at $550{ }^{\circ} \mathrm{C}$ in $\mathrm{H}_{2} /$ air condition. Reproduced with permission from Ref. [82]. Copyright 2019 RSC

electrolyte interface and are then supposed to flow through the anode to the outer circuit when the circuit is connected. Meanwhile, no electrons are expected to flow through the electrolyte; otherwise, short circuiting occurs (Fig. 18b). Therefore, the electrons in the anode should be blocked by the electrolyte from the perspective of energy band theory. In a typical Ni-YSZ (Y-stabilized $\mathrm{ZrO}_{2}$ ) fuel cell, the redox potential of $\mathrm{H}_{2} / \mathrm{H}^{+}$is approximately $4.5 \mathrm{eV}$ relative to the vacuum energy (RVE), and the work function for a typical anode material $\mathrm{Ni}$ is approximately $5.1 \mathrm{eV}$ RVE, which is lower than the potential of $\mathrm{H}_{2} / \mathrm{H}^{+}$; hence, electrons stemming from the oxidation of $\mathrm{H}_{2}$ can flow to the anode. Meanwhile, the $\mathrm{CB}$ of the YSZ electrolyte is higher than the redox potential of $\mathrm{H}_{2} / \mathrm{H}^{+}$; electrons cannot jump to the $\mathrm{CB}$ of the electrolyte; namely, the electrons are blocked by the electrolyte. However, if an electrolyte material has a lower CB level, then short-circuiting problems might occur (Fig. 18c). For example, the CB level of SDC, which is measured to be at approximately $5.65 \mathrm{eV}$, then the electron may flow to electrolyte, and the short-circuiting problem is often observed in SDC electrolyte fuel cells. When SDC is reduced by $\mathrm{H}_{2}$ in fuel cell operation, its electronic conductivity rapidly increases, and electrons can flow through it [145]. This is why the short-circuiting problem was observed in an SDC electrolyte fuel cell after a period of operation. In short, the energy band structure of a good SOFC should obey the following rules: (1) the $\mathrm{CB}$ level of the electrolyte should be higher than the redox potential of $\mathrm{H}_{2} / \mathrm{H}^{+}$, (2) the Fermi 


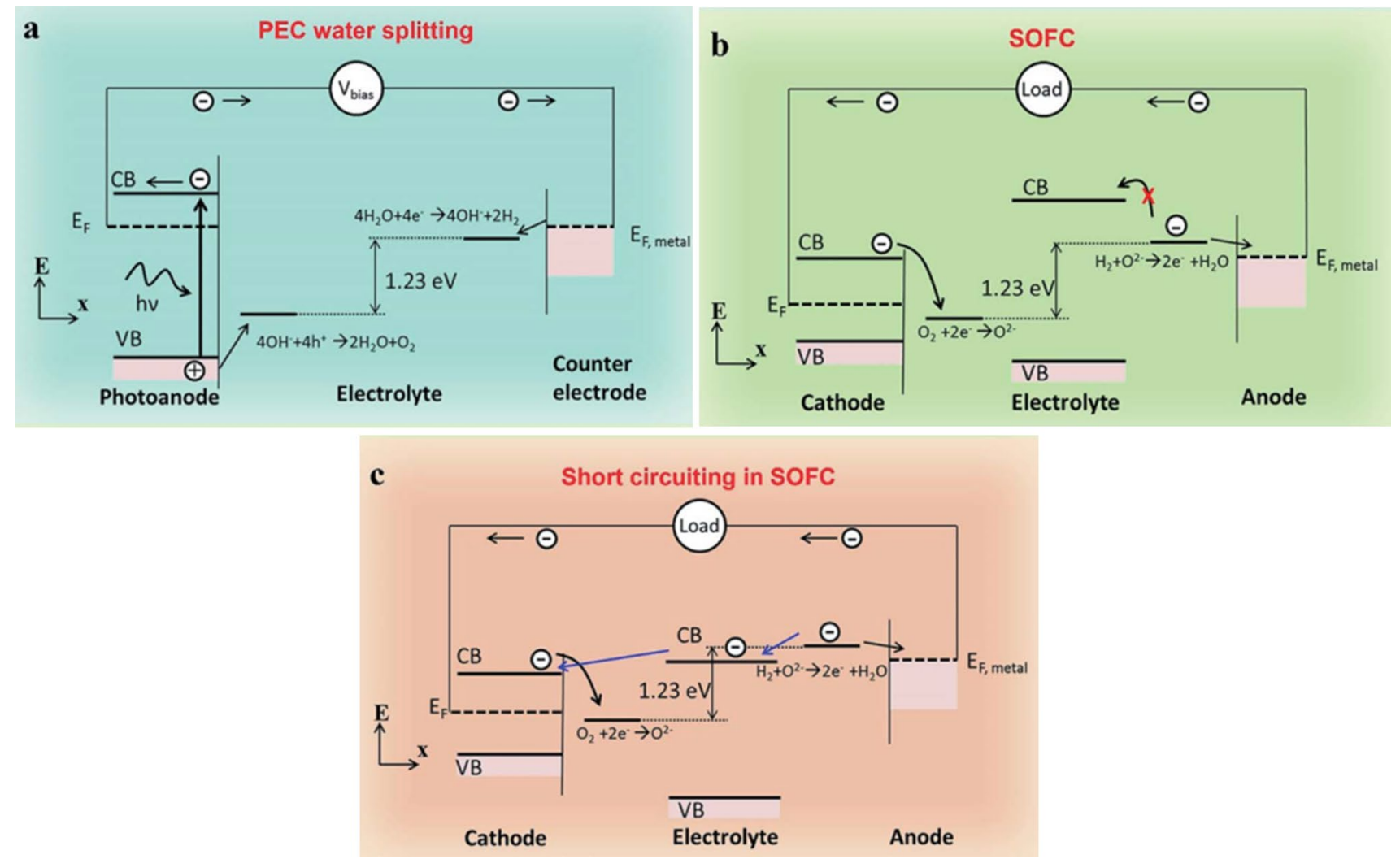

Fig. 18 Energy band diagrams of a PEC water splitting (the HondaFujishima effect), $\mathbf{b}$ a fuel cell, and $\mathbf{c}$ the fuel cell with the occurrence of short circuiting. If the anode of the fuel cell is not a metal but a semiconductor, then the $\mathrm{CB}$ level of this semiconductor should be

level of the metal anode (or the CB level of the semiconductor anode) should be lower than the redox potential of $\mathrm{H}_{2} /$ $\mathrm{H}^{+}$, (3) the VB level of the electrolyte should be lower than the redox potential of $\mathrm{O}_{2} / \mathrm{O}^{2-}$, and (4) the $\mathrm{CB}$ level of the cathode should be higher than the redox potential of $\mathrm{O}_{2} / \mathrm{O}^{2-}$.

In addition to wide applications of semiconductors in fuel cells, coupling or integrating semiconductors/bands and fuel cell electrochemistry has recently emerged, involving metalair batteries, photocatalytic fuel cells, photoenhanced fuel cells and many others $[110,146-152]$. Rechargeable Li-O batteries are frequently reported to be intensified by the photoassisted process. Generally, rechargeable Li-air batteries show high energy density above that of Li-ion batteries. However, their practical application is limited by the high voltage loss related to the cathode processes, oxygen reduction and evolution reactions, and coupling with the low conductivity lithium oxide that forms [153-155]. Reduction of the energy loss to accelerate the formation and decomposition of $\mathrm{Li}_{2} \mathrm{O}_{2}$ and $\mathrm{O}_{2}$ evolution is the key. $\mathrm{C}_{3} \mathrm{~N}_{4}$-carbon is the key to realizing such a coupling process of lithium-air batteries to realize high energy efficiency. Such a system consists of a $\mathrm{Li}$ anode, a nonaqueous electrolyte combined with an lower than the energy level of $\mathrm{H}^{+} / \mathrm{H}_{2}$, as the electrons generated by $\mathrm{H}_{2}$ oxidation are expected to flow to the CB level of this semiconductor. Reproduced with permission from Ref. [82]. Copyright 2019 RSC

$\mathrm{I}^{-}$ion redox mediator and $\mathrm{g}-\mathrm{C}_{3} \mathrm{~N}_{4}$ grown on carbon paper simultaneously as an oxygen electrode and a photoelectrode, as shown in Fig. 19a. Upon charging under illumination, the $\mathrm{I}^{-}$ions are oxidized to $\mathrm{I}_{3}{ }^{-}$ions by photoexcited holes from the photocatalyst, and subsequently, $\mathrm{I}_{3}{ }^{-}$ions diffuse to the oxygen electrode surface, oxidize $\mathrm{Li}_{2} \mathrm{O}_{2}$ to $\mathrm{O}_{2}$ and are reduced back to complete a full redox cycle. Meanwhile, the photoexcited electrons transfer to the anode through the external circuit and reduce $\mathrm{Li}^{+}$to $\mathrm{Li}$ metal. Accordingly, the charging voltage of a $\mathrm{Li}-\mathrm{O}_{2}$ battery is compensated by the photovoltage generated on the photoelectrode. The photoassisted charging voltage equals the energy difference between the redox potential of the $\mathrm{Li}^{+} / \mathrm{Li}$ couple and the $\mathrm{CB}$ of the photocatalyst, as shown in Fig. 19b. A suitable photocatalyst for photoassisted rechargeable batteries must fulfill two essential conditions: the $\mathrm{CB}$ potential should be lower than the $\mathrm{O}_{2} / \mathrm{Li}_{2} \mathrm{O}_{2}$ couple potential (that is, $2.96 \mathrm{~V}$ ), and the VB potential should be higher than the $\mathrm{I}^{-} / \mathrm{I}_{3}{ }^{-}$couple potential to realize oxidization of $\mathrm{I}^{-}$ions to $\mathrm{I}_{3}{ }^{-}$ions. The battery can deliver discharge and charge voltages of 2.76 and $3.56 \mathrm{~V}$, respectively, proving that $\mathrm{g}-\mathrm{C}_{3} \mathrm{~N}_{4}$ can act as an ORR catalyst for $\mathrm{Li}-\mathrm{O}_{2}$ batteries. Solar cells and solid battery/fuel cells 
Fig. 19 Schematic illustration of the photoassisted a rechargeable $\mathrm{Li}-\mathrm{O}_{2}$ battery and b zinc-air battery and $\mathbf{c}, \mathbf{d}$ their corresponding energy band as well as the proposed mechanism of the sunlight-promoted process. Reproduced with permission from Ref. [161] and [157]. Copyright 2015 RSC and Copyright 2019 Springer Nature, respectively
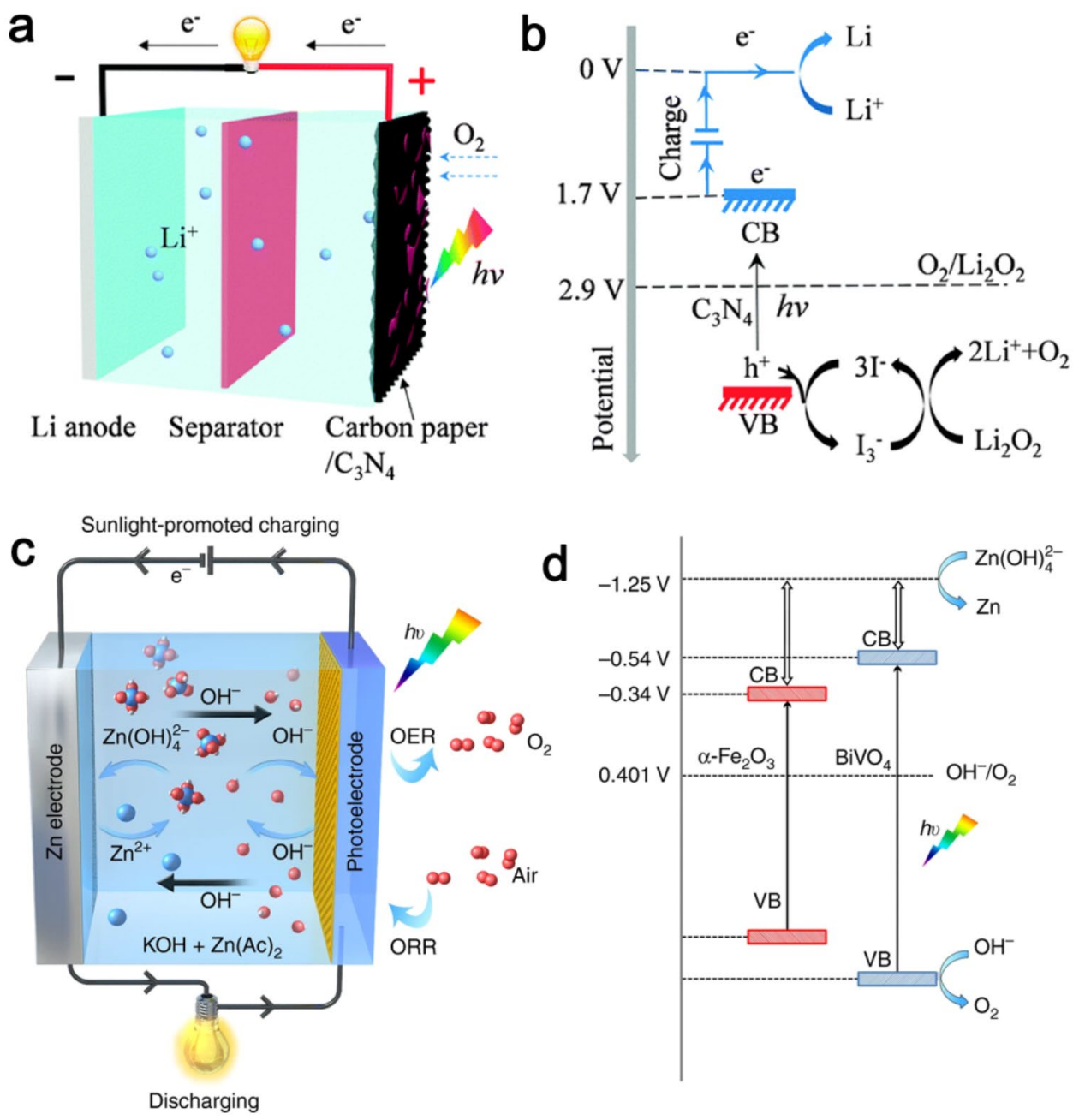

both convert energy of different forms into electricity. A combination of these two battery systems has demonstrated clean and energy-efficient functional integrity [7, 156-159]. $\mathrm{Li}-\mathrm{O}_{2}$ batteries have been the most focused on system to be successfully loaded with a photoresponsive electrode, where the in situ generated holes possessing positive charges directly or indirectly catalyze the oxygen evolution reaction (OER) [157, 160, 161]. Therefore, the notoriously large overpotential of the OER has been efficiently suppressed via this synergistic process, where solar energy is nominally stored in the rechargeable battery system and further consumed to compensate for the energy needed for battery charge. Additionally, recently, the utilization of solar energy to improve the OER kinetics has also been demonstrated in zinc-air batteries, which consist of a $\mathrm{Zn}$ electrode and a $\mathrm{BiVO}_{4} / \alpha-\mathrm{Fe}_{2} \mathrm{O}_{3}$ heterostructure semiconductor photoelectrode as an air electrode assembled in an alkaline electrolyte (Fig. 19c). The charging process is associated with the OER on the air electrode, which has intrinsically sluggish reaction kinetics, resulting in a large overpotential and low energy efficiency. As illustrated in the proposed sunlight-promoted charging mechanism (Fig. 19d), a photovoltage is generated when the photoelectrode undergoes photoexcitation, which compensates for the high charge potential of the zinc-air battery; therefore, a higher electrical efficiency is achieved, as expected [157, 161]. These results can benefit from a more comprehensive understanding of fuel cell semiconductor electrochemistry and motivate new interesting frontier research and breakthroughs in scientific fundamentals, technologies, and applications.

Another interesting topic is the solar photocatalytic fuel cell (PFC), which can realize wastewater treatment and electricity generation simultaneously [163]. Figure 20a schematically shows the configuration of such a device, which consists of an effective photoanode and an ORR cathode. The photoanode is made of a CdS quantum dot-sensitized $\mathrm{TiO}_{2}$ nanorod array deposited on FTO glass, and a gas diffusion electrode was employed to improve the ORR at the cathode. The ORR reaction utilizes protons produced from wastewater treatment to complete the fuel cell cathode reaction for power generation. Another interesting PFC constructed by using a photoanode made of heterostructured $\mathrm{ZnFe}_{2} \mathrm{O}_{4} /$ 

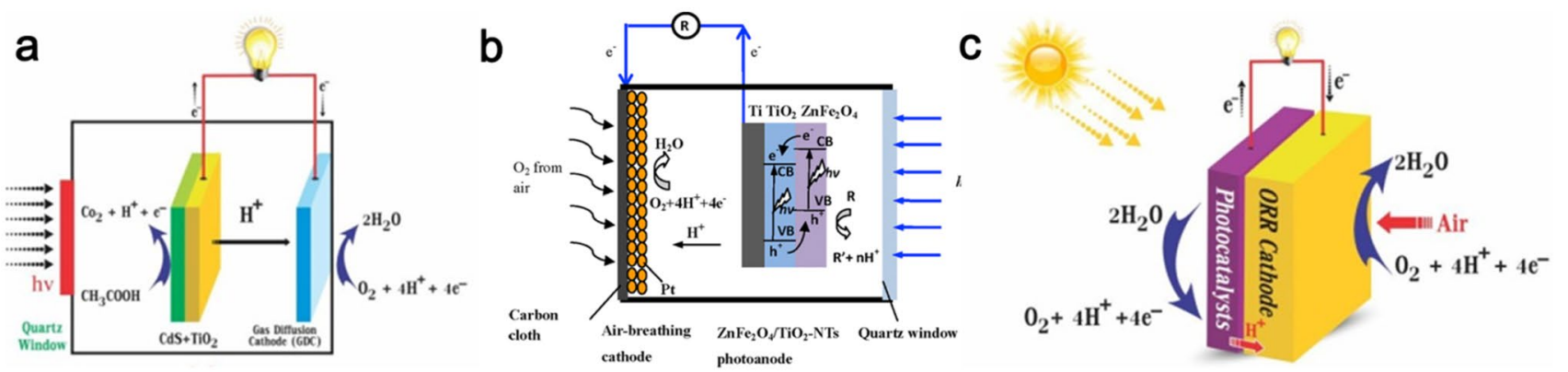

Fig. 20 Schematic diagram of a photocatalytic fuel cell (PFC) a for treating wastewater and simultaneously converting chemically stored energy from wastewater into electricity [162]. b Schematic diagram of the PFC system with the $\mathrm{ZnFe}_{2} \mathrm{O}_{4} / \mathrm{TiO}_{2}$-NT photoanode and airbreathing cathode for simultaneous pollutant removal and power production [163]. c Schematic diagram of the PFC system with a photo-water splitting anode and an air diffusion catalyst cathode for simultaneous water oxidation and power production. Reproduced with permission from Ref. [157]. Copyright 2019 Springer Nature

should not be limited to the listed examples, e.g., photovoltachromic supercapacitors [7] and others.

In photoelectrolysis, semiconductor heterostructure materials are often employed, in which the energy band and semiconducting physics play important roles, as shown in Fig. 22. The basic mechanism and process of photocatalysis are focused on two strategies: (1) energy band modification to broaden the light absorption and (2) surface modification (surface sensitization, semiconductor combination, and noble metal deposition) to increase the lifetime of the carrier, as well as the reaction kinetics. Overall, a suitable band structure is key for visible-light harvesting and effective separation of the carriers of semiconductor photocatalysts. Following a similar working principle for novel semiconductor-based fuel cells, what is required is rather the same, that is, in terms of charge creation, separation, transport and reaction ('closing the circuit'), with $\mathrm{h}^{+} / \mathrm{e}^{-}$being the key charges on electrodes and $\mathrm{H}^{+} / \mathrm{O}^{2-}$ being the charge carriers, to realize the charge transfer and redox reactions based on the band design.

Even in the photovoltaic field, typically, a perovskitetype solar cell is a very emerging concept [164], which greatly involves a deep fundamental understanding and technology scaling up and applications. Ion transport is responsible for unusual phenomena such as current-voltage hysteresis in photovoltaic devices, band structure changes, durability and anomalous above-bandgap photovoltages. Ion transport is governed in PSCs by intrinsic (ions, e.g., $\mathrm{MA}^{+}, \mathrm{Pb}^{2+}, \mathrm{I}^{-}$, and $\mathrm{O}^{2-}$; and point and extended defects) and extrinsic (light, heat, electrical fields, and chemical gradients) factors $[165,166]$. These factors affect the photonic conductivity and offer valuable directions for both limiting ion transport, where required, and harnessing it to enable new functionalities, as shown in Fig. 23 $[167,168]$. The transport of these ion defects exerts strong effects on the PSC performance, suggesting that electrons and ions are coupled and correlated in energy conversion will be explored and developed for practical uses, which 
Fig. 21 Schematic illustration of Energy band alignment for photocatalytic hydrogen evolution (a), with the corresponding $\mathrm{H}_{2}$ production performance (b), and for fuel cell applications (c), with the full cell performance of the $\mathrm{ZnO} / \mathrm{SrTiO}_{3}$ heterostructure (d). The performances of control samples are also given in (d). Reproduced with permission from Ref. [96]. Copyright 2018 Elsevier

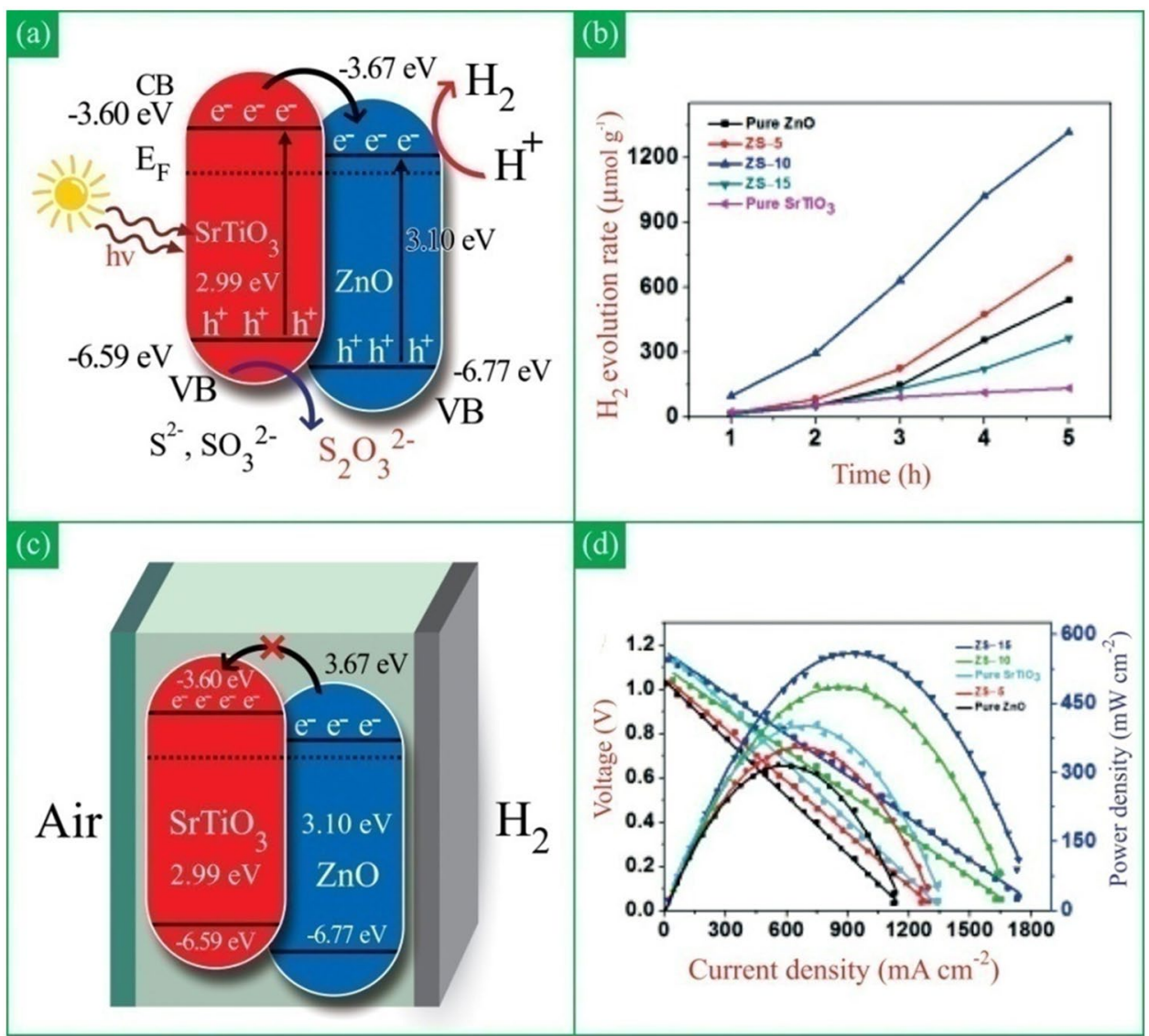

Fuel cell vs. Photoelectrolysis cell
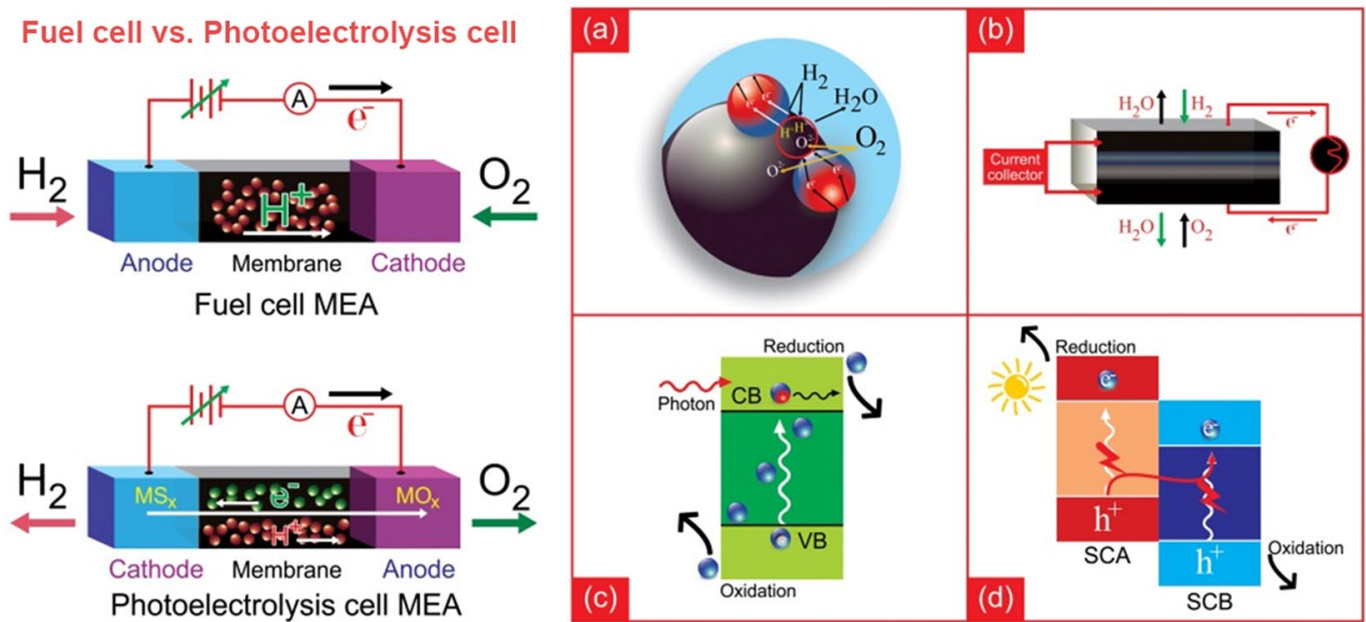

Fig. 22 Schematic comparison of a fuel cell and a PEC. a Single-layer EFFC and $\mathbf{b}$ double-layer devices driven by the similar semiconductor $\mathrm{p}-\mathrm{n}$ junction principle; $\mathbf{c}, \mathbf{d}$ photoelectrolysis realized by semiconductor band structure design and alignment

and storage systems, although the focuses and applications are different because the device performances are dominated by either ions or electrons/holes. In our recent development, a semiconductor-ionic oxide was used as the PV functional layer, with successful demonstration of a PV cell with significant enhancement of both the device voltage and photocurrent output (see Fig. 24) [169]. $\mathrm{Co}_{3} \mathrm{O}_{4}$ is a p-type semiconductor that is incorporated with lithium to form an ionic-type $\mathrm{Li}_{x} \mathrm{Co}_{3-x} \mathrm{O}_{4}$ semiconductor oxide. The use of both $\mathrm{Co}_{3} \mathrm{O}_{4}$ and $\mathrm{Li}_{x} \mathrm{Co}_{3-x} \mathrm{O}_{4}$ as the PV functional layer resulted in a very different device performance; an $\mathrm{OCV}$ enhanced by more than double and a 


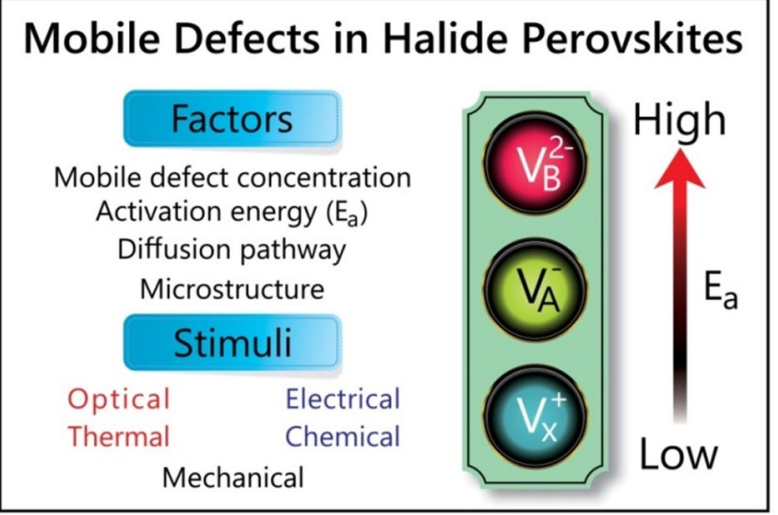

Fig. 23 Effect of factors on mobile defects and the consequences for physical and chemical properties. Reproduced with permission from Ref. [168]. Copyright 2018 ACS
For example, the solar cell field is experiencing a highly interesting phase of development from physical $\mathrm{p}-\mathrm{n}$ junction devices to electrochemical dye-sensitized and new perovskite-type solar cells. The latest developments show a trend of combining multiple types of energy devices (silicon solar cell (SSC), $\mathrm{Cu}(\mathrm{In}, \mathrm{Ga})(\mathrm{Sn}, \mathrm{Se})_{2}$ (CIGS), organic solar cell (OSC), dye-sensitized solar cell (DSSC), perovskite solar cell (PSC), lithium-ion battery (LIB), nanogenerator (NG), supercapacitor (SC), photoelectrosynthetic cell (PESC), biofuel cell (BFC), photodetector (PD), and electrolysis cell (ELC), etc.,) into a single device, two of them, at most cases, can be integrated into one unit, such as DSSC/LIB, DSSC/ SC, DSSC/NG, DSSC/LIB/NG, PSC/OSC, PSC/CIGS, $\mathrm{PSC} / \mathrm{PSC}, \mathrm{PSC} / \mathrm{SSC}, \mathrm{SSC} / \mathrm{SC}, \mathrm{PSC} / \mathrm{SC}, \mathrm{OSC} / \mathrm{SC}, \mathrm{DSSC} /$ PESC, PSC/PESC, PSC/ELC, LIB/SC, LIB/NG, BFC/NG, $\mathrm{PD} / \mathrm{BFC}, \mathrm{SC} / \mathrm{PD}$, and NG/SC/DSSC, for various applications $[15,123]$. This field is strongly affected by interdisci-
Fig. $24 \mathrm{PV}$ devices using $\mathrm{Co}_{3} \mathrm{O}_{4}$ and $\mathrm{Li}_{x} \mathrm{Co}_{3-x} \mathrm{O}_{4}$ as the functional layer. a $\mathrm{Li}_{x} \mathrm{Co}_{3-x} \mathrm{O}_{4}$ structure; $\mathbf{b}$ schematic diagram of $\mathrm{TiO}_{2} / \mathrm{Li}_{x} \mathrm{Co}_{3-x} \mathrm{O}_{4}$ heterojunction solar cells; $\mathbf{c}$ energy alignment diagram for $\mathrm{TiO}_{2} /$ $\mathrm{Li}_{x} \mathrm{Co}_{3-x} \mathrm{O}_{4}$ heterojunction solar cells; $\mathbf{d} J-V$ characteristics of the device under $100 \mathrm{~mW} \mathrm{~cm}^{-2}$. Reproduced with permission from Ref. [169]. Copyright 2016 Elsevier
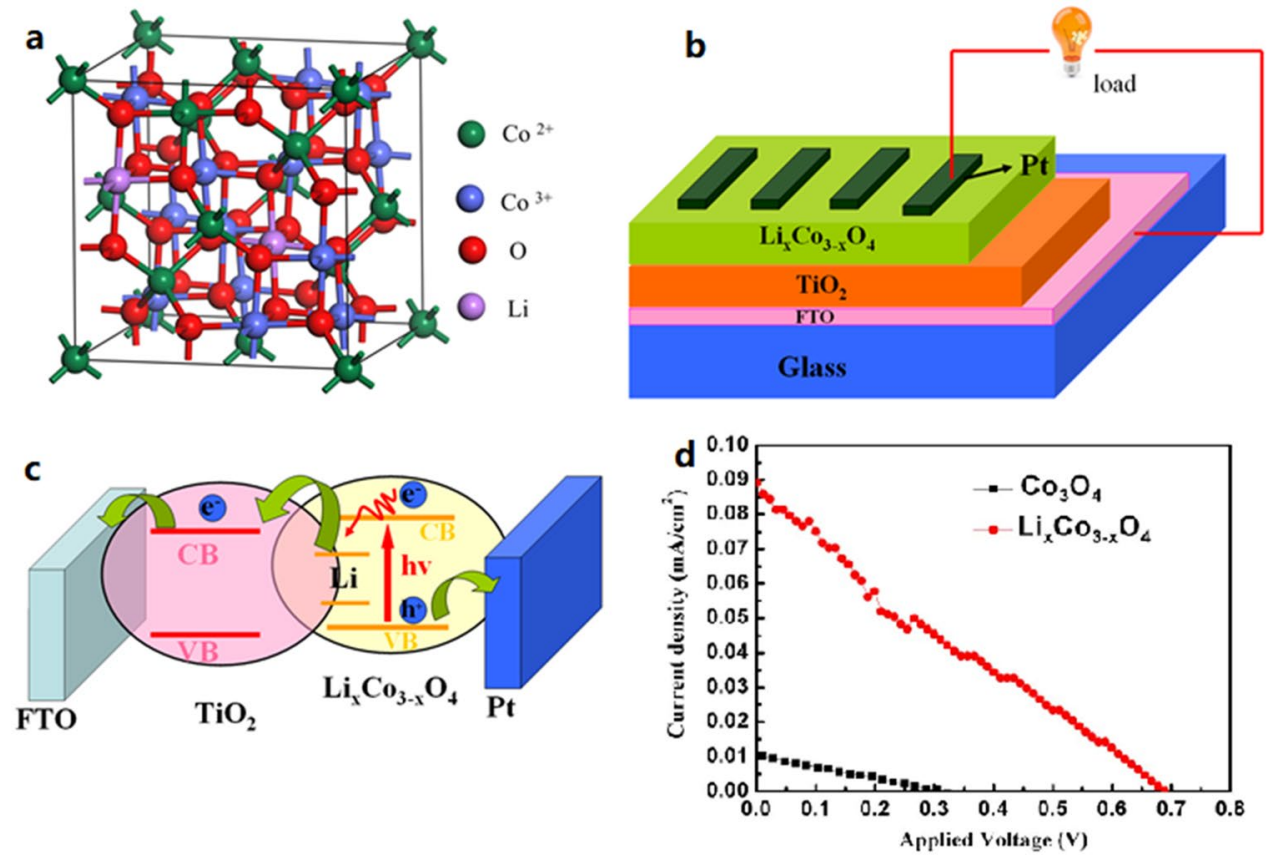

current output enhanced nine times were obtained, suggesting the feasibility of the project.

\section{Summary and Remarks}

This review intends to present new ideas and explore new solutions to clean electrochemical energy conversion and storage going beyond the existing knowledge raising a fundamental question: are there other ways to further develop fuel cells, e.g., by employing semiconductors and semiconductor electrochemistry? Other rapidly developing energy research could be taken as examples for further exploration. plinary approaches. It is often complementary to traditional semiconductor $\mathrm{p}-\mathrm{n}$ junction devices progressing towards new types of practical uses as well as new science. We also recognized early on the SLFC with a joint solar cell and fuel cell as the working principle [87]. Photoelectrolysis or water splitting by photons was well developed around the PEC in the past, but today, photocatalysis can be realized by using semiconductors and band structures [8-10, 170]. Notably, there is a very high degree of similarity historically between the fuel cell and the PEC.

The traditional electrolyte in the fuel cell has served as both an ionic conductor and as an electronic insulator 


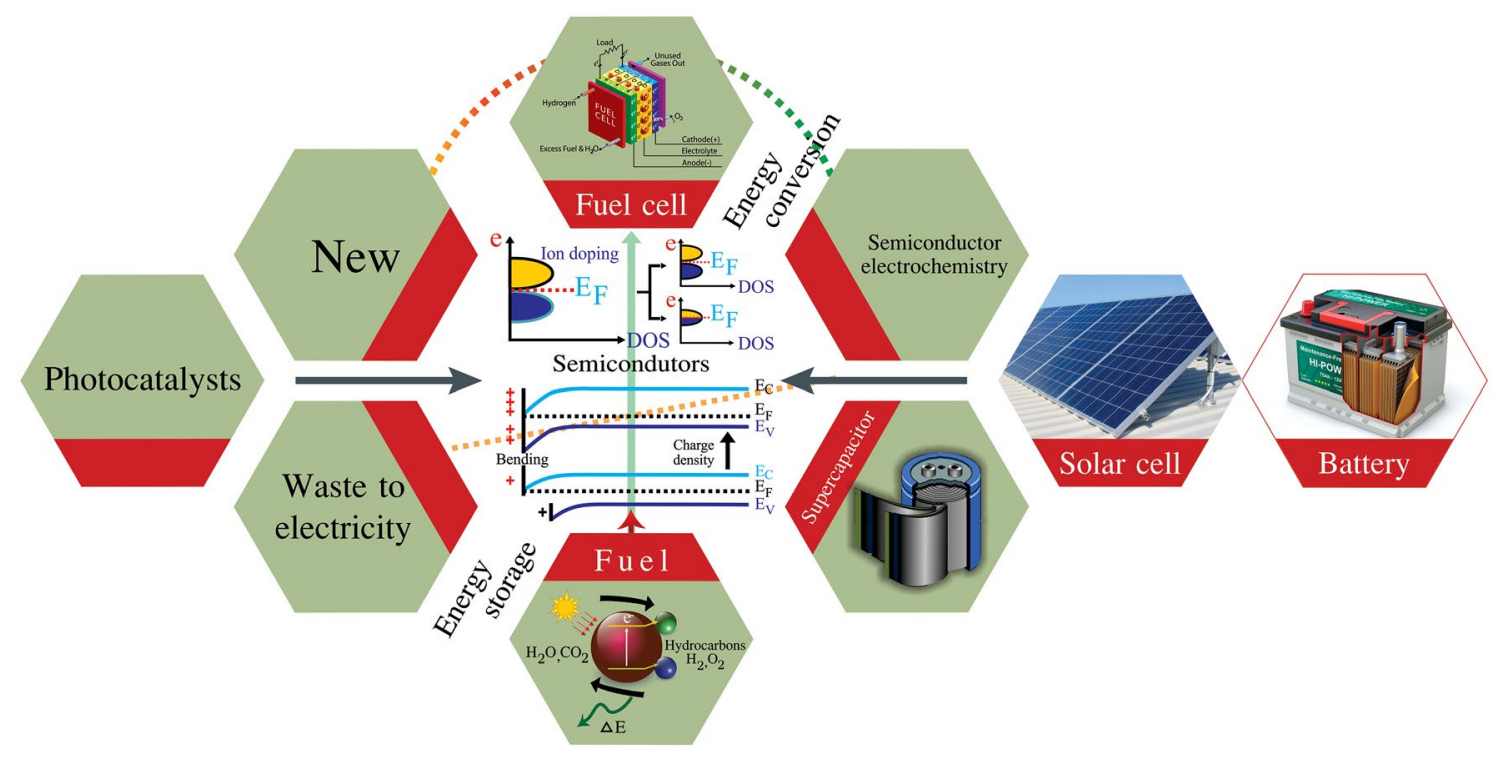

Fig. 25 Overview of semiconductors for a wide range of applications for energy conversion and storage, where the fuel cell area is just beginning

preventing short circuiting. In semiconductor and heterostructure membrane fuel cells, the short-circuiting problem can be solved through energy band alignment/junction formation and design, which have been successfully demonstrated in solar cells and photoelectrolysis, but now also adopted for fuel cells, e.g., SLFCs or semiconductor membrane fuel cells. Understanding of semiconductor bands and physics enabled conventional electrochemical photoelectrolysis and lithium battery to make use from the new aspects, which now may extend to fuel cell electrochemistry. A wide range of energy conversion and storage applications from the new scientific discoveries across the different disciplines of materials, technology, engineering, physics, and chemistry/electrochemistry could be envisioned as summarized in Fig. 25, where an overall understanding of semiconductors and semiconductor electrochemistry plays a vital role.

Authors' Contributions BZ Conceptualization, Supervision, Original draft preparation, Writing-Review \& editing, Project administration, Funding acquisition. LF Conceptualization, Literature survey \& analysis, Original draft preparation, Writing-Review \& editing, Funding acquisition. NM Original draft preparation and editing, Literature survey \& analysis. RR Writing-Review \& editing, Figure edition, Literature survey. MS Figure re-edition and beautification. YW Literature survey \& analysis, Writing — Review \& editing. WL Writing-Review \& editing. J-SK Writing-Review \& editing, Funding acquisition. PDL Writing-Review \& editing. SY Literature survey, Original draft preparation, Writing—Review \& editing, Funding acquisition.

Funding This work was supported by the National Natural Science Foundation of China (51772080, 51672208, 51774259, and $51402093)$, the Natural Science Foundation of Guangdong Province (2021A1515012356 and 2017A030313289) and the project foundation from the Ministry of Education of Guangdong
Province (2019KTSCX151), Shenzhen Government Plan of Science and Technology (JCYJ20180305125247308), the National Laboratory of Solid State Microstructures, Nanjing University, EPSRC (EP/ I013229/1), Royal Society and Newton Fund (NAF\R1\191294), and Key Program for International S\&T Cooperation Projects of Shaanxi Province (2019JZ-20, 2019KWZ-03). The leading author Prof. Bin Zhu acknowledges the Hubei Provincial 100-Talent Distinguished Professor Grant at the China University of Geoscience and Hubei University. Authors thank PhD student Jingjing Yang for correcting. References by using Endnote and getting high-resolution Figures from the original literatures.

Availability of Data and Material Please contact Professor Bin Zhu (Email: binzhu@kth.se).

\section{Declarations}

Conflict of interest All authors claim no conflicts of interest.

Open Access This article is licensed under a Creative Commons Attribution 4.0 International License, which permits use, sharing, adaptation, distribution and reproduction in any medium or format, as long as you give appropriate credit to the original author(s) and the source, provide a link to the Creative Commons licence, and indicate if changes were made. The images or other third party material in this article are included in the article's Creative Commons licence, unless indicated otherwise in a credit line to the material. If material is not included in the article's Creative Commons licence and your intended use is not permitted by statutory regulation or exceeds the permitted use, you will need to obtain permission directly from the copyright holder. To view a copy of this licence, visit http://creativecommons.org/licenses/by/4.0/. 


\section{References}

1. Zhu, B., Yun, S.N., Lund, P.D.: Semiconductor-ionic materials could play an important role in advanced fuel-to-electricity conversion. Int. J. Energy Res. 42, 3413-3415 (2018). https://doi. org/10.1002/er.4105

2. Lund, P.D., Zhu, B., Li, Y.D., et al.: Standardized procedures important for improving single-component ceramic fuel cell technology. ACS Energy Lett. 2, 2752-2755 (2017). https://doi. org/10.1021/acsenergylett.7b00997

3. Singh, K., Nowotny, J., Thangadurai, V.: Amphoteric oxide semiconductors for energy conversion devices: a tutorial review. Chem. Soc. Rev. 42, 1961-1972 (2013). https://doi.org/10.1039/ c2 $\operatorname{cs} 35393$

4. Asghar, M.I., Jouttijärvi, S., Jokiranta, R., et al.: Wide bandgap oxides for low-temperature single-layered nanocomposite fuel cell. Nano Energy 53, 391-397 (2018). https://doi.org/10.1016/j. nanoen.2018.08.070

5. Fan, L.D., Zhu, B., Su, P.C., et al.: Nanomaterials and technologies for low temperature solid oxide fuel cells: recent advances, challenges and opportunities. Nano Energy 45, 148-176 (2018). https://doi.org/10.1016/j.nanoen.2017.12.044

6. Garcia-Barriocanal, J., Rivera-Calzada, A., Varela, M., et al.: Colossal ionic conductivity at interfaces of epitaxial $\mathrm{ZrO}_{2}: \mathrm{Y}_{2} \mathrm{O}_{3} /$ $\mathrm{SrTiO}_{3}$ heterostructures. Science 321, 676-680 (2008). https:// doi.org/10.1126/science. 1156393

7. Zhou, F.C., Ren, Z.W., Zhao, Y.D., et al.: Perovskite photovoltachromic supercapacitor with all-transparent electrodes. ACS Nano 10, 5900-5908 (2016). https://doi.org/10.1021/acsnano. 6b01202

8. Feng, X.J., LaTempa, T.J., Basham, J.I., et al.: $\mathrm{Ta}_{3} \mathrm{~N}_{5}$ nanotube arrays for visible light water photoelectrolysis. Nano Lett. 10, 948-952 (2010). https://doi.org/10.1021/n1903886e

9. Osterloh, F.E.: Inorganic nanostructures for photoelectrochemical and photocatalytic water splitting. Chem. Soc. Rev. 42, 22942320 (2013). https://doi.org/10.1039/c2cs35266d

10. Linsebigler, A.L., Lu, G.Q., Yates, J.T., Jr.: Photocatalysis on $\mathrm{TiO}_{2}$ surfaces: principles, mechanisms, and selected results. Chem. Rev. 95, 735-758 (1995). https://doi.org/10.1021/cr000 $35 \mathrm{a} 013$

11. Xia, T., Zhang, W., Murowchick, J., et al.: Built-in electric fieldassisted surface-amorphized nanocrystals for high-rate lithiumion battery. Nano Lett. 13, 5289-5296 (2013). https://doi.org/10. $1021 / \mathrm{nl} 402810 \mathrm{~d}$

12. Zheng, Y., Zhou, T.F., Zhao, X.D., et al.: Atomic interface engineering and electric-field effect in ultrathin $\mathrm{Bi}_{2} \mathrm{MoO}_{6}$ nanosheets for superior lithium ion storage. Adv. Mater. 29, 1700396 (2017). https://doi.org/10.1002/adma.201700396

13. Fong, D.D., Ramanathan, S.: Preface for special topic: ionotronics. APL Mater. 5, 042201 (2017). https://doi.org/10.1063/1. 4982238

14. Gerischer, H.: The impact of semiconductors on the concepts of electrochemistry. Electrochim. Acta 35, 1677-1699 (1990). https://doi.org/10.1016/0013-4686(90)87067-C

15. Yun, S.N., Vlachopoulos, N., Qurashi, A., et al.: Dye sensitized photoelectrolysis cells. Chem. Soc. Rev. 48, 3705-3722 (2019). https://doi.org/10.1039/c8cs00987b

16. Zhou, Y., Guan, X.F., Zhou, H., et al.: Strongly correlated perovskite fuel cells. Nature 534, 231-234 (2016). https://doi.org/ 10.1038/nature17653

17. Fan, L.D., Ma, Y., Wang, X.D., et al.: Understanding the electrochemical mechanism of the core-shell ceria-LiZnO nanocomposite in a low temperature solid oxide fuel cell. J. Mater. Chem. A 2, 5399 (2014). https://doi.org/10.1039/c3ta14098
18. Boukamp, B.A.: Fuel cells: The amazing perovskite anode. Nat Mater 2, 294-296 (2003). https://doi.org/10.1038/nmat892

19. Shao, Z.P., Haile, S.M.: A high-performance cathode for the next generation of solid-oxide fuel cells. Nature 431, 170-173 (2004). https://doi.org/10.1038/nature02863

20. Huang, Y.H., Dass, R.I., Xing, Z.L., et al.: Double perovskites as anode materials for solid-oxide fuel cells. Science 312, 254-257 (2006). https://doi.org/10.1126/science.1125877

21. Tao, S.W., Irvine, J.T.S.: A redox-stable efficient anode for solidoxide fuel cells. Nat. Mater. 2, 320-323 (2003). https://doi.org/ 10.1038/nmat871

22. Neagu, D., Tsekouras, G., Miller, D.N., et al.: In situ growth of nanoparticles through control of non-stoichiometry. Nat. Chem. 5, 916-923 (2013). https://doi.org/10.1038/nchem.1773

23. Duan, C.C., Tong, J.H., Shang, M., et al.: Readily processed protonic ceramic fuel cells with high performance at low temperatures. Science 349, 1321-1326 (2015). https://doi.org/10.1126/ science.aab3987

24. Sengodan, S., Choi, S., Jun, A., et al.: Layered oxygen-deficient double perovskite as an efficient and stable anode for direct hydrocarbon solid oxide fuel cells. Nat. Mater. 14, 205-209 (2015). https://doi.org/10.1038/nmat4166

25. Vøllestad, E., Strandbakke, R., Tarach, M., et al.: Mixed proton and electron conducting double perovskite anodes for stable and efficient tubular proton ceramic electrolysers. Nat. Mater. 18, 752-759 (2019). https://doi.org/10.1038/s41563-019-0388-2

26. Liu, Q., Dong, X.H., Xiao, G.L., et al.: A novel electrode material for symmetrical SOFCs. Adv. Mater. 22, 5478-5482 (2010). https://doi.org/10.1002/adma.201001044

27. Su, C., Wang, W., Liu, M.L., et al.: Progress and prospects in symmetrical solid oxide fuel cells with two identical electrodes. Adv. Energy Mater. 5, 1500188 (2015). https://doi.org/10.1002/ aenm. 201500188

28. Steele, B.C.H.: Appraisal of $\mathrm{Ce}_{1-y} \mathrm{Gd}_{y} \mathrm{O}_{2-y / 2}$ electrolytes for ITSOFC operation at $500{ }^{\circ} \mathrm{C}$. Solid State Ion. 129, 95-110 (2000). https://doi.org/10.1016/S0167-2738(99)00319-7

29. Ishihara, T., Matsuda, H., Takita, Y.: Doped $\mathrm{LaGaO}_{3}$ perovskite type oxide as a new oxide ionic conductor. J. Am. Chem. Soc. 116, 3801-3803 (1994). https://doi.org/10.1021/ja00088a016

30. Yang, L., Wang, S.Z., Blinn, K., et al.: Enhanced sulfur and coking tolerance of a mixed ion conductor for SOFCs: $\mathrm{BaZr}_{0.1} \mathrm{Ce}_{0.7} \mathrm{Y}_{0.2-x} \mathrm{Yb}_{x} \mathrm{O}_{3-\delta}$. Science 326, 126-129 (2009). https://doi.org/10.1126/science.1174811

31. Nakayama, S., Aono, H., Sadaoka, Y.: Ionic conductivity of $\mathrm{Ln}_{10}\left(\mathrm{SiO}_{4}\right)_{6} \mathrm{O}_{3}(\mathrm{Ln}=\mathrm{La}, \mathrm{Nd}, \mathrm{Sm}, \mathrm{Gd}$ and Dy). Chem. Lett. 24, 431-432 (1995). https://doi.org/10.1246/cl.1995.431

32. Haugsrud, R., Norby, T.: Proton conduction in rare-earth orthoniobates and ortho-tantalates. Nat. Mater. 5, 193-196 (2006). https://doi.org/10.1038/nmat1591

33. Li, M., Pietrowski, M.J., de Souza, R.A., et al.: A family of oxide ion conductors based on the ferroelectric perovskite $\mathrm{Na}_{0.5} \mathrm{Bi}_{0.5} \mathrm{TiO}_{3}$. Nat. Mater. 13, 31-35 (2014). https://doi.org/ $10.1038 /$ nmat 3782

34. Singh, P., Goodenough, J.B.: Monoclinic $\mathrm{Sr}_{1-x} \mathrm{Na}_{x} \mathrm{SiO}_{3-0.5 x}$ : new superior oxide ion electrolytes. J. Am. Chem. Soc. 135, 1014910154 (2013). https://doi.org/10.1021/ja4042737

35. Norby, T.: The promise of protonics. Nature 410, 877-878 (2001). https://doi.org/10.1038/35073718

36. Duan, C.C., Kee, R.J., Zhu, H.Y., et al.: Highly durable, coking and sulfur tolerant, fuel-flexible protonic ceramic fuel cells. Nature 557, 217-222 (2018). https://doi.org/10.1038/ s41586-018-0082-6

37. An, H., Lee, H.W., Kim, B.K., et al.: A $5 \times 5 \mathrm{~cm}^{2}$ protonic ceramic fuel cell with a power density of $1.3 \mathrm{~W} \mathrm{~cm}^{-2}$ at $600{ }^{\circ} \mathrm{C}$. 
Nat. Energy 3, 870-875 (2018). https://doi.org/10.1038/ s41560-018-0230-0

38. Duan, C.C., Kee, R., Zhu, H.Y., et al.: Highly efficient reversible protonic ceramic electrochemical cells for power generation and fuel production. Nat. Energy 4, 230-240 (2019). https://doi.org/ 10.1038/s41560-019-0333-2

39. Zhu, B.: Advantages of intermediate temperature solid oxide fuel cells for tractionary applications. J. Power Sources 93, 82-86 (2001). https://doi.org/10.1016/S0378-7753(00)00564-4

40. Zhu, B.: Functional ceria-salt-composite materials for advanced ITSOFC applications. J. Power Sources 114, 1-9 (2003). https:// doi.org/10.1016/S0378-7753(02)00592-X

41. Zhu, B., Yang, X.T., Xu, J., et al.: Innovative low temperature SOFCs and advanced materials. J. Power Sources 118, 47-53 (2003). https://doi.org/10.1016/S0378-7753(03)00060-0

42. Zhu, B.: Next generation fuel cell R\&D. Int. J. Energy Res. 30, 895-903 (2006). https://doi.org/10.1002/er.1195

43. Wang, X.D., Ma, Y., Raza, R., et al.: Novel core-shell SDC/amorphous $\mathrm{Na}_{2} \mathrm{CO}_{3}$ nanocomposite electrolyte for low-temperature SOFCs. Electrochem. Commun. 10, 1617-1620 (2008). https:// doi.org/10.1016/j.elecom.2008.08.023

44. Zhu, B., Li, S., Mellander, B.E.: Theoretical approach on ceriabased two-phase electrolytes for low temperature (300-600 $\left.{ }^{\circ} \mathrm{C}\right)$ solid oxide fuel cells. Electrochem. Commun. 10, 302-305 (2008). https://doi.org/10.1016/j.elecom.2007.11.037

45. Zhu, B.: Solid oxide fuel cell (SOFC) technical challenges and solutions from nano-aspects. Int. J. Energy Res. 33, 1126-1137 (2009). https://doi.org/10.1002/er.1600

46. Ma, Y., Wang, X.D., Li, S.H., et al.: Samarium-doped ceria nanowires: novel synthesis and application in low-temperature solid oxide fuel cells. Adv. Mater. 22, 1640-1644 (2010). https:// doi.org/10.1002/adma.200903402

47. Raza, R., Wang, X.D., Ma, Y., et al.: Improved ceria-carbonate composite electrolytes. Int. J. Hydrog. Energy 35, 2684-2688 (2010). https://doi.org/10.1016/j.ijhydene.2009.04.038

48. Fan, L.D., Wang, C.Y., Chen, M.M., et al.: Recent development of ceria-based (nano)composite materials for low temperature ceramic fuel cells and electrolyte-free fuel cells. J. Power Sources 234, 154-174 (2013). https://doi.org/10.1016/j.jpowsour.2013. 01.138

49. Fan, L.D., Zhang, G.Q., Chen, M.M., et al.: Proton and oxygen ionic conductivity of doped ceria-carbonate composite by modified Wagner polarization. Int. J. Electrochem. Sci. 7, 8420-8435 (2012). https://doi.org/10.1002/cvde.201206981

50. Zhu, B., Mat, M.D.: Studies on dual phase ceria-based composites in electrochemistry. Int. J. Electrochem. Sci. 1, 383-402 (2006).

51. Zhu, B., Albinsson, I., Andersson, C., et al.: Electrolysis studies based on ceria-based composites. Electrochem. Commun. 8, 495-498 (2006). https://doi.org/10.1016/j.elecom.2006.01.011

52. Zhu, B., Liu, X.R., Schober, T.: Novel hybrid conductors based on doped ceria and BCY20 for ITSOFC applications. Electrochem. Commun. 6, 378-383 (2004). https://doi.org/10.1016/j. elecom.2004.01.015

53. Huang, J.B., Mao, Z.Q., Liu, Z.X., et al.: Development of novel low-temperature SOFCs with co-ionic conducting SDC-carbonate composite electrolytes. Electrochem. Commun. 9, 2601-2605 (2007). https://doi.org/10.1016/j.elecom.2007.07.036

54. Zhao, Y.C., Xia, C., Wang, Y.J., et al.: Quantifying multi-ionic conduction through doped ceria-carbonate composite electrolyte by a current-interruption technique and product analysis. Int. J. Hydrog. Energy 37, 8556-8561 (2012). https://doi.org/10.1016/j. ijhydene.2012.02.053

55. Zhao, Y.C., Xia, C., Xu, Z.R., et al.: Validation of $\mathrm{H}^{+} / \mathrm{O}_{2-}$ conduction in doped ceria-carbonate composite material using an electrochemical pumping method. Int. J. Hydrog. Energy 37,
11378-11382 (2012). https://doi.org/10.1016/j.ijhydene.2012. 05.015

56. Zhao, Y.C., Xu, Z.R., Xia, C., et al.: Oxide ion and proton conduction in doped ceria-carbonate composite materials. Int. J. Hydrog. Energy 38, 1553-1559 (2013). https://doi.org/10.1016/j. ijhydene.2012.11.004

57. Xia, C., Li, Y., Tian, Y., et al.: Intermediate temperature fuel cell with a doped ceria-carbonate composite electrolyte. J. Power Sources 195, 3149-3154 (2010). https://doi.org/10.1016/j.jpows our.2009.11.104

58. Xia, C., Li, Y., Tian, Y., et al.: A high performance composite ionic conducting electrolyte for intermediate temperature fuel cell and evidence for ternary ionic conduction. J. Power Sources 188, 156-162 (2009). https://doi.org/10.1016/j.jpowsour.2008. 11.068

59. Zhang, G.H., Li, W.J., Huang, W., et al.: Strongly coupled $\mathrm{Sm}_{0.2} \mathrm{Ce}_{0.8} \mathrm{O}_{2} \mathrm{Na}_{2} \mathrm{CO}_{3}$ nanocomposite for low temperature solid oxide fuel cells: one-step synthesis and super interfacial proton conduction. J. Power Sources 386, 56-65 (2018). https://doi.org/ 10.1016/j.jpowsour.2018.03.035

60. Wang, X.D., Ma, Y., Zhu, B.: State of the art ceria-carbonate composites (3C) electrolyte for advanced low temperature ceramic fuel cells (LTCFCs). Int. J. Hydrog. Energy 37, 1941719425 (2012). https://doi.org/10.1016/j.ijhydene.2011.09.096

61. Benamira, M., Ringuedé, A., Hildebrandt, L., et al.: Gadoliniadoped ceria mixed with alkali carbonates for SOFC applications: II-an electrochemical insight. Int. J. Hydrog. Energy 37, 19371-19379 (2012). https://doi.org/10.1016/j.jhydene.2011.10. 062

62. Afzal, M., Raza, R., Du, S.F., et al.: Synthesis of $\mathrm{Ba}_{0.3} \mathrm{Ca}_{0.7} \mathrm{Co}_{0.8} \mathrm{Fe}_{0.2} \mathrm{O}_{3-\delta}$ composite material as novel catalytic cathode for ceria-carbonate electrolyte fuel cells. Electrochimica Acta 178, 385-391 (2015). https://doi.org/10.1016/j.electacta. 2015.07.183

63. Sun, X.L., Li, S., Sun, J.C., et al.: Electrochemical performances of BSCF cathode materials for ceria-composite electrolyte low temperature solid oxide fuel cells. Int. J. Electrochem. Sci. 2, 462-468 (2007)

64. Asghar, M.I., Heikkilä, M., Lund, P.D.: Advanced low-temperature ceramic nanocomposite fuel cells using ultra high ionic conductivity electrolytes synthesized through freeze-dried method and solid-route. Mater. Today Energy 5, 338-346 (2017). https:// doi.org/10.1016/j.mtener.2017.07.017

65. Rajesh, S., Pereira, J.R.S., Figueiredo, F.M.L., et al.: Performance of carbonate $-\mathrm{LaCoO}_{3}$ and $\mathrm{La}_{0.8} \mathrm{Sr}_{0.2} \mathrm{Co}_{0.2} \mathrm{Fe}_{0.8} \mathrm{O}_{3-\delta}$ composite cathodes under carbon dioxide. Electrochimica Acta 125, 435-442 (2014). https://doi.org/10.1016/j.electacta.2014.01.157

66. Huang, J.B., Gao, R.F., Mao, Z.Q., et al.: Investigation of $\mathrm{La}_{2} \mathrm{NiO}_{4+\delta}$-based cathodes for SDC-carbonate composite electrolyte intermediate temperature fuel cells. Int. J. Hydrog. Energy 35, 2657-2662 (2010). https://doi.org/10.1016/j.ijhydene.2009. 04.022

67. Xia, C., Mi, Y.Q., Wang, B.Y., et al.: Shaping triple-conducting semiconductor $\mathrm{BaCo}_{0.4} \mathrm{Fe}_{0.4} \mathrm{Zr}_{0.1} \mathrm{Y}_{0.1} \mathrm{O}_{3-\delta}$ into an electrolyte for low-temperature solid oxide fuel cells. Nat. Commun. 10, 1707 (2019). https://doi.org/10.1038/s41467-019-09532-Z

68. Xing, Y.M., Wu, Y., Li, L.Y., et al.: Proton shuttles in $\mathrm{CeO}_{2} /$ $\mathrm{CeO}_{2-}{ }_{\delta}$ core-shell structure. ACS Energy Lett. 4, 2601-2607 (2019). https://doi.org/10.1021/acsenergylett.9b01829

69. Kim, J., Jun, A., Gwon, O., et al.: Hybrid-solid oxide electrolysis cell: a new strategy for efficient hydrogen production. Nano Energy 44, 121-126 (2018). https://doi.org/10.1016/j.nanoen. 2017.11.074

70. Wang, B.Y., Zhu, B., Yun, S.N., et al.: Fast ionic conduction in semiconductor $\mathrm{CeO}_{2-\delta}$ electrolyte fuel cells. NPG Asia Mater. 11, 51 (2019). https://doi.org/10.1038/s41427-019-0152-8 
71. Duncan, K.L., Lee, K.T., Wachsman, E.D.: Dependence of opencircuit potential and power density on electrolyte thickness in solid oxide fuel cells with mixed conducting electrolytes. J. Power Sources 196, 2445-2451 (2011). https://doi.org/10.1016/j. jpowsour.2010.10.034

72. Riess, I.: The possible use of mixed ionic electronic conductors instead of electrolytes in fuel cells. Solid State Ion. 52, 127-134 (1992). https://doi.org/10.1016/0167-2738(92)90098-A

73. Zhu, B., Ma, Y., Wang, X.D., et al.: A fuel cell with a single component functioning simultaneously as the electrodes and electrolyte. Electrochem. Commun. 13, 225-227 (2011). https:// doi.org/10.1016/j.elecom.2010.12.019

74. Zhu, B., Qin, H.Y., Raza, R., et al.: A single-component fuel cell reactor. Int. J. Hydrog. Energy 36, 8536-8541 (2011). https://doi. org/10.1016/j.ijhydene.2011.04.082

75. Zhu, B., Raza, R., Abbas, G., et al.: An electrolyte-free fuel cell constructed from one homogenous layer with mixed conductivity. Adv. Funct. Mater. 21, 2465-2469 (2011). https://doi.org/10. 1002/adfm.201002471

76. Zhu, B., Raza, R., Qin, H.Y., et al.: Single-component and threecomponent fuel cells. J. Power Sources 196, 6362-6365 (2011). https://doi.org/10.1016/j.jpowsour.2011.03.078

77. Zhu, B., Raza, R., Qin, H.Y., et al.: Fuel cells based on electrolyte and non-electrolyte separators. Energy Environ. Sci. 4, 2986 (2011). https://doi.org/10.1039/c1ee01202a

78. He, H.P., Huang, X.J., Chen, L.Q.: A practice of single layer solid oxide fuel cell. Ionics 6, 64-69 (2000). https://doi.org/10.1007/ BF02375548

79. He, H.P., Huang, X.J., Chen, L.Q.: Sr-doped $\mathrm{LaInO}_{3}$ and its possible application in a single layer SOFC. Solid State Ion. 130, 183-193 (2000). https://doi.org/10.1016/S0167-2738(00) 00666-4

80. Lan, R., Tao, S.W.: Novel proton conductors in the layered oxide material $\mathrm{Li}_{\mathrm{x}} \mathrm{Al}_{0.5} \mathrm{Co}_{0.5} \mathrm{O}_{2}$. Adv. Energy Mater. 4: 1301683 . (2014). https://doi.org/10.1002/aenm.201401461

81. Dong, W.J., Yaqub, A., Janjua, N.K., et al.: All in one multifunctional perovskite material for next generation SOFC. Electrochim. Acta 193, 225-230 (2016). https://doi.org/10.1016/j.elect acta.2016.02.061

82. Dong, W.J., Tong, Y.Z., Zhu, B., et al.: Semiconductor $\mathrm{TiO}_{2}$ thin film as an electrolyte for fuel cells. J. Mater. Chem. A 7, 16728-16734 (2019). https://doi.org/10.1039/c9ta01941c

83. Xia, C., Qiao, Z., Shen, L.P., et al.: Semiconductor electrolyte for low-operating-temperature solid oxide fuel cell: Li-doped $\mathrm{ZnO}$. Int. J. Hydrog. Energy 43, 12825-12834 (2018). https://doi.org/ 10.1016/j.ijhydene.2018.04.121

84. Chen, G., Zhu, B., Deng, H., et al.: Advanced fuel cell based on perovskite $\mathrm{La}-\mathrm{SrTiO}_{3}$ semiconductor as the electrolyte with superoxide-ion conduction. ACS Appl. Mater. Interfaces 10, 33179-33186 (2018). https://doi.org/10.1021/acsami.8b10087

85. Chen, G., Liu, H.L., He, Y., et al.: Electrochemical mechanisms of an advanced low-temperature fuel cell with a $\mathrm{SrTiO}_{3}$ electrolyte. J. Mater. Chem. A 7, 9638-9645 (2019). https://doi.org/10. 1039/c9ta00499h

86. Shi, Y.N., Wang, L.Y., Wang, Z.Y., et al.: Defect engineering for tuning the photoresponse of ceria-based solid oxide photoelectrochemical cells. ACS Appl. Mater. Interfaces 13, 541-551 (2021). https://doi.org/10.1021/acsami.0c17921

87. Zhu, B., Raza, R., Liu, Q.H., et al.: A new energy conversion technology joining electrochemical and physical principles. RSC Adv. 2, 5066 (2012). https://doi.org/10.1039/c2ra01234k

88. Zhu, B., Lund, P., Raza, R., et al.: A new energy conversion technology based on nano-redox and nano-device processes. Nano Energy 2, 1179-1185 (2013). https://doi.org/10.1016/j.nanoen. 2013.05.001
89. Wang, G.J., Wu, X.Y., Cai, Y.X., et al.: Design, fabrication and characterization of a double layer solid oxide fuel cell (DLFC). J. Power Sources 332, 8-15 (2016). https://doi.org/10.1016/j.jpows our.2016.09.011

90. Shao, K., Li, F.J., Zhang, G.H., et al.: Approaching durable single-layer fuel cells: promotion of electroactivity and charge separation via nanoalloy redox exsolution. ACS Appl. Mater. Interfaces 11, 27924-27933 (2019). https://doi.org/10.1021/ acsami.9b08448

91. Fan, L.D., Wang, C.Y., Osamudiamen, O., et al.: Mixed ion and electron conductive composites for single component fuel cells: I. Effects of composition and pellet thickness. J. Power Sources 217, 164-169 (2012). https://doi.org/10.1016/j.jpowsour.2012. 05.045

92. Wu, J.S., Zhu, B., Mi, Y.Q., et al.: A novel core-shell nanocomposite electrolyte for low temperature fuel cells. J. Power Sources 201, 164-168 (2012). https://doi.org/10.1016/j.jpows our.2011.10.084

93. Cai, Y.X., Chen, Y., Akbar, M., et al.: A bulk-heterostructure nanocomposite electrolyte of $\mathrm{Ce}_{0.8} \mathrm{Sm}_{0.2} \mathrm{O}_{2-\delta}-\mathrm{SrTiO}_{3}$ for lowtemperature solid oxide fuel cells. Nano Micro Lett. 13, 1-14 (2021). https://doi.org/10.1007/s40820-020-00574-3

94. Rauf, S., Zhu, B., Yousaf Shah, M.A.K., et al.: Application of a triple-conducting heterostructure electrolyte of $\mathrm{Ba}_{0.5} \mathrm{Sr}_{0.5} \mathrm{Co}_{0.1} \mathrm{Fe}_{0.7} \mathrm{Zr}_{0.1} \mathrm{Y}_{0.1} \mathrm{O}_{3-\delta}$ and $\mathrm{Ca}_{0.04} \mathrm{Ce}_{0.80} \mathrm{Sm}_{0.16} \mathrm{O}_{2-\delta}$ in a high-performance low-temperature solid oxide fuel cell. ACS Appl. Mater. Interfaces 12, 35071-35080 (2020). https://doi. org/10.1021/acsami.0c10061

95. Lu, Y.Z., Akbar, M., Xia, C., et al.: Catalytic membrane with high ion-electron conduction made of strongly correlated perovskite $\mathrm{LaNiO}_{3}$ and $\mathrm{Ce}_{0.8} \mathrm{Sm}_{0.2} \mathrm{O}_{2-\delta}$ for fuel cells. J. Catal. 386, 117-125 (2020). https://doi.org/10.1016/j.jcat.2020.04.004

96. Wu, Y., Dong, B., Zhang, J., et al.: The synthesis of $\mathrm{ZnO} /$ $\mathrm{SrTiO}_{3}$ composite for high-efficiency photocatalytic hydrogen and electricity conversion. Int. J. Hydrog. Energy 43, 12627 12636 (2018). https://doi.org/10.1016/j.ijhydene.2018.03.206

97. Cai, Y.X., Wang, B.Y., Wang, Y., et al.: Validating the technological feasibility of yttria-stabilized zirconia-based semiconducting-ionic composite in intermediate-temperature solid oxide fuel cells. J. Power Sources 384, 318-327 (2018). https:// doi.org/10.1016/j.jpowsour.2018.03.012

98. Han, F., Yun, S.N., Shi, J., et al.: Efficient dual-function catalysts for triiodide reduction reaction and hydrogen evolution reaction using unique 3D network aloe waste-derived carbonsupported molybdenum-based bimetallic oxide nanohybrids. Appl. Catal. B: Environ. 273, 119004 (2020). https://doi.org/ 10.1016/j.apcatb.2020.119004

99. Fuel cells: Three in one. Nat. Nanotechnol. 6, 330 (2011). https://doi.org/10.1038/nnano.2011.93.

100. Zhu, B., Lund, P.D., Raza, R., et al.: Schottky junction effect on high performance fuel cells based on nanocomposite materials. Adv. Energy Mater. 5, 1401895 (2015). https://doi.org/10. 1002/aenm.201401895

101. Afzal, M., Saleemi, M., Wang, B.Y., et al.: Fabrication of novel electrolyte-layer free fuel cell with semi-ionic conductor $\left(\mathrm{Ba}_{0.5} \mathrm{Sr}_{0.5} \mathrm{Co}_{0.8} \mathrm{Fe}_{0.2} \mathrm{O}_{3-\delta^{-}} \mathrm{Sm}_{0.2} \mathrm{Ce}_{0.8} \mathrm{O}_{1.9}\right)$ and Schottky barrier. J. Power Sources 328, 136-142 (2016). https://doi.org/10. 1016/j.jpowsour.2016.07.093

102. Zhu, B., Huang, Y.Z., Fan, L.D., et al.: Novel fuel cell with nanocomposite functional layer designed by perovskite solar cell principle. Nano Energy 19, 156-164 (2016). https://doi. org/10.1016/j.nanoen.2015.11.015

103. Zhu, B., Wang, B.Y., Wang, Y., et al.: Charge separation and transport in $\mathrm{La}_{0.6} \mathrm{Sr}_{0.4} \mathrm{Co}_{0.2} \mathrm{Fe}_{0.8} \mathrm{O}_{3-\delta}$ and ion-doping ceria heterostructure material for new generation fuel cell. Nano Energy 
37, 195-202 (2017). https://doi.org/10.1016/j.nanoen.2017.05. 003

104. Yun, S.N., Zhou, H.W., Wang, L., et al.: Economical hafnium oxygen nitride binary/ternary nanocomposite counter electrode catalysts for high-efficiency dye-sensitized solar cells. J. Mater. Chem. A 1, 1341-1348 (2013). https://doi.org/10.1039/c2ta0 0680d

105. Yun, S.N., Zhang, H., Pu, H.H., et al.: Metal oxide/carbide/ carbon nanocomposites: in situ synthesis, characterization, calculation, and their application as an efficient counter electrode catalyst for dye-sensitized solar cells. Adv. Energy Mater. 3, 1407-1412 (2013). https://doi.org/10.1002/aenm.201300242

106. Yun, S.N., Wu, M.X., Wang, Y.D., et al.: Pt-like behavior of high-performance counter electrodes prepared from binary tantalum compounds showing high electrocatalytic activity for dyesensitized solar cells. Chemsuschem 6, 411-416 (2013). https:// doi.org/10.1002/cssc.201200845

107. Yun, S.N., Wang, L., Zhao, C.Y., et al.: A new type of lowcost counter electrode catalyst based on platinum nanoparticles loaded onto silicon carbide $(\mathrm{Pt} / \mathrm{SiC})$ for dye-sensitized solar cells. Phys. Chem. Chem. Phys. 15, 4286 (2013). https://doi. org/10.1039/c3cp44048f

108. Yun, S.N., Wang, L., Guo, W., et al.: Non-Pt counter electrode catalysts using tantalum oxide for low-cost dye-sensitized solar cells. Electrochem. Commun. 24, 69-73 (2012). https://doi. org/10.1016/j.elecom.2012.08.008

109. Vedhanarayanan, B., Shi, J., Lin, J.Y., et al.: Enhanced activity and stability of $\mathrm{MoS}_{2}$ through enriching 1T-phase by covalent functionalization for energy conversion applications. Chem. Eng. J. 403, 126318 (2021). https://doi.org/10.1016/j.cej.2020. 126318

110. Yun, S.N., Si, Y.M., Shi, J., et al.: Electronic structures and catalytic activities of niobium oxides as electrocatalysts in liquidjunction photovoltaic devices. Sol. RRL 4, 1900430 (2020). https://doi.org/10.1002/solr.201900430

111. Filip, M.R., Hillman, S., Haghighirad, A.A., et al.: Band gaps of the lead-free halide double perovskites $\mathrm{Cs}_{2} \mathrm{BiAgCl}_{6}$ and $\mathrm{Cs}_{2} \mathrm{BiAgBr}_{6}$ from theory and experiment. J. Phys. Chem. Lett. 7, 2579-2585 (2016). https://doi.org/10.1021/acs.jpclett.6b010 41

112. Pessoa, R.S., Fraga, M.A., Santos, L.V., et al.: Nanostructured thin films based on $\mathrm{TiO}_{2}$ and/or $\mathrm{SiC}$ for use in photoelectrochemical cells: a review of the material characteristics, synthesis and recent applications. Mater. Sci. Semicond. Process. 29, 56-68 (2015). https://doi.org/10.1016/j.mssp.2014.05.053

113. Xing, Y.M., Hu, E.Y., Wang, F.Z., et al.: Cubic silicon carbide/ zinc oxide heterostructure fuel cells. Appl. Phys. Lett. 117, 162105 (2020). https://doi.org/10.1063/5.0021460

114. Mushtaq, N., Xia, C., Dong, W.J., et al.: Tuning the energy band structure at interfaces of the $\mathrm{SrFe}_{0.75} \mathrm{Ti}_{0.25} \mathrm{O}_{3-\delta^{-}} \mathrm{Sm}_{0.25} \mathrm{Ce}_{0.75} \mathrm{O}_{2-\delta}$ heterostructure for fast ionic transport. ACS Appl. Mater. Interfaces 11, 38737-38745 (2019). https://doi.org/10.1021/acsami. 9b13044

115. Meng, Y.J., Wang, X.Y., Zhang, W., et al.: Novel high ionic conductivity electrolyte membrane based on semiconductor $\mathrm{La}_{0.65} \mathrm{Sr}_{0.3} \mathrm{Ce}_{0.05} \mathrm{Cr}_{0.5} \mathrm{Fe}_{0.5} \mathrm{O}_{3-\delta}$ for low-temperature solid oxide fuel cells. J. Power Sources 421, 33-40 (2019). https://doi.org/ 10.1016/j.jpowsour.2019.02.100

116. Chen, G., Sun, W.K., Luo, Y.D., et al.: Advanced fuel cell based on new nanocrystalline structure $\mathrm{Gd}_{0.1} \mathrm{Ce}_{0.9} \mathrm{O}_{2}$ electrolyte. ACS Appl. Mater. Interfaces 11, 10642-10650 (2019). https://doi.org/ 10.1021/acsami.8b20454

117. Wu, Y., Liu, L., Yu, X.X., et al.: Natural hematite ore composited with $\mathrm{ZnO}$ nanoneedles for energy applications. Compos. B: Eng. 137, 178-183 (2018). https://doi.org/10.1016/j.compo sitesb.2017.11.020
118. Qiao, Z., Xia, C., Cai, Y.X., et al.: Electrochemical and electrical properties of doped $\mathrm{CeO}_{2}-\mathrm{ZnO}$ composite for low-temperature solid oxide fuel cell applications. J. Power Sources 392, 33-40 (2018). https://doi.org/10.1016/j.jpowsour.2018.04.096

119. Xia, C., Cai, Y.X., Wang, B.Y., et al.: Strategy towards cost-effective low-temperature solid oxide fuel cells: a mixed-conductive membrane comprised of natural minerals and perovskite oxide. J. Power Sources 342, 779-786 (2017). https://doi.org/10.1016/j. jpowsour.2016.12.120

120. Wu, Y., Xia, C., Zhang, W., et al.: Natural hematite for nextgeneration solid oxide fuel cells. Adv. Funct. Mater. 26, 938-942 (2016). https://doi.org/10.1002/adfm.201503756

121. Wang, B.Y., Wang, Y., Fan, L.D., et al.: Preparation and characterization of Sm and Ca co-doped ceria- $\mathrm{La}_{0.6} \mathrm{Sr}_{0.4} \mathrm{Co}_{0.2} \mathrm{Fe}_{0.8} \mathrm{O}_{3-\delta}$ semiconductor-ionic composites for electrolyte-layer-free fuel cells. J. Mater. Chem. A 4, 15426-15436 (2016). https://doi.org/ 10.1039/c6ta05763b

122. Yun, S.N., Zhang, Y.W., Xu, Q., et al.: Recent advance in newgeneration integrated devices for energy harvesting and storage. Nano Energy 60, 600-619 (2019). https://doi.org/10.1016/j. nanoen.2019.03.074

123. Yun, S.N., Qin, Y., Uhl, A.R., et al.: New-generation integrated devices based on dye-sensitized and perovskite solar cells. Energy Environ. Sci. 11, 476-526 (2018). https://doi.org/10. 1039/c7ee03165c

124. Goodenough, J.B., Park, K.-S.: The Li-ion rechargeable battery: a perspective. J. Am. Chem. Soc. 135(4), 1167-1176 (2013). https://doi.org/10.1021/ja3091438

125. Goodenough, J.B., Kim, Y.: Challenges for rechargeable Li batteries. Chem. Mater. 22, 587-603 (2010). https://doi.org/10. $1021 / \mathrm{cm} 901452 \mathrm{z}$

126. Ensling, D., Cherkashinin, G., Schmid, S., et al.: Nonrigid band behavior of the electronic structure of $\mathrm{LiCoO}_{2}$ thin film during electrochemical Li deintercalation. Chem. Mater. 26, 3948-3956 (2014). https://doi.org/10.1021/cm501480b

127. Jaegermann, W., Klein, A., Mayer, T.: Interface engineering of inorganic thin-film solar cells - materials-science challenges for advanced physical concepts. Adv. Mater. 21, 4196-4206 (2009). https://doi.org/10.1002/adma.200802457

128. Maier, J.: Physical chemistry of ionic materials. Chichester, UK: John Wiley \& Sons, Ltd, 2004. https://doi.org/10.1002/04700 20229

129. Sato, N.: Mixed electrodes. Electrochemistry at Metal and Semiconductor Electrodes. Amsterdam: Elsevier, 1998: 373-389. https://doi.org/10.1016/b978-044482806-4/50011-8

130. Becker, D., Cherkashinin, G., Hausbrand, R., et al.: Adsorption of diethyl carbonate on $\mathrm{LiCoO}_{2}$ thin films: formation of the electrochemical interface. J. Phys. Chem. C 118, 962-967 (2014). https://doi.org/10.1021/jp405714x

131. Sun, Y.F., Kotiuga, M., Lim, D., et al.: Strongly correlated perovskite lithium ion shuttles. PNAS 115, 9672-9677 (2018). https://doi.org/10.1073/pnas.1805029115

132. Wang, C., Yun, S.N., Fan, Q.Y., et al.: A hybrid niobium-based oxide with bio-based porous carbon as an efficient electrocatalyst in photovoltaics: a general strategy for understanding the catalytic mechanism. J. Mater. Chem. A 7, 14864-14875 (2019). https://doi.org/10.1039/c9ta03540k

133. Yun, S.N., Zhou, X., Even, J., et al.: Theoretical treatment of $\mathrm{CH}_{3} \mathrm{NH}_{3} \mathrm{PbI}_{3}$ perovskite solar cells. Angewandte Chemie Int. Ed. 56, 15806-15817 (2017). https://doi.org/10.1002/anie.20170 2660

134. Yun, S.N., Hagfeldt, A., Ma, T.L.: Pt-free counter electrode for dye-sensitized solar cells with high efficiency. Adv. Mater. 26, 6210-6237 (2014). https://doi.org/10.1002/adma.201402056

135. Yun, S.N., Wang, X.L., Li, J.F., et al.: Investigation of dielectric relaxation mechanism in bismuth doped barium calcium titanate 
ceramics by dielectric and Raman spectroscopy. Mater. Chem. Phys. 116, 339-343 (2009). https://doi.org/10.1016/j.match emphys.2009.02.057

136. Yun, S.N., Wang, X.L., Li, J.F., et al.: Linear dielectric response and dielectric relaxation behavior of bismuth-doped $\left(\mathrm{Ba}_{1-x} \mathrm{Ca}_{x / 2} \mathrm{Sr}_{x / 2}\right) \mathrm{TiO}_{3}$ ceramics. Phys. Stat. Sol. (a) 206, 303-310 (2009). https://doi.org/10.1002/pssa.200824272

137. Yun, S.N., Wang, X.L.: Dielectric properties of $\left(\mathrm{Ba}_{1-2 x} \mathrm{Sr}_{x} \mathrm{Ca}_{x}\right)$ $\mathrm{TiO}_{3}$ ferroelectric ceramics. J. Electroceramics 21, 585-588 (2008). https://doi.org/10.1007/s10832-007-9252-x

138. Yun, S.N., Wang, X.L.: Dielectric properties of bismuth doped $\mathrm{Ba}_{1-x} \mathrm{Ca}_{x} \mathrm{TiO}_{3}$ ceramics. Mater. Lett. 60, 2211-2213 (2006). https://doi.org/10.1016/j.matlet.2005.12.122

139. Braga, M.H., Ferreira, J.A., Murchison, A.J., et al.: Electric dipoles and ionic conductivity in a $\mathrm{Na}^{+}$glass electrolyte. $\mathrm{J}$. Electrochem. Soc. 164, A207-A213 (2016). https://doi.org/10. 1149/2.0691702jes

140. Yan, C.S., Zhu, Y., Li, Y.T., et al.: Local built-in electric field enabled in carbon-doped $\mathrm{Co}_{3} \mathrm{O}_{4}$ nanocrystals for superior lithium-ion storage. Adv. Funct. Mater. 28, 1705951 (2018). https://doi.org/10.1002/adfm.201705951

141. Ni, J.F., Sun, M.L., Li, L.: Highly efficient sodium storage in iron oxide nanotube arrays enabled by built-in electric field. Adv. Mater. 31, 1902603 (2019). https://doi.org/10.1002/adma. 201902603

142. Luo, W., Li, F., Li, Q., et al.: Heterostructured $\mathrm{Bi}_{2} \mathrm{~S}_{3}-\mathrm{Bi}_{2} \mathrm{O}_{3}$ nanosheets with a built-in electric field for improved sodium storage. ACS Appl. Mater. Interfaces 10, 7201-7207 (2018). https://doi.org/10.1021/acsami.8b01613

143. Li, C., Dong, S., Tang, R., et al.: Heteroatomic interface engineering in MOF-derived carbon heterostructures with builtin electricfield effects for high performance Al-ion batteries. Energy Environ. Sci. 11, 3201-3211 (2018). https://doi.org/10. 1039/c8ee01046c

144. Yun, S.N., Freitas, J.N., Nogueira, A.F., et al.: Dye-sensitized solar cells employing polymers. Prog. Polym. Sci. 59, 1-40 (2016). https://doi.org/10.1016/j.progpolymsci.2015.10.004

145. Shen, S.L., Yang, Y.P., Guo, L.J., et al.: A polarization model for a solid oxide fuel cell with a mixed ionic and electronic conductor as electrolyte. J. Power Sources 256, 43-51 (2014). https://doi.org/10.1016/j.jpowsour.2014.01.041

146. Zhang, H., Luo, Z.M., Liu, Y.L., et al.: Noble-metal-free $\mathrm{Ni}_{3} \mathrm{C}$ as co-catalyst on $\mathrm{LaNiO}_{3}$ with enhanced photocatalytic activity. Appl. Catal. B: Environ. 277, 119166 (2020). https://doi. org/10.1016/j.apcatb.2020.119166

147. Zeng, Q., Lai, Y.Q., Jiang, L.X., et al.: Integrated photorechargeable energy storage system: next-generation power source driving the future. Adv. Energy Mater. 10, 1903930 (2020). https://doi.org/10.1002/aenm.201903930

148. Ishii, Y., Kurimoto, K., Hosoe, K., et al.: Photo-rechargeable fuel cell using photo-hydrogenation reactions of quinone molecules. New J. Chem. 44, 2275-2280 (2020). https://doi.org/ $10.1039 / \mathrm{c} 9 \mathrm{nj} 04782 \mathrm{~d}$

149. Zhu, Z., Shi, X.M., Fan, G.L., et al.: Photo-energy conversion and storage in an aprotic Li- $\mathrm{O}_{2}$ battery. Angew. Chem. Int. Ed. 58, 19021-19026 (2019). https://doi.org/10.1002/anie.201911228

150. Zhu, D.D., Zhao, Q.C., Fan, G.L., et al.: Photoinduced oxygen reduction reaction boosts the output voltage of a zinc-air battery. Angew. Chem. Int. Ed. 58, 12460-12464 (2019). https://doi.org/ 10.1002/anie. 201905954

151. Wang, K., Mo, Z.H., Tang, S.T., et al.: Photo-enhanced Zn-air batteries with simultaneous highly efficient in situ $\mathrm{H}_{2} \mathrm{O}_{2}$ generation for wastewater treatment. J. Mater. Chem. A 7, 14129-14135 (2019). https://doi.org/10.1039/c9ta04253a

152. Xu, X.Y., Zhao, H., Wang, R., et al.: Identification of few-layer $\mathrm{ReS}_{2}$ as photo-electro integrated catalyst for hydrogen evolution.
Nano Energy 48, 337-344 (2018). https://doi.org/10.1016/j. nanoen.2018.03.078

153. Lv, J., Abbas, S.C., Huang, Y.Y., et al.: A photo-responsive bifunctional electrocatalyst for oxygen reduction and evolution reactions. Nano Energy 43, 130-137 (2018). https://doi.org/10. 1016/j.nanoen.2017.11.020

154. Cai, C., Han, S.B., Caiyang, W.N., et al.: Tracing the origin of visible light enhanced oxygen evolution reaction. Adv. Mater. Interfaces 6, 1801543 (2019). https://doi.org/10.1002/admi. 201801543

155. Liu, Z.R., Wang, L.W., Yu, X., et al.: Piezoelectric-effectenhanced full-spectrum photoelectrocatalysis in p-n heterojunction. Adv. Funct. Mater. 29, 1807279 (2019). https://doi.org/10. 1002/adfm.201807279

156. Chen, P., Li, G.R., Li, T.T., et al.: Solar-driven rechargeable lithium-sulfur battery. Adv. Sci. 6, 1900620 (2019). https://doi. org/10.1002/advs.201900620

157. Liu, X.R., Yuan, Y.F., Liu, J., et al.: Utilizing solar energy to improve the oxygen evolution reaction kinetics in zinc-air battery. Nat. Commun. 10, 1-10 (2019). https://doi.org/10.1038/ s41467-019-12627-2

158. Liu, Y., Li, N., Liao, K.M., et al.: Lowering the charge voltage of $\mathrm{Li}-\mathrm{O}_{2}$ batteries via an unmediated photoelectrochemical oxidation approach. J. Mater. Chem. A 4, 12411-12415 (2016). https:// doi.org/10.1039/c6ta03583c

159. Zhang, B.Q., Wang, S.Y., Fan, W.J., et al.: Photoassisted oxygen reduction reaction in $\mathrm{H}_{2}-\mathrm{O}_{2}$ fuel cells. Angew. Chem. Int. Ed. 55, 14748-14751 (2016). https://doi.org/10.1002/anie.201607118

160. Paolella, A., Faure, C., Bertoni, G., et al.: Light-assisted delithiation of lithium iron phosphate nanocrystals towards photorechargeable lithium ion batteries. Nat. Commun. 8, 1-10 (2017). https://doi.org/10.1038/ncomms 14643

161. Liu, Y., Li, N., Wu, S.C., et al.: Reducing the charging voltage of a Li- $\mathrm{O}_{2}$ battery to $1.9 \mathrm{~V}$ by incorporating a photocatalyst. Energy Environ. Sci. 8, 2664-2667 (2015). https://doi.org/10.1039/c5ee0 $1958 \mathrm{c}$

162. Wang, B., Zhang, H., Lu, X.Y., et al.: Solar photocatalytic fuel cell using $\mathrm{CdS}-\mathrm{TiO}_{2}$ photoanode and air-breathing cathode for wastewater treatment and simultaneous electricity production. Chem. Eng. J. 253, 174-182 (2014). https://doi.org/10.1016/j. cej.2014.05.041

163. Shan, X., Ke, O.Y., Yan, S.: A solar responsive photocatalytic fuel cell with a heterostructured $\mathrm{ZnFe}_{2} \mathrm{O}_{4} / \mathrm{TiO}_{2}$-NTs photoanode and an air-breathing cathode. Int. J. Hydrog. Energy 42, 2920129209 (2017). https://doi.org/10.1016/j.ijhydene.2017.10.059

164. Huang, J.S., Yuan, Y.B., Shao, Y.C., et al.: Understanding the physical properties of hybrid perovskites for photovoltaic applications. Nat. Rev. Mater. 2, 17042 (2017). https://doi.org/10. 1038/natrevmats.2017.42

165. Aristidou, N., Eames, C., Sanchez-Molina, I., et al.: Fast oxygen diffusion and iodide defects mediate oxygen-induced degradation of perovskite solar cells. Nat. Commun. 8, 15218 (2017). https:// doi.org/10.1038/ncomms 15218

166. Li, C., Guerrero, A., Huettner, S., et al.: Unravelling the role of vacancies in lead halide perovskite through electrical switching of photoluminescence. Nat. Commun. 9, 5113 (2018). https:// doi.org/10.1038/s41467-018-07571-6

167. Eames, C., Frost, J.M., Barnes, P.R.F., et al.: Ionic transport in hybrid lead iodide perovskite solar cells. Nat. Commun. 6, 7497 (2015). https://doi.org/10.1038/ncomms8497

168. Walsh, A., Stranks, S.D.: Taking control of ion transport in halide perovskite solar cells. ACS Energy Lett. 3, 1983-1990 (2018). https://doi.org/10.1021/acsenergylett.8b00764

169. Wang, B.Y., Cai, Y.X., Dong, W.J., et al.: Photovoltaic properties of $\mathrm{Li}_{x} \mathrm{Co}_{3-x} \mathrm{O}_{4} / \mathrm{TiO}_{2}$ heterojunction solar cells with high 
open-circuit voltage. Sol. Energy Mater. Sol. Cells 157, 126-133 (2016). https://doi.org/10.1016/j.solmat.2016.05.036

170. Christoforidis, K.C., Fornasiero, P.: Photocatalytic hydrogen production: a rift into the future energy supply. ChemCatChem 9, 1523-1544 (2017). https://doi.org/10.1002/cctc.201601659

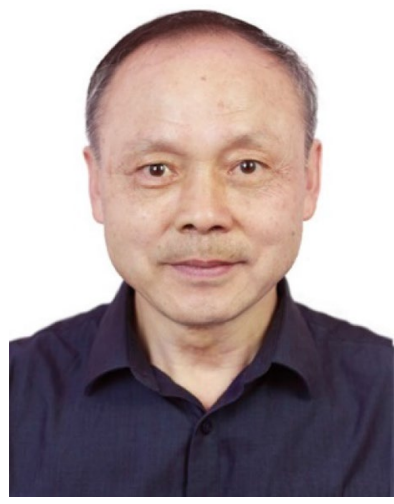

Bin Zhu Chief scientist in Jiangsu Provincial Key Laboratory of Solar Energy Science and Technology/Energy Storage Joint Research Center, School of Energy and Environment, Southeast University. Since 1998 he started the research as principal investigator at KTH and 1999 became associate professor/senior researcher in KTH until 2018 , then as a visiting professor position in Loughborough University, UK. In 2013, based on the great invention of single layer electrolyte-free fuel cell - a research breakthrough, he was selected by Hubei provincial 100-overseas talents program to establish and lead research team in Hubei University, then extended to China University of Geoscience (Wuhan). 2019-now, a lecturer professor in Xi' an Jiaotong University, and 2020now, Southeast University. He has published about 400 research papers. Together with Prof. Peter Lund, Aalto University as the recipient of 2018 WSSET (World Society of Sustainable Energy Technologies) Innovation award for Power Generation. He is one of the Most Cited scholars in China (Energy sector, Elsevier) since 2014. His current research interests lie in the energy conversion, especially next generation semiconductors based LTSOFCs, PCFCs (proton ceramic fuel cells), and joint fuel cells and solar fuels or battery science and technology based on semiconductor-ionics and semiconductor electrochemistry, where electron-ion coupling enhanced ionic transport, multi-charge transfer and super proton transport processes, surficial and interfacial superionic conduction, nano-redox process and nano-redox units/ devices for high ion-flux energy devices and technologies.

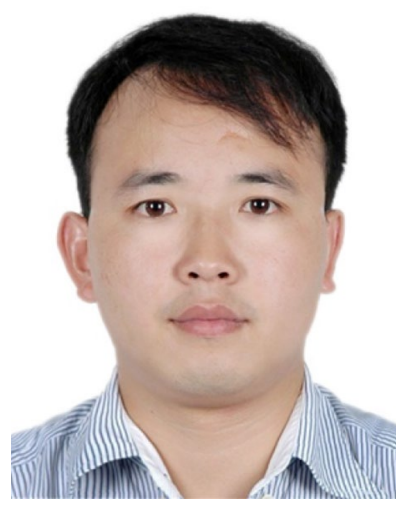

Liangdong Fan is a Research Associate Professor in the Department of New Energy Science and Technology, College of Chemistry and Environmental Engineering, Shenzhen University, China. He received his double $\mathrm{Ph} . \mathrm{D}$. degree, one in Energy Technology from the Royal Institute of Technology (KTH, Sweden) in 2014 and another in Chemical Technology from Tianjin University, in 2012. He was a postdoctoral Research Fellow at Nanyang Technological University (2014.062015.11). Since the end of 2015, Dr. Fan joined Shenzhen University as a Lecturer/Research Associate Professor (Principal Investigator). His current research interests are developing inorganic functional materials such as perovskite oxides for high temperature fuel cells/electrolysis cells and low temperature electrocatalysis applications.

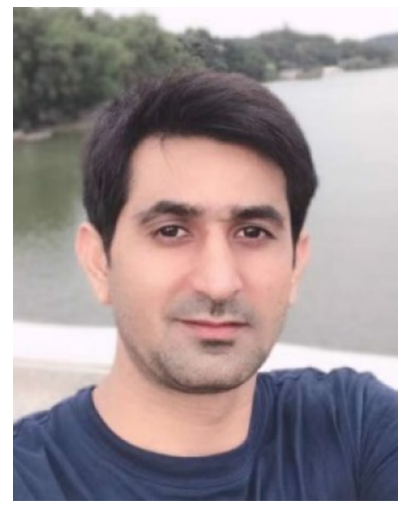

Naveed Mushtaq is a Post-doctoral researcher at Jiangsu Provincial Key Laboratory of Solar Energy Science and Technology/ Energy Storage Joint Research Center, School of Energy and Environment, Southeast University, Nanjing. Dr. Naveed obtained his Master degree in Physics from COMSATS University Islamabad, Lahore campus and Ph.D. from Hubei University, Wuhan, China. His main research interests include fuel cells oxygen reduction electrocatalysts and nanostructured functional materials for energy devices. Dr. Naveed has published $~ 30$ journal papers in his research.

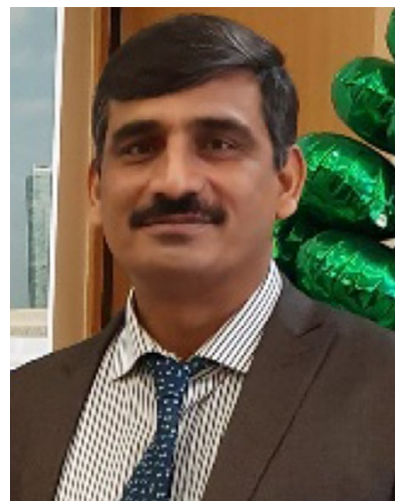

Rizwan Raza is a Tenured Associate Professor at COMSATS University Islamabad, Lahore Campus, Pakistan and Visiting Researcher at Linkoping University and Chalmers University of Technology, Sweden. Raza completed PhD in Energy Technology from KTH, Sweden in 2012. Dr. Raza has 15 years of experience in Energy materials research and teaching. Raza has published more than 200 journal papers. He has edited 02 books and 10 book chapters. He has been working on several multidisciplinary projects regarding "Energy conversion \& Energy storage devices (Fuel cells, Solar cells, Batteries, Supercapacitor)". He received some of the remarkable awards the world over; Gold Medalist from Pakistan Academy of Sciences 2018, Winner of the Award "idea to product "I2P ® Stockholm-2011", Raza is awarded a "Youngest Scientist in Pakistan" for 2016 and 2017. Raza has also established a well-equipped fuel cell research laboratory in Pakistan. It is one of the earliest fuel cell research laboratories in Pakistan.

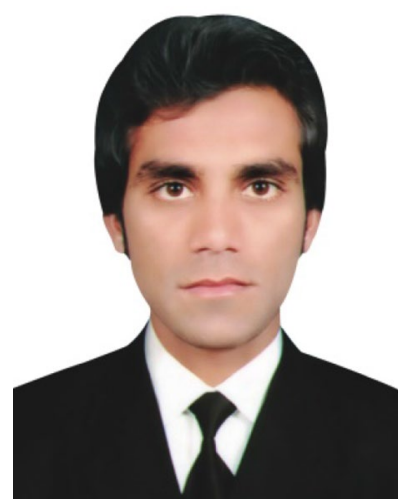

Muhammad Sajid is currently doing his Ph.D. from School of Chemistry and Materials Science, University of Science and Technology of China (USTC), China. He received his MS in Physics from COMSATS University Islamabad, Lahore Campus, Pakistan under supervision of Dr. Rizwan Raza. His research interests mainly focus on Batteries, water electrolysis, catalysis, nanomaterials and SOFCs. 


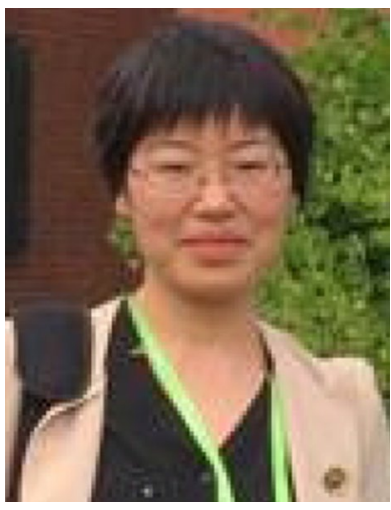

Yan Wu is an Associate Professor at the Faculty of Material Science and Chemistry, China University of Geoscience (Wuhan). She received a Ph.D. from the Royal Institute of Technology in 2010, with Prof. K.V. Rao and Lyuba Belova. Then She joined the China University of Geoscience and was promoted to Associate Professor in Dec. 2011. Her current research interests are advanced energy and resources utilization with nanotechnology and new semiconducting photocatalysis.

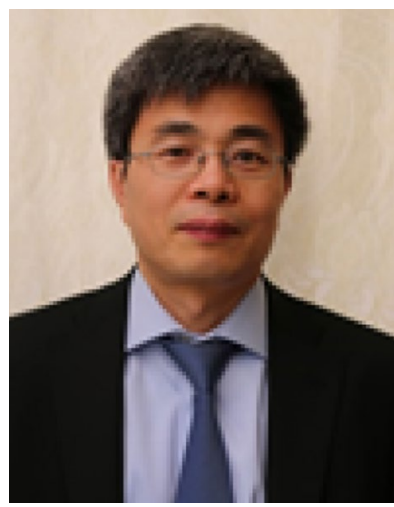

Wenfeng Lin FRSC (Fellow of Royal Society of Chemistry, UK), is the Professor of Chemical Engineering and Departmental Research Director at Loughborough University, England. He obtained his BSc, MSc and PhD from Xiamen University, with his $\mathrm{PhD}$ thesis work on combined studies of quantum chemistry and spectro-electrochemistry on electrocatalysis and interfaces, under the supervision of Profs. Z. W. Tian, S. G. Sun and Z. Q. Tian. He was awarded two prestigious Humboldt-Foundation and Max-Planck-Society Postdoc Research Fellowships and worked with Nobel Laureate Prof. Ertl in the Fritz-Haber-Institute in Berlin, Germany. In the UK, he worked in Newcastle University and Queen's University Belfast before joining Loughborough University in 2015. The primary themes of his research are related to electrochemical energy and environmental technologies. He collaborates internationally and has led a significant number of externally funded projects, ranging from fundamental understanding of electro-catalysis at atomic and molecular levels to applied R\&D in energy materials, fuel cells, batteries, hydrogen production, carbon dioxide utilization, ozone generation and advanced oxidation technology. He has over 170 publications and contributed to 2 high tech spin-outs in UK.

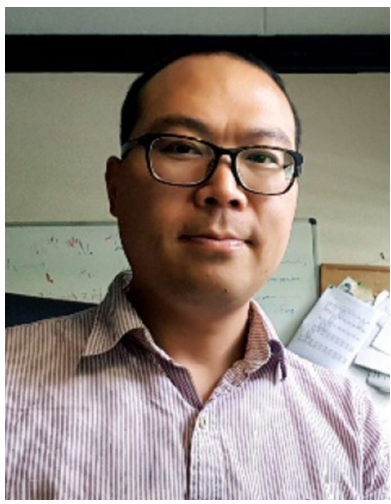

Jung-Sik Kim is a senior lecturer at the Department of Aero \& Auto Eng. Loughborough University, UK. He is an experienced researcher and teacher specialising in the investigation of electrochemical processes for energy conversion and storage. His work in the field of solid oxide fuel cells has been supervised by Professor Alan Atkinson and Professor John Kilner at the Department of Materials, Imperial College London since
2006, and commenced his research activity at Loughborough University since 2010 as a lecturer and then senior lecturer since 2015. Dr Kim has obtained his $\mathrm{PhD}$ in the Department of Mechanical Engineering \& at the University of Birmingham, UK in 2006. His component level SOFC research commitments have been evolved into their system level R\&D based on thermo-electrochemical analysis, deploying multithermal sensing technology which generates an enormous amount of data, so that he continues contributing effectively in this role by suggesting hybrid interconversion energy systems utilising renewable and traditional energy materials.

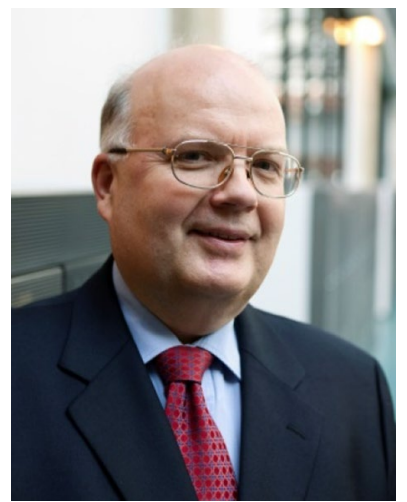

Peter D. Lund is Professor in Engineering Physics and Advanced Energy Systems at Aalto University, Finland. His D.Sc. is from Helsinki University of Technology; he is a London Business School Alumni. He has had visiting positions in China and Germany, and he is Honorary Professor at Southeast University in Nanjing. He has chaired the Advisory Group Energy of the European Commission and the Energy Steering Panel of European Academies Science Advisory Council. He is vice-chair of the Finnish Climate Change Panel. He is member of the Finnish Academy Science and Letters and Swedish Engineering Academy in Finland. His research interest encompasses sustainable energy, nanomaterials, fuel cell, and solar cells. He has published 350 journal papers and has received several international awards.

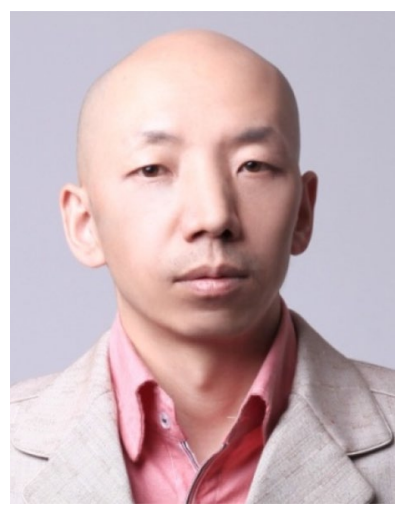

Sining Yun is a Professor in School of Materials Science and Engineering, Xi' an University of Architecture and Technology, China. He obtained his $\mathrm{PhD}$ at $\mathrm{Xi}$ 'an Jiaotong University in 2007 and was a postdoctoral fellow in Yonsei University (Korea). He is a visiting professor at State Key Lab. of Fine Chemicals (China), University of Reading (UK), Prof. Michael Grätzel and Prof. Anders Hagfeldt's laboratory at EPFL (Switzerland). $\mathrm{He}$ is currently a Research Director and Group Leader of Functional Materials Laboratory and Key Lab of Nanomaterials and Nanotechnology of Shaanxi Province (China). His research focuses on the new energy such as solar cells, fuel cells, supercapacitors, hydrogen generation and anaerobic digestion. Details can be found at: http://xy.xauat.edu.cn/gnclyjs/listyjsgk.asp?id=262\&bh=2080; https://www.X-mol.com/groups/Sining_Yun. 


\section{Authors and Affiliations}

\section{Bin Zhu ${ }^{1} \cdot$ Liangdong Fan ${ }^{2} \cdot$ Naveed Mushtaq $^{1} \cdot$ Rizwan Raza $^{3} \cdot$ Muhammad Sajid ${ }^{3} \cdot$ Yan Wu ${ }^{4} \cdot$ Wenfeng Lin $^{5}$. Jung-Sik Kim ${ }^{6}$. Peter D. Lund ${ }^{7}$. Sining Yun ${ }^{8}$}

1 Jiangsu Provincial Key Laboratory of Solar Energy Science and Technology/Energy Storage Joint Research Center,

School of Energy and Environment, Southeast University, Nanjing 210096, Jiangsu, China

2 Shenzhen Key Laboratory of New Lithium-Ion Batteries and Mesoporous Materials, College of Chemistry and Environmental Engineering, Shenzhen University, Shenzhen 518060, Guangdong, China

3 Clean Energy Research Lab (CERL), Department of Physics, COMSATS University Islamabad, Lahore Campus, Lahore 54000, Pakistan

4 Engineering Research Center of Nano-Geo Materials of Ministry of Education, Faculty of Materials Science and Chemistry, China University of Geosciences, Wuhan 430074, Hubei, China
5 Department of Chemical Engineering, School of Aeronautical, Automotive, Chemical and Materials Engineering, Loughborough University, Loughborough LE11 3TU, UK

6 Department of Aeronautical \& Automotive Engineering, School of Aeronautical, Automotive, Chemical and Materials Engineering, Loughborough University, Loughborough LE11 3TU, UK

7 Department of Engineering Physics/Advanced Energy Systems, School of Science, Aalto University, 00076 Aalto, Espoo, Finland

8 Functional Materials Laboratory (FML), School of Materials Science and Engineering, Xi' an University of Architecture and Technology, Xi'an 710055, Shaanxi, China 